Environmental Geophysics at Kings Creek Disposal Site and 30th Street Landfill, Aberdeen Proving Ground, Maryland

\section{$I \perp S O$ \\ G66! $\varepsilon 0$ dd $\forall$ \\ वコภヨอコบ}

Energy Systems Division Argonne National Laboratory

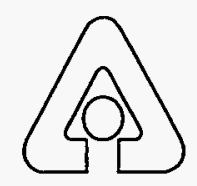

Operated by The University of Chicago, under Contract W-31-109-Eng-38, for the

United States Department of Energy 


\section{Argonne National Laboratory}

Argonne National Laboratory, with facilities in the states of Illinois and Idaho, is owned by the United States Government, and operated by the University of Chicago under the provisions of a contract with the Department of Energy.

This technical memo is a product of Argonne's Energy Systems (ES)

Division. For information on the division's scientific and engineering activities, contact:

Director, Energy Systems Division

Argonne National Laboratory

Argonne, Illinois 60439-4815

Telephone (708) 252-3724

Presented in this technical memo are preliminary results of ongoing work or work that is more limited in scope and depth than that described in formal reports issued by the ES Division.

Publishing support services were provided by Argonne's Information and Publishing Division.

\section{Disclaimer}

This report was prepared as an account of work sponsored by an agency of the United States Government. Neither the United States Govemment nor any agency thereof, nor any of their employees, makes any warranty, express or implied, or assumes any legal liability or responsibility for the accuracy, completeness, or usefulness of any information, apparatus, product, or process disclosed, or represents that its use would not infringe privately owned rights. Reference herein to any specific commercial product, process, or service by trade name, trademark, manufacturer, or otherwise, does not necessarily constitute or imply its endorsement, recommendation, or favoring by the United States Government or any agençy thereof. The views and opinions of authors expressed herein do not necessarily state or reflect those of the United States Government or any agency thereof.

Available to DOE and DOE contractors from the Office of Scientific and Technical Information, P.O. Box 62, Oak Ridge, TN 37831; prices available from (615) $576-8401$

Available to the public from the National Technical Information Service, U.S. Department of Commerce, 5285 Port Royal Road, Springfield, VA 22161. 


\section{DISCLAIMER}

Portions of this document may be illegible in electronic image products. Images are produced from the best available original document. 


\section{Environmental Geophysics at Kings Creek Disposal Site and 30th Street Landfill, Aberdeen Proving Ground, Maryland}

by B.E. Davies, S.F. Miller, L.D. McGinnis, C.R. Daudt, M.D. Thompson, J.E. Stefanov, M.A. Benson, and C.A. Padar

Center for Environmental Restoration Systems, Energy Systems Division, Argonne National Laboratory, 9700 South Cass Avenue, Argonne, Illinois 60439

\section{Published as}

Environmental Geophysics at Aberdeen Proving Ground, Maryland:

Kings Creek Disposal Site and 30th Street Landfill

for sponsor's use only

January 1995

WISTAIBUTION OF THIS DOCUMENT IS UNLIMITED

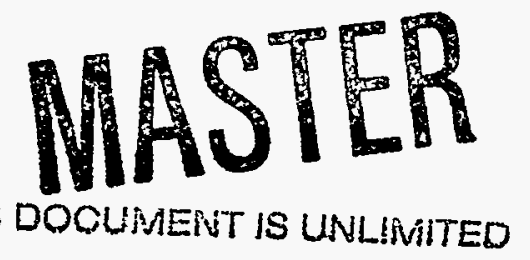

Work sponsored by United States Department of Defense, United States Army, Aberdeen Proving Ground, Maryland 
This report is printed on recycled paper, with the exception of color reproductions. 


\section{Preface}

This report provides administrative and technical staff, responsible for environmental planning and remediation at Aberdeen Proving Ground, with the final results and conclusions drawn from geophysical studies begun in April 1994. Three technologies, not listed in the work plan, were added to the study to improve diagnostic interpretations, and one technology was removed because it was considered redundant. The technologies added were downhole induction logging and downhole gamma logging, which were used to interpret subsurface lithologies, and downhole seismic velocity measurements, used to assist in the interpretation of seismic reflection data. Resistivity sounding was deleted from the study. Staff at Aberdeen Proving Ground, Directorate of Safety, Health, and Environment, and Argonne National Laboratory guided the work scope and its objectives. 



\section{Contents}

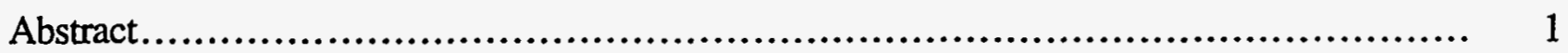

1 Introduction......................................................................... 1

1.1 Physiographic Setting and Site Survey......................................... 4

1.2 Geology and Hydrogeology .............................................................. 5

1.3 Instrumentation and Software .................................................. 8

2 Magnetic Surveys ................................................................. 11

2.1 Continuous Profiling Magnetometry ......................................... 11

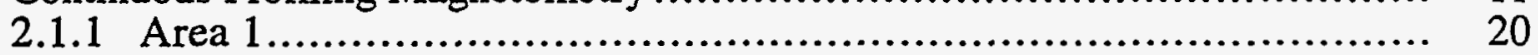

2.1.2 Area 2..................................................................................... 23

2.1.3 Area 3............................................................................ 23

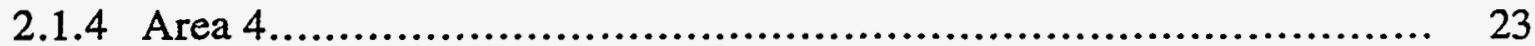

2.2 Magnetic Gradiometer Survey ............................................ 24

3 Electrical Conductivity Survey......................................................... 28

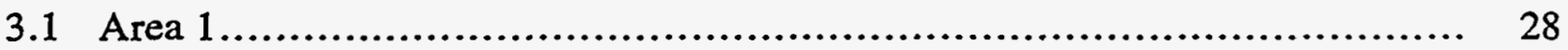

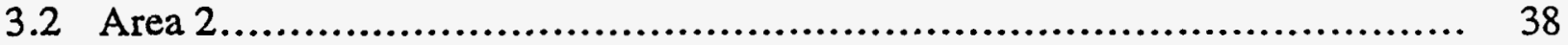

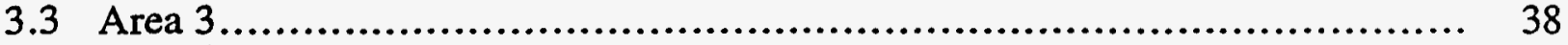

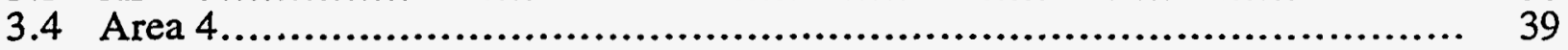

4 Geophysical Well Logging...................................................... 42

5 Ground-Penetrating Radar Surveys............................................. 43

5.1 Offshore GPR Surveys ....................................................... 43

5.2 Onshore GPR Surveys.................................................... 44

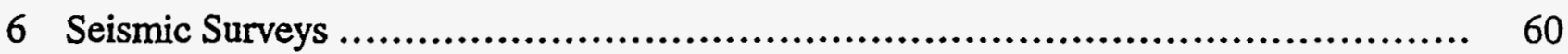

6.1 Seismic Refraction Surveys .................................................. 60

6.2 Downhole Seismic Velocity Measurements.............................................. 64

6.3 Seismic Reflection Surveys ................................................. 65

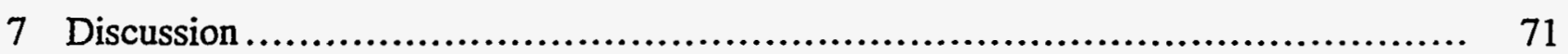

7.1 Areal Extent of Kings Creek Disposal Site and 30th Street Landfill............ 71

7.2 Hydrogeologic Framework ....................................................... 72

7.3 Subsurface Paleochannel Locations ............................................... 73

8 Summary and Conclusions......................................................... 75

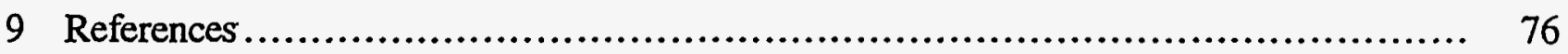

Appendix A: Soil Boring Logs......................................................... $\quad 79$

Appendix B: Gamma and Induction Logs ....................................... 109 


\section{Tables}

1 Location and Description of Magnetic Anomalies Detected

in the Kings Creek Study Area..

2 Seismic Refraction Profiles near the Kings Creek Study Area.................... 61

3 Seismic Reflection Profiles near the Kings Creek Study Area .................... 66

\section{Figures}

1 Kings Creek Study Area in the Aberdeen Proving Ground, Edgewood Area......

2 Topography and Site Features of the Bush River Peninsula ...................... 3

3 Geophysical Survey Grid, Kings Creek Study Area ............................ 5

4 Geologic Cross Section of the Bush River Peninsula................................. 7

$5 \quad$ Kings Creek Study Area Subdivisions and Magnetic Survey

Profile Locations

6 Kings Creek Study Area Total Field Magnetics Map

7 Area 1, Total Field Magnetics Map

8 Area 2, Total Field Magnetics Map

9 Area 3, Total Field Magnetics Map

10 Area 4, Total Field Magnetics Map

11 Total Field Magnetics Map Overlain by Magnetic Gradiometer Anomalies, North of Former Kings Creek Disposal Site.

12 Total Field Magnetics Map Overlain by Magnetic Gradiometer Anomalies, East of 30th Street Landfill

13 Kings Creek Study Area, EM-31 Electromagnetics Map.............................. 29

14 Area 1, EM-31 Electromagnetics Map ......................................... 31

15 A: Area 2, EM-31 Electromagnetics Map

B: Area 2, EM-31 Overlain by Magnetic Contours ............................ 33

16 Area 3, EM-31 Electromagnetics Map ..................................... 35

17 Area 4, EM-31 Electromagnetics Map ....................................... 37 


\section{Figures (Cont.)}

18 Location of EM-31 Offshore Profiles ........................................... 39

19 Kings Creek Offshore EM-31 Electromagnetics Map ............................ 40

20 Monitor Well Location Map, Bush River Peninsula ............................... 41

21 Ground-Penetrating Radar Profile Locations ................................... 44

22 A: GPR Profile \#16

B: GPR Profile \#16 with Interpretation..................................... 46

23 A: GPR Profile \#12

B: GPR Profile \#12 with Interpretation...................................... 47

24 A: GPR Profile \#13

B: GPR Profile \#13 with Interpretation....................................... 49

25 A: GPR Profile \#15

B: GPR Profile \#15 with Interpretation..................................... 51

26 A: GPR Profile \#14

B: GPR Profile \#14 with Interpretation........................................ 53

27 A: GPR Profile \#6

B: GPR Profile \#6 with Interpretation ...................................... 55

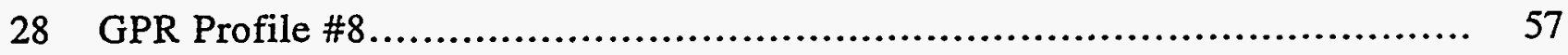

29 A: GPR Profile \#9

B: GPR Profile \#9 with Interpretation ........................................ 59

30 Seismic Profile Locations ..................................................... 61

31 First Arrival Time versus Distance Data from Seismic Refraction Lines BRP-2 (A) and BRP-3 (B) .............................. 62

32 First Arrival Time versus Distance Data from Seismic Refraction Line BRP-1

33 Velocity-Depth Model Obtained by Inverting Seismic Refraction Data and Borehole Seismic Data.

34 Seismic Reflection Profile for Line BRP-4 ................................... 67

35 Seismic Reflection Profile for Line BRP-5 ................................. 68

36 Seismic Reflection Profile for Line BRP-6 .................................... 70

37 Approximate Paleochannel Locations Inferred from GPR Data .................... 73 


\title{
Environmental Geophysics at Kings Creek Disposal Site and 30th Street Landfill, Aberdeen Proving Ground, Maryland
}

by

\author{
B.E. Davies, S.F. Miller, L.D. McGinnis, C.R. Daudt, M.D. Thompson, \\ J.E. Stefanov, M.A. Benson, and C.A. Padar
}

\begin{abstract}
Geophysical studies on the Bush River Peninsula in the Edgewood Area of Aberdeen Proving Ground, Maryland, delineate landfill areas and provide diagnostic signatures of the hydrogeologic framework and possible contaminant pathways. These studies indicate that, during the Pleistocene Epoch, alternating stands of high and low sea levels resulted in a complex pattern of shallow channelfill deposits in the Kings Creek area. Ground-penetrating radar studies reveal a paleochannel greater than $50 \mathrm{ft}$ deep, with a thalweg trending offshore in a southwest direction into Kings Creek. Onshore, the ground-penetrating radar data indicate a 35-ft-deep branch to the main channel, trending to the north-northwest directly beneath the 30th Street Landfill. Other branches are suspected to meet the offshore paleochannel in the wetlands south and east of the 30th Street Landfill. This paleochannel depositional system is environmentally significant because it may control the shallow groundwater flow regime beneath the site. Electromagnetic surveys have delineated the pre-fill lowland area currently occupied by the 30th Street Landfill. Magnetic and conductive anomalies outline surficial and buried debris throughout the study area. On the basis of geophysical data, largescale dumping has not occurred north of the Kings Creek Disposal Site or east of the 30th Street Landfill.
\end{abstract}

\section{Introduction}

An environmental geophysical study was conducted north of Kings Creek at Aberdeen Proving Ground (APG), Edgewood Area (Figure 1). The study area includes two solid waste management units (SWMUs) identified in the RCRA Facility Assessment Report, Edgewood Area, Aberdeen Proving Ground, Maryland (Nemeth 1989). The two SWMUs, referred to as the Kings Creek Disposal Site and the 30th Street Landfill, are located outside the security fence within Cluster 15 (Figure 2).

Open burning of chemical munitions reportedly occurred at the Kings Creek Disposal Site during the 1920s and 1930s. Drummed wastes were also stored on the surface in this area. It is not known whether chemical munitions or wastes were buried at the disposal site. 


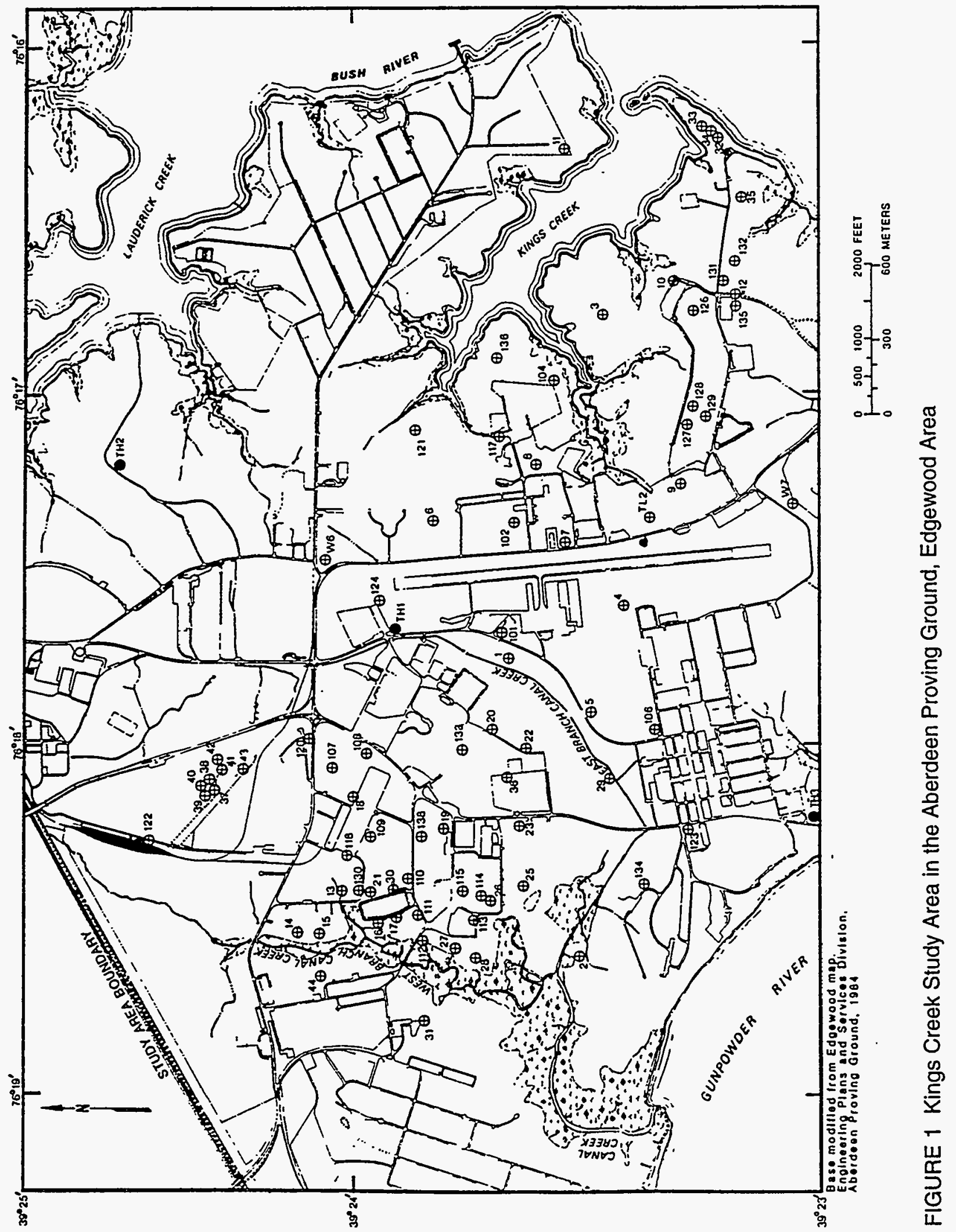




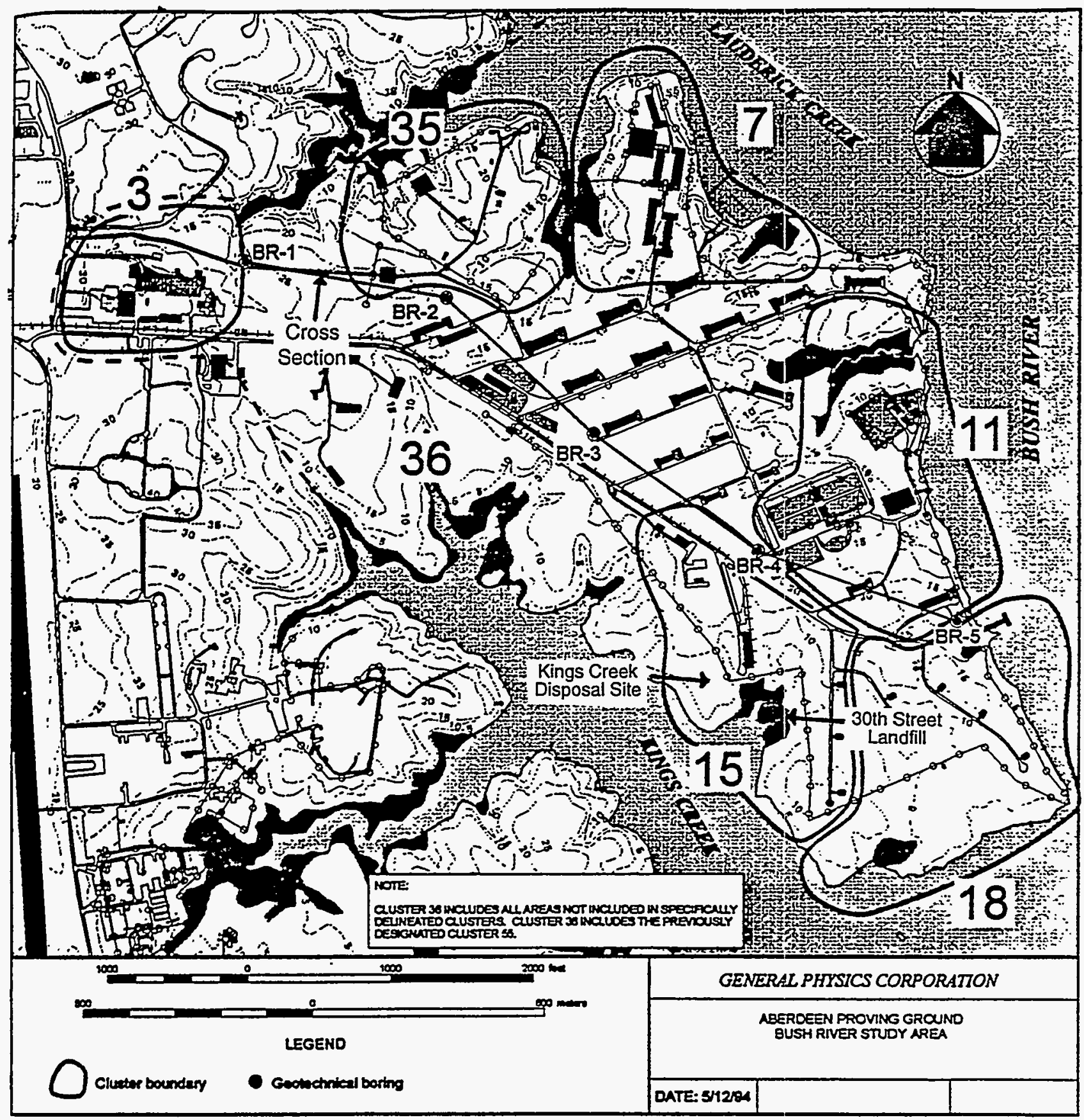

FIGURE 2 Topography and Site Features of the Bush River Peninsula (adapted from U.S. Army Corps of Engineers 1994) 
The 30th Street Landfill is located east of and adjacent to the Kings Creek Disposal Site, in a former wetland. Dumping occurred at the landfill in the 1960s and probably into the early 1970 s. The area is currently covered with vegetation, and some debris is visible on the surface. Buried munitions were discovered at the landfill during the summer of 1994, but no records of munitions disposal in this area exist (Nemeth 1989).

The objectives of the geophysical investigation (as outlined in the workplan) are as follows:

1. Define the areal extent of the affected sites,

2. Characterize the hydrogeologic framework beneath the sites to provide information to support the current site monitor well installation program, and

3. Provide information on the geologic integrity and continuity of strata underlying the embayment and wetlands adjacent to the sites.

Field activities were conducted during the spring and summer of 1994. Geophysical techniques used during this study to meet the objectives listed above included seismic reflection and refraction, downhole seismic induction and gamma well logging, magnetics, electromagnetics, and ground-penetrating radar (GPR). Magnetic, electromagnetic, and GPR surveys were performed to define the approximate areal extent of solid (and potentially liquid) wastes.

\subsection{Physiographic Setting and Site Survey}

The Kings Creek area lies within the Atlantic Coastal Plain physiographic province of Maryland. The study area is located in the south-central portion of the Bush River Peninsula, which is bounded by Lauderick Creek to the north, Bush River to the east, and Kings Creek to the south (Figure 2). The peninsula is a remnant of subareal erosion that occurred during a low-sealevel stand followed by a sea-level rise and estuarine encroachment into Kings Creek and Lauderick Creek, which are tributaries of the Bush River. This river is one of the major tidal estuarine channels on the western shore of Chesapeake Bay. Elevations of the Bush River Peninsula range from greater than $20 \mathrm{ft}$ above mean sea level $(\mathrm{msl})$ in the central portion of the peninsula to sea level at the shoreline (Figure 2). The elevation of the study area ranges from sea level to approximately $14 \mathrm{ft}$ above msl at the northernmost survey point. The average elevation of the site is 5 to $6 \mathrm{ft}$ above msl.

The area surveyed covers approximately 11 acres surrounding a small embayment on the north shore of Kings Creek. The northern and eastern portions of the site are covered by trees and surface obstructions (fallen trees, vines, and brush). The Kings Creek Disposal Site is partially wooded and contains numerous fallen trees. The 30th Street Landfill is covered with low grassy vegetation and is surrounded to the south and southeast by phragmite and cattail marsh. 
Geophysical survey coordinate 00N/O0E corresponds to control point CP-12 of a survey performed by Gilmore and Associates, Inc., in October 1992 (Figure 3). CP-12 is located at 620823.72 north, 1517457.09 east in the Maryland State Plane Coordinate System. A 50-ft grid was established, using wooden survey stakes, to guide the geophysical surveys (Figure 3). The grid was laid out by using 300-ft surveyor's tapes and a Brunton compass. Geophysical profiles in the eastern section of the survey area are skewed slightly from those in the main survey area to better fit this irregularly shaped section.

\subsection{Geology and Hydrogeology}

The Precambrian crystalline basement platform lies approximately $450 \mathrm{ft}$ beneath the land surface of the Bush River Peninsula. Basement lithologies are similar to those found at the surface in the Piedmont Province, which is located northwest of the fall line (Oliveros and Vroblesky 1989). The crystalline basement surface dips to the southeast at an angle of less than one degree

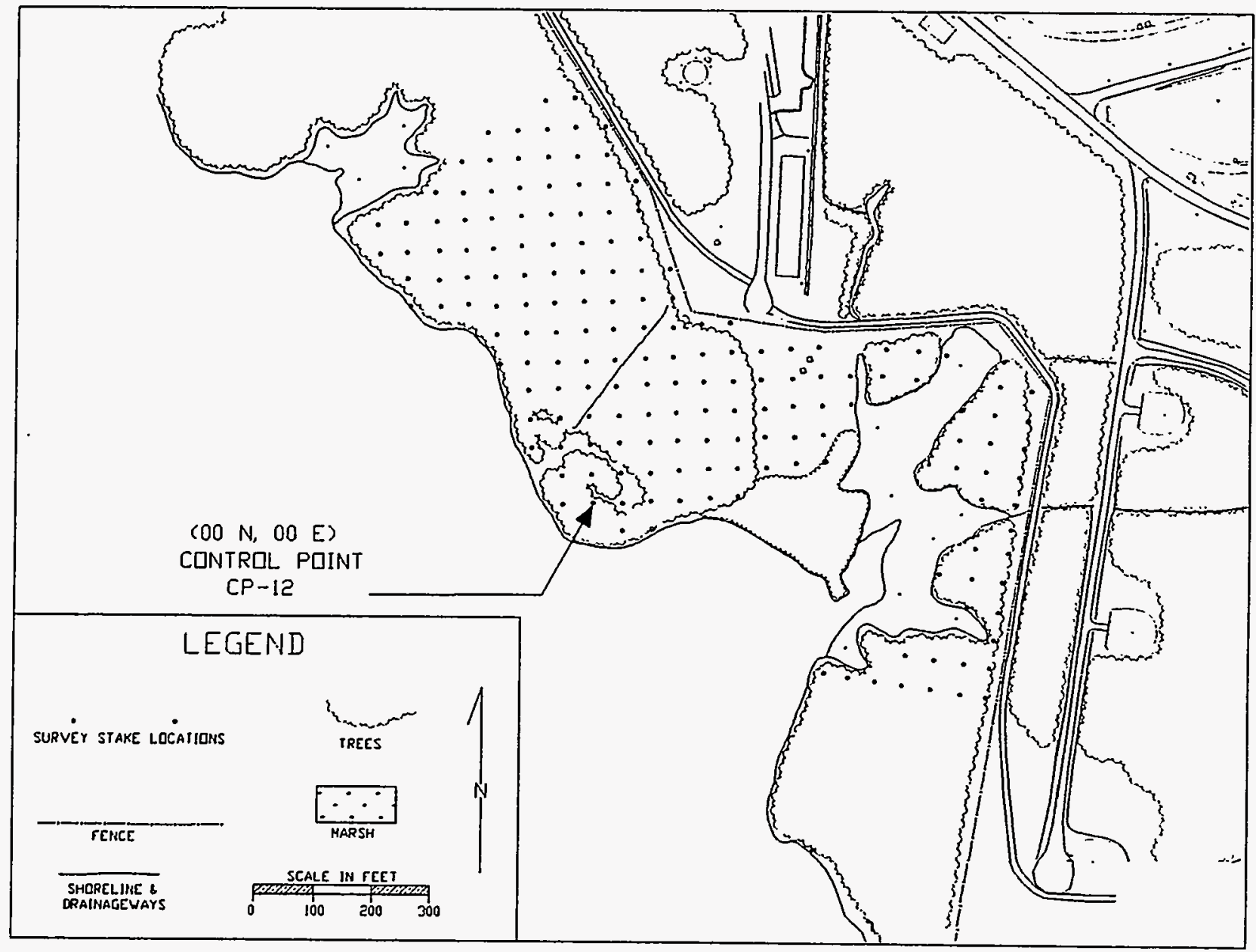

FIGURE 3 Geophysical Survey Grid, Kings Creek Study Area 
(Bennett and Meyer 1952; Dingman et al. 1956; Southwick, Owens, and Edwards 1969). Previous geophysical studies at Beach Point, approximately 3,000 ft south, revealed the Precambrian basement approximately $560 \mathrm{ft}$ beneath the land surface (McGinnis et al. 1994a). In areas east of the fall line, including all of the areas discussed in this report, unconsolidated Atlantic Coastal Plain sediments overlie Piedmont basement rocks.

Atlantic Coastal Plain sediments beneath the Edgewood area of APG were deposited during the Cretaceous Period and the Pleistocene Epoch (Oliveros and Vroblesky 1989; Thurmond 1993). A thin layer of Holocene estuarine sediments covers the wetland areas at APG. Most of the unconsolidated sediments, which comprise the Potomac Group, were deposited during the Cretaceous Period. The Potomac Group units are continentally derived and represent several depositional systems: mostly fluvial, channel, and overbank or levee deposits. Cretaceous deposits in the area generally consist of interbedded clays and fine- to medium-grained quartzsands. These Cretaceous sediments likely belong to the Patapsco Formation of the Potomac Group.

The Pleistocene Talbot Formation, which rests unconformably on the Potomac Group, contains minor amounts of Quaternary alluvium (Oliveros and Vroblesky 1989). The gravelly sand, sand, and silty clay deposits are marginal marine in origin and consist primarily of fluvial and estuarine deposits (Southwick, Owens, and Edwards 1969). During the Pleistocene Epoch, the sea level fluctuated and channels were cut into the Cretaceous sediments. The Talbot Formation is commonly found as paleochannel-fill complexes deposited during subsequent rises in sea level (Kehrin et al. 1988). Beneath the Bush River Peninsula, the Talbot Formation is thickest in these paleochannel-fill complexes.

Figure 4 presents a hydrogeologic cross section running northwest to southeast along the Bush River Peninsula (adapted from Thurmond 1993). The location of the cross section is shown in Figure 2. The sediments beneath the Bush River Peninsula are a complex mix of interfingering clays, silts, sands, and gravels. Lorah and Vroblesky (1989) describe a similar section as follows: "Hydrogeologic units were defined partly on the basis of hydrogeologic characteristics of the units; therefore, the boundaries between the hydrogeologic units do not necessarily correspond with the contacts between geologic units." The surficial aquifer sediments are primarily composed of the Talbot Formation and appear to pinch out in the northwestern end of the cross section (Figure 4).

The Pleistocene disconformity is developed on the clay aquitard, which is a member of the Potomac Group sediments. The disconformity, where the base of the Pleistocene sediments is also clayey, is not readily discernible in drill core or geophysical logs. In the discussions to follow, the term "base of the surficial aquifer" refers to the contact between the sandy sediments and the underlying clay, regardless of the relative ages of the two units.

On the basis of observations at the Kings Creek study area and studies conducted in other portions of the Edgewood Area, including Beach Point (McGinnis et al. 1994a) and Canal Creek (Lorah and Vroblesky 1989 and McGinnis et al. 1994b), it is evident that a well-integrated 


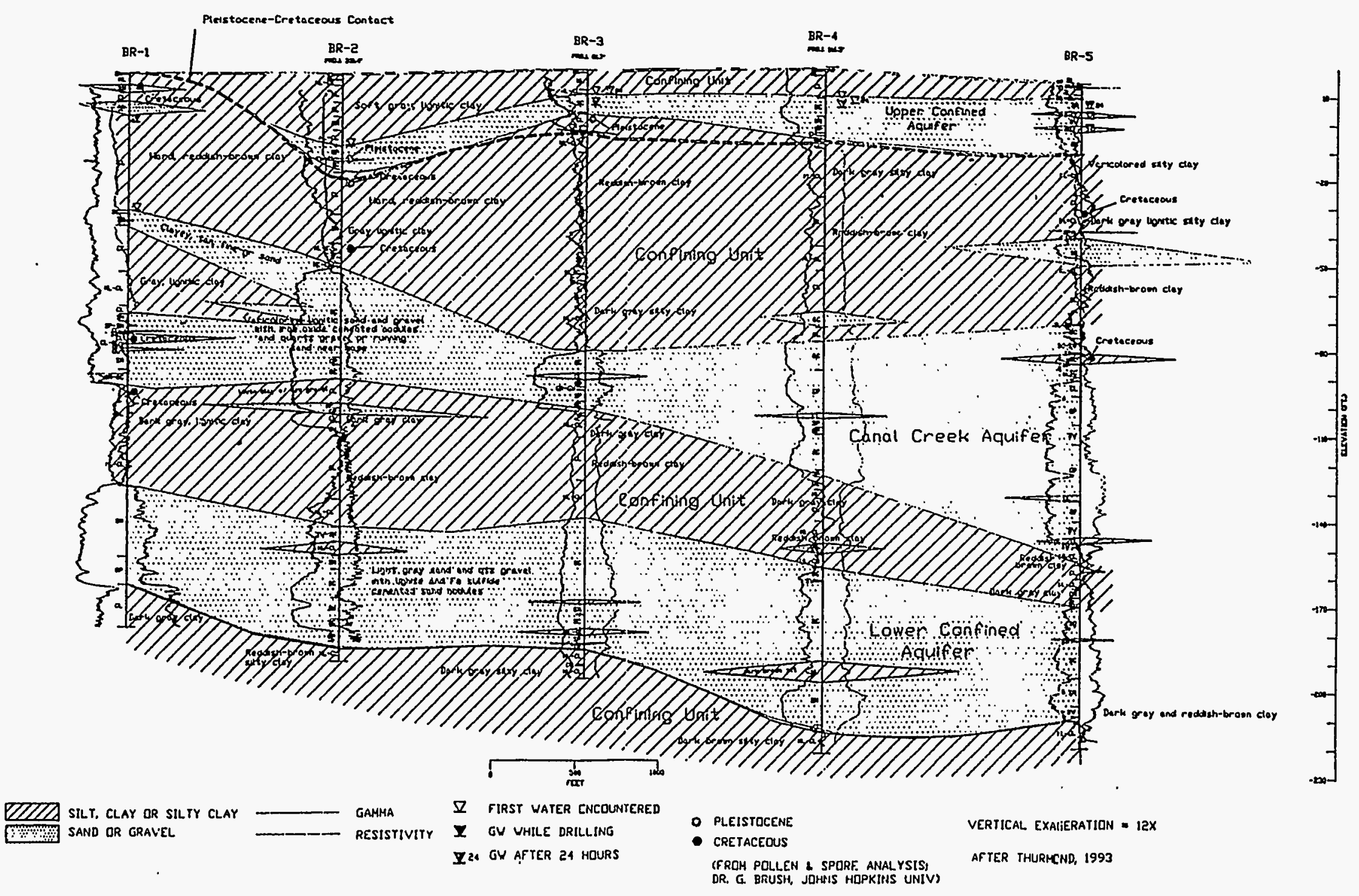

FIGURE 4 Geologic Cross Section of the Bush River Peninsula (Thurmond 1993) 
Pleistocene tributary system was deeply incised into the Potomac Group sediments as a result of successive lowering of the sea level. The tributary system provides the framework for shallow groundwater flow and for potential recharge into the Potomac Group aquifers. Mapping the configuration of this system is one of the objectives of the geophysical studies conducted at the Kings Creek Disposal Area/30th Street Landfill.

\subsection{Instrumentation and Software}

Instruments used to collect geophysical data at the site included the following:

- Magnetic gradiometer,

- Cesium vapor magnetometer,

- Electrical conductivity instrument,

- Induction probe and logging unit,

- Natural gamma probe and logging unit,

- SIR-2 and SIR-3 ground-penetrating radar,

- Engineering seismographs,

- Elastic wave generator, and

- Geophones.

The following paragraphs describe each of these instruments and the software used to reduce the electromagnetic data, process the magnetic data, process the seismic reflection and refraction data, and produce contour maps.

The Model Mac-51B, a magnetic gradiometer and cable locator manufactured by Schonstedt, Inc., is a dual-mode instrument designed to detect shallow buried iron and steel objects and trace underground cables and pipes. The system consists of a transmitter and a dualfunction receiver designed to detect anomalous magnetic gradients. The magnetic gradiometer was used during this study to (1) clear survey areas prior to driving the wooden stake grid markers and geophones and (2) perform magnetic surveys. 
Total field magnetic data were acquired by using the Model G-822L cesium vapor magnetometer manufactured by EG\&G Geometrics. The magnetometer is a continuous-recording (T0 readings per second), total-field, microprocessor-based instrument capable of resolution of anomalies to one nanotesla $(1 \mathrm{nT})$.

Electrical conductivity measurements were made with a Model EM-31, an electromagnetic instrument manufactured by Geonics Limited that provides mean values of conductivity, in millisiemens per meter $(\mathrm{mS} / \mathrm{m})$, for soils ranging from 0 to approximately $18 \mathrm{ft}$ in depth. Apparent conductivities measured by the EM-31 are weighted mean values measured over the entire depth range, with greater weights applied to shallower depths.

Initial reduction of the electromagnetic and total field magnetic data was completed using DAT 31 software provided by Geonics. The United States Geological Survey (USGS) minimum curvature gridding program MINC (Cordell et al. 1992) was used to plot the data on a grid. Color contour maps presenting the electromagnetic and total field magnetic data were produced by using software developed by Argonne National Laboratory (ANL).

Two geophysical well logging techniques, induction and gamma logging, were employed at selected wells on the Bush River Peninsula. An EM-39 induction probe, manufactured by Geonics Limited and adapted to an MGX model logging unit manufactured by Mount Sopris Instrument Company, was used to produce conductivity logs. A Mount Sopris Instrument Company Model HLP-2375/S was used with the MGX model logging unit to produce gamma logs.

GPR surveying was accomplished by using Geophysical Survey Systems, Inc. (GSSI), models SIR-3 and SIR-2. The SIR-3 was equipped with a Model 38 video display and digital audio tape (DAT) recorder; data were recorded on DAT and downloaded to a personal computer in the field office. Data from the SIR-2 system were downloaded directly to the personal computer. Continuous profiling was performed by using both the 100- and 300-megahertz (MHz)-frequency antennas in the bistatic mode. The control/video display was mounted directly on an all-terrain vehicle, which was used to pull the different antenna arrays through the onshore survey area. For offshore GPR profiles, the antennas rested directly on the bottom of an inflated rubber raft that was towed by a small aluminum bass boat across the survey areas. An IBM-compatible processing computer was located in a field office to download and check the radar profiles and to allow preliminary data processing in the field. Radan III computer software written by GSSI was used for processing the GPR data.

A 24-channel engineering seismograph (EG\&G model ES-2401) was employed to determine the depths and seismic velocities of the sediments underlying the Kings Creek study area. Seismic refraction data of the entire sedimentary section were obtained using a trailermounted elastic wave generator (EWG) manufactured by Bison Instruments, Inc., for a source and geophones with a natural frequency of 16 hertz $(\mathrm{Hz})$ for receivers. Shallow and deep highresolution reflection data were obtained by using the EWG and a 16-pound sledgehammer for sources and geophones with a natural frequency of $60 \mathrm{~Hz}$ for receivers. The different geophones 
were manufactured by Mark, Inc. Multiple EWG hits or hammer hits were stacked as needed to increase the signal-to-noise ratio. Full 24-channel reflection data were obtained using a Model RLS- $120^{\circ}$ roll-along switch with common-depth-point (CDP) cables, manufactured by Input/Output, Inc.

Two shallow seismic refraction lines and downhole seismic data collection techniques were used to further characterize the seismic velocities of the sediments underlying the Bush River Peninsula. A Bison Instruments Model 5012, 12-channel engineering seismograph was utilized to collect these data; a 12-pound sledgehammer served as a sound source. Surveyors used $60-\mathrm{Hz}$ geophones manufactured by Mark, Inc., to collect data from the two shallow refraction lines and a Mark L-10, 8-Hz, three-component geophone to obtain the downhole seismic data.

EAVESDROPPER reflection software, developed by the Kansas Geological Survey (1993), was employed for reflection data processing. The seismic refraction data were processed by using SIPT2 refraction programs, developed by RIMROCK Geophysics, Inc. (1992). 


\section{Magnetic Surveys}

The objectives of the gradiometer and total field magnetic surveys performed at the Kings Creek site were to (1) delineate the boundaries of fill areas containing ferromagnetic debris, and (2) avoid shallow magnetic debris (unexploded ordinance) during the placement of the geophones and survey stakes. The results of these surveys are presented below.

\subsection{Continuous Profiling Magnetometry}

The study area was divided into four sections (Area 1 through Area 4) to obtain total field magnetometry data. Figure 5 shows the magnetic profile locations and indicates the boundaries of the four subdivisions of the study area. Magnetic maps of the entire study area and the four sections are presented in Figures 6 through 10.

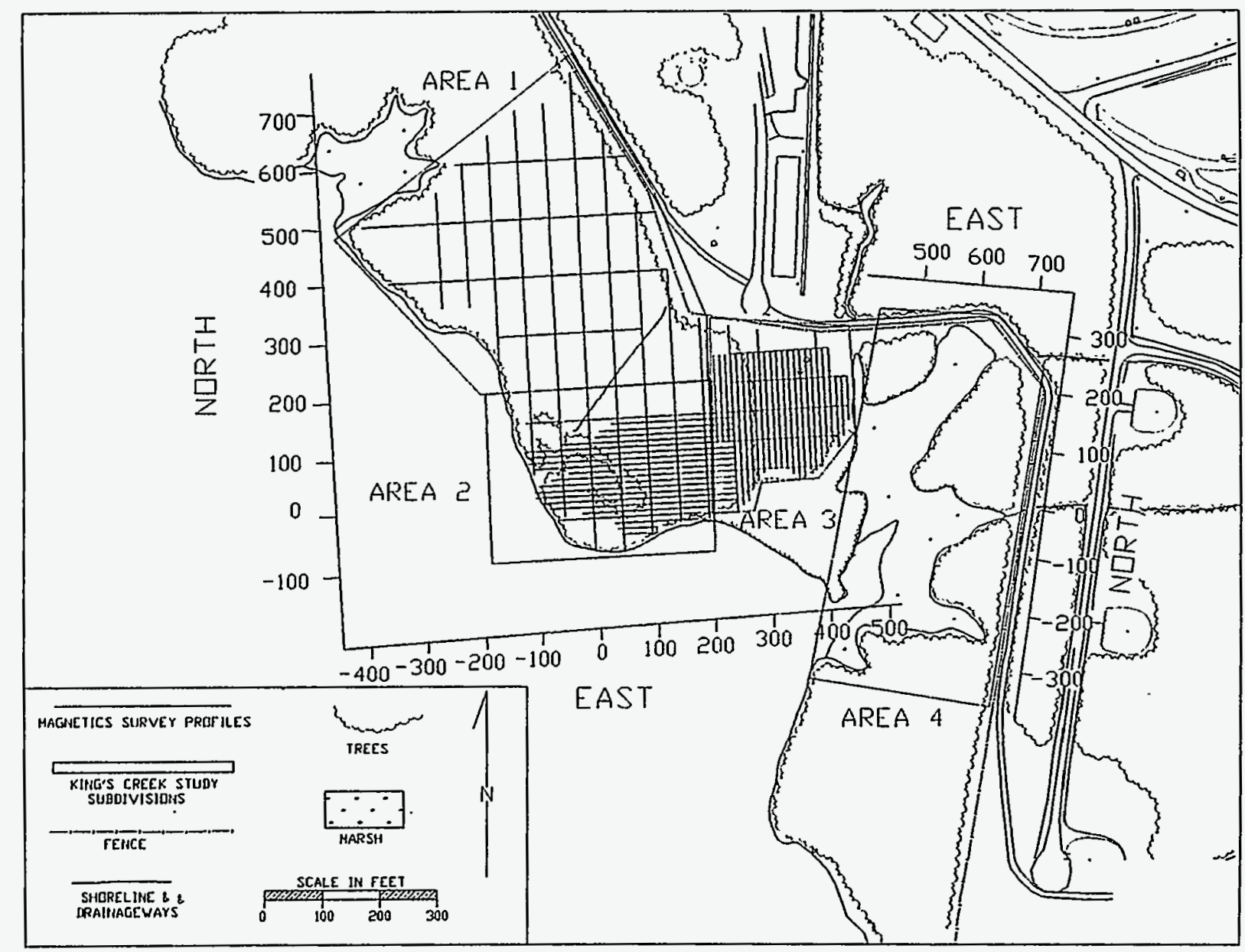

FIGURE 5 Kings Creek Study Area Subdivisions (Areas 1 through 4) and Magnetic Survey Profile Locations 


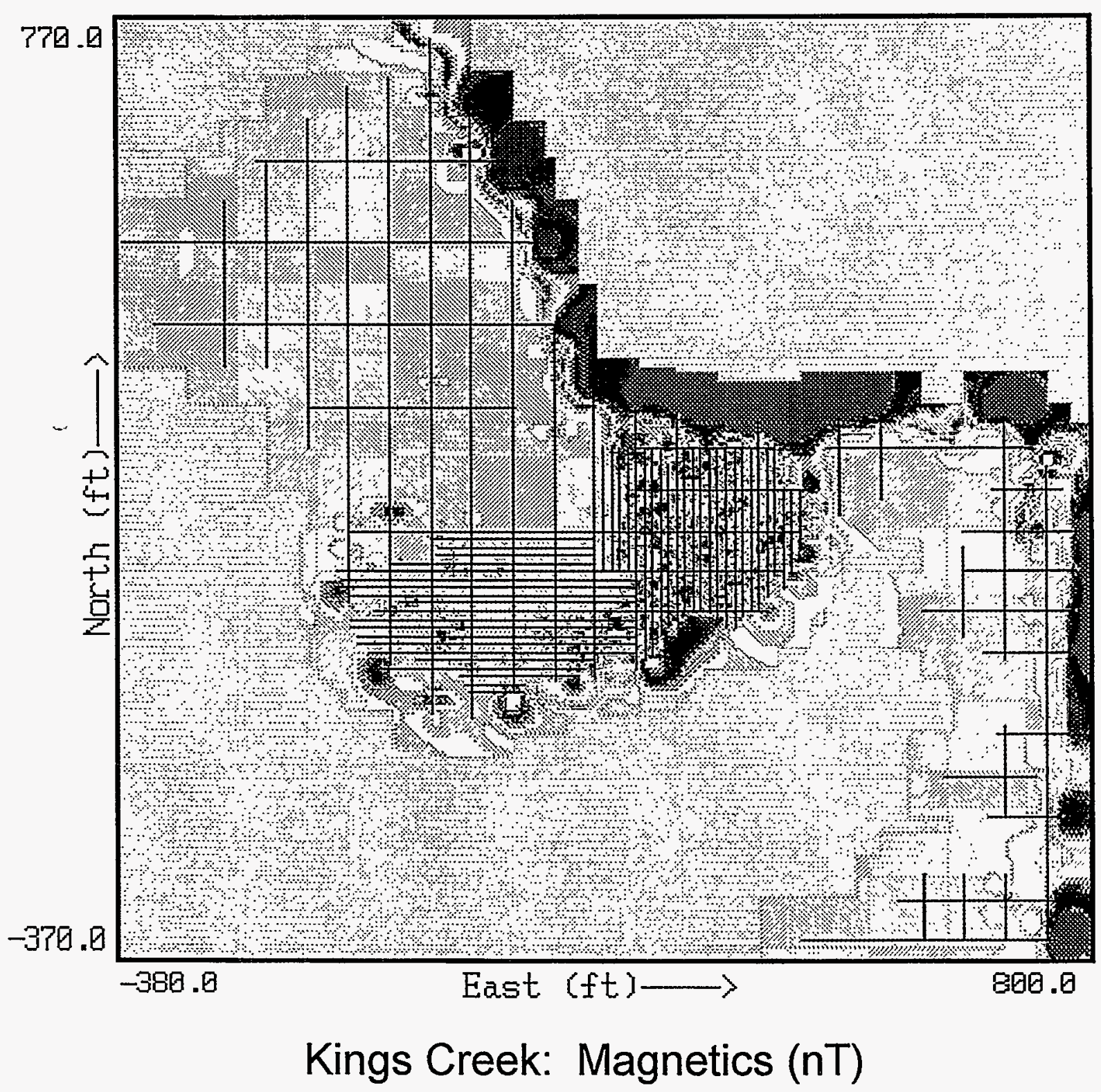

Color Scale

\begin{tabular}{|c|c|c|}
\hline $51,200 \mathrm{nT}$ & 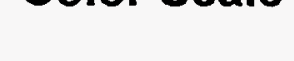 & $56,000 \mathrm{nT}$ \\
\hline TII & 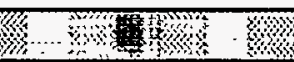 & 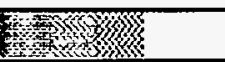 \\
\hline
\end{tabular}

FIGURE 6 Kings Creek Study Area Total Field Magnetics Map 


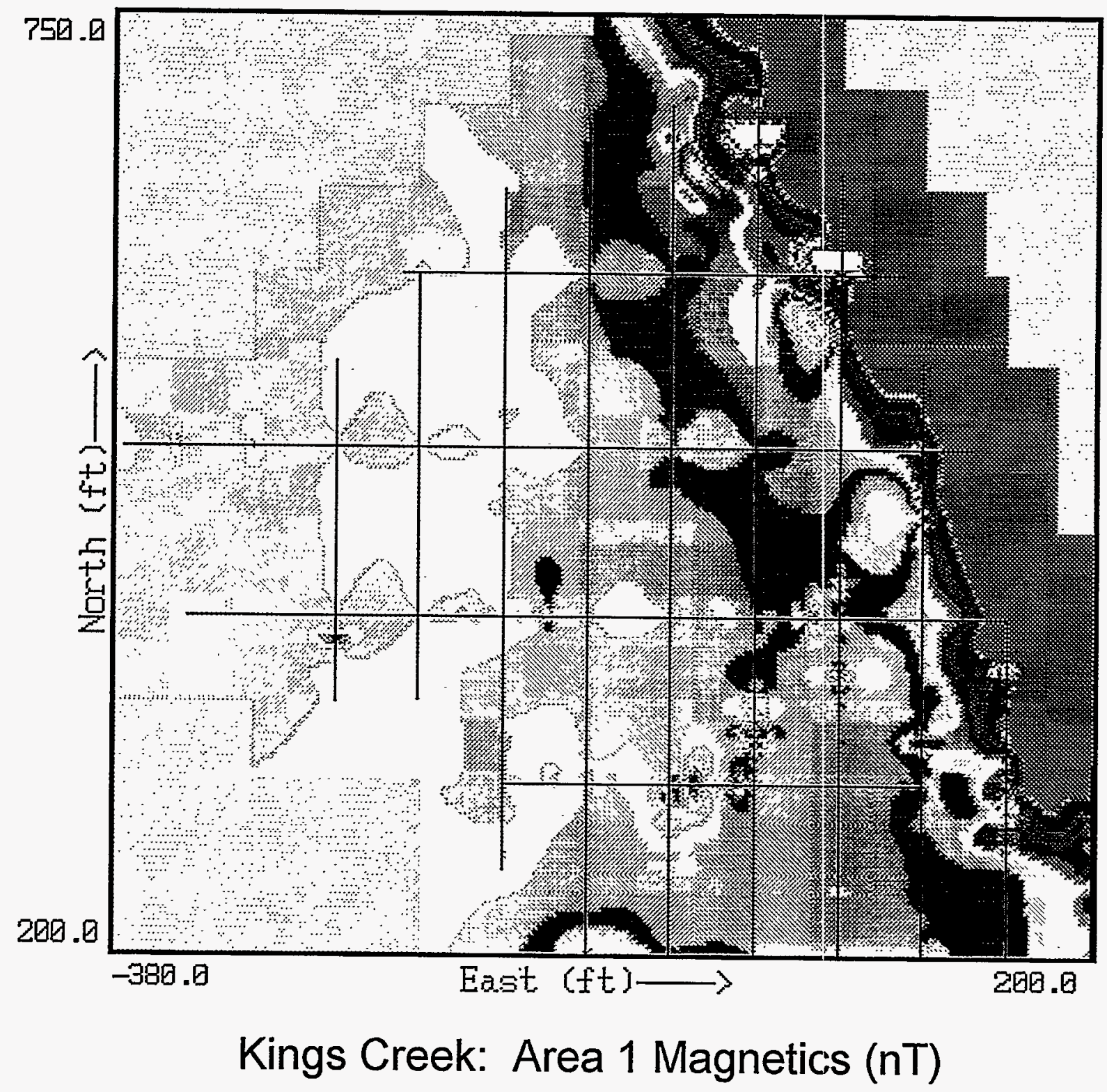

Color Scale

$53,600 \mathrm{nT}$

$54,300 \mathrm{nT}$

櫂

W

FIGURE 7 Area 1, Total Field Magnetics Map 


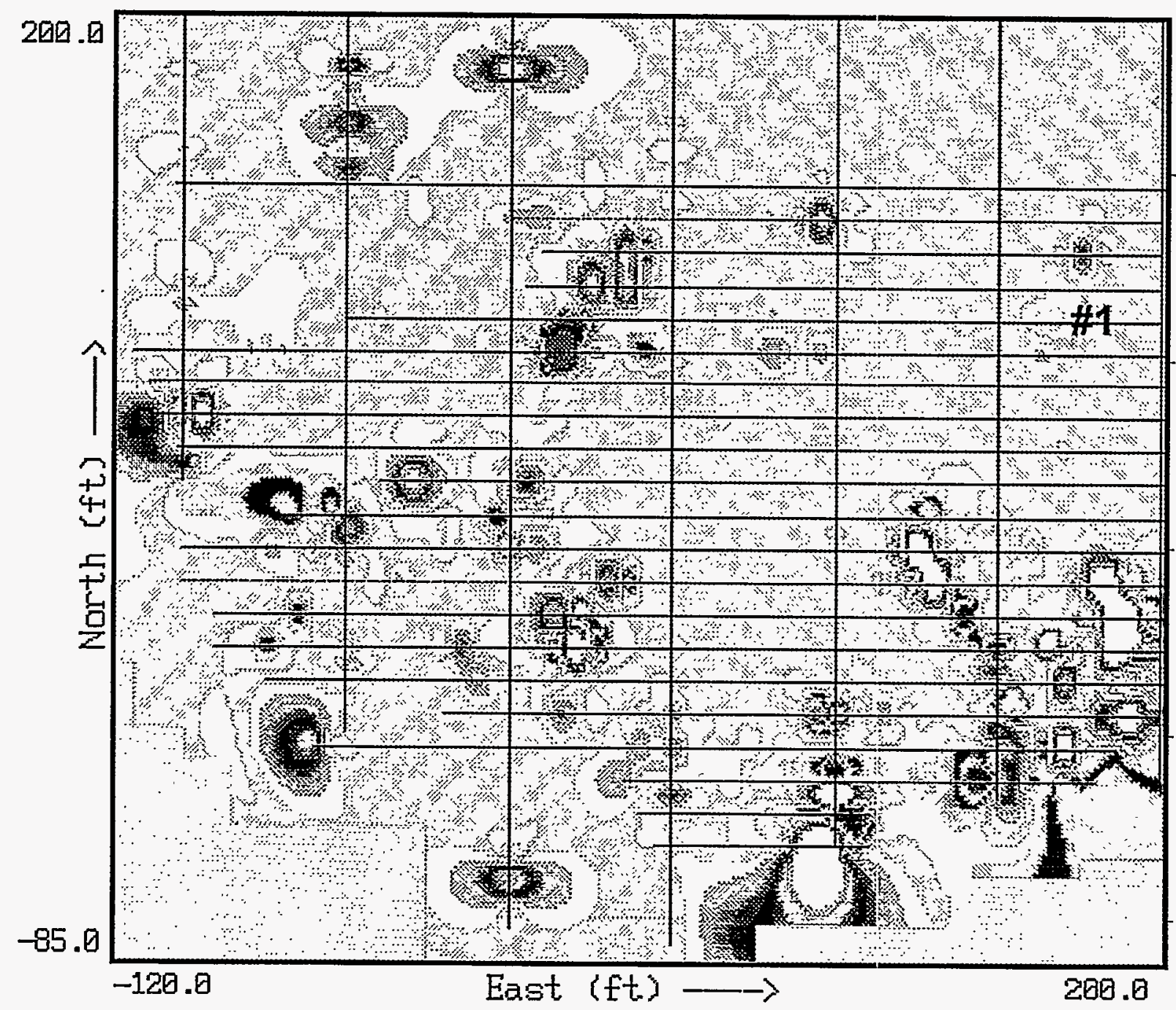

Kings Creek: Area 2 Magnetics (nT)

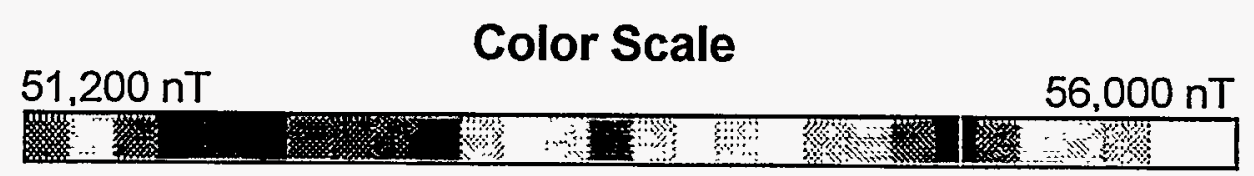

FIGURE 8 Area 2, Total Field Magnetics Map 


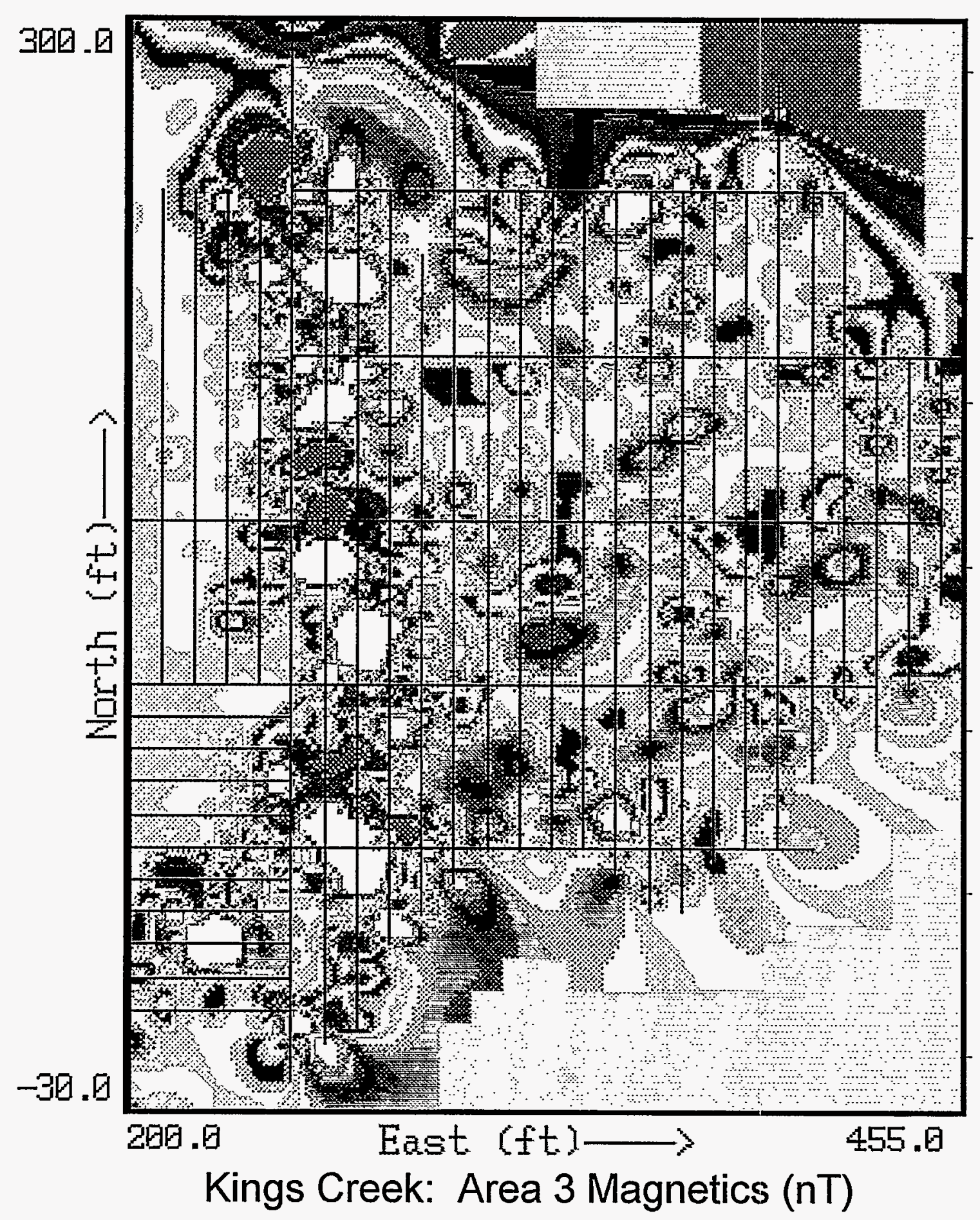

\begin{tabular}{|c|c|c|}
\hline $51,200 \mathrm{nT}$ & Color Scale & $56,000 \mathrm{nT}$ \\
\hline 紧 & \% & कर \\
\hline
\end{tabular}

FIGURE 9 Area 3, Total Field Magnetics Map 


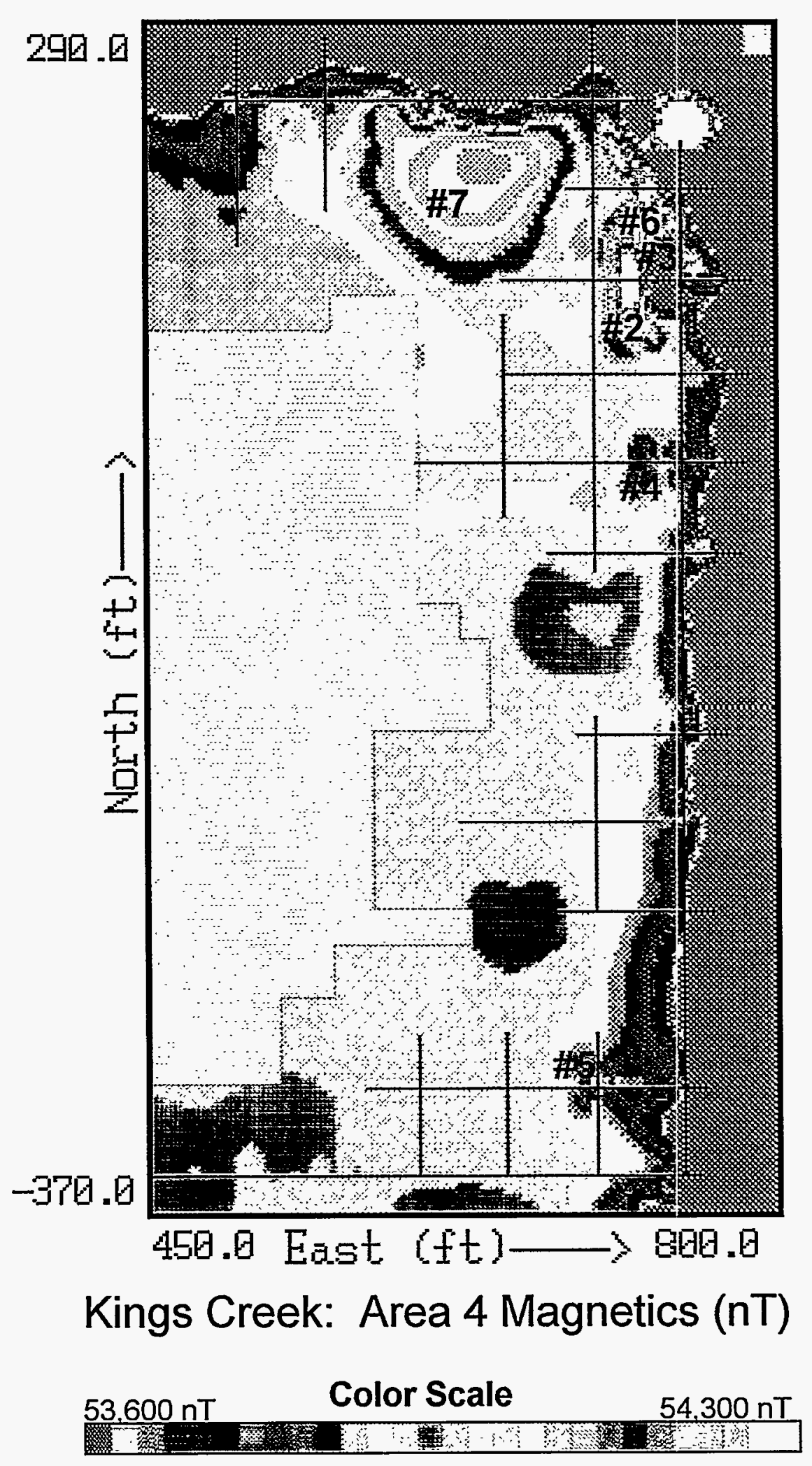

FIGURE 10 Area 4, Total Field Magnetics Map 
Initially, the Kings Creek study area was surveyed along north-south traverses spaced $50 \mathrm{ft}$ apart. East-west tie line traverses were collected at approximate $100-\mathrm{ft}$ intervals where allowed by the vegetation cover. In-field analysis of the preliminary data indicated that Areas 2 and 3 (Figures 8 and 9) contained anomalies that required more detailed examination. Additional surveys were conducted in these two areas (the Kings Creek Disposal Site and the 30th Street Landfill) with profiles spaced $10 \mathrm{ft}$ apart to further delineate the boundaries of the anomalies. Gradiometer surveys were performed between the total field survey profiles in Areas 1 and 4 to determine whether smaller clusters or point source ferrous features were inadvertently missed during the total field magnetic survey (see Section 2.2).

Errors introduced into the magnetic data due to uncorrected diurnal variations and insufficient response speed to changing signals were small compared with the amplitudes of the anomalies detected. Therefore, the anomalies displayed on the magnetic maps are qualitatively significant. Some error, however, can be introduced through inadvertent changes in instrument position or attitude relative to the ground surface. Moving around obstacles or changing walking pace may also produce some positioning error. Marks were placed on the data at 50-ft intervals and at the beginning and end of each survey line. Digital and graphic data readouts are included with the data logging computer. If significant errors were noted while conducting the survey, the profile was redone. Careful control of data acquisition and processing procedures kept errors to a minimum.

Magnetic anomalies detected in the survey area can, in many cases, be explained by ferrous objects on the surface; however, others remain unexplained. Anomalies were observed throughout the Edgewood area where amphibolite was used as road fill. Table 1 lists 71 magnetic anomalies (by area), their coordinates (at the center of each anomaly), and a brief description of each. If the anomaly encompassed a large area, a coordinate range is listed. Anomalies associated with the roadway and security fence systems, bounding the areas to the east and north, are not listed.

\subsubsection{Area 1}

Area 1 is a wooded location north of the Kings Creek Disposal Site (Figure 5). This area was surveyed to identify the northern boundary of the disposal site and determine whether this section was used as an undocumented burial site. Figure 7 presents the total field magnetic data for Area 1. The color contour interval for Figure 7 is reduced by a factor of seven from that presented in the map of the entire study area (Figure 6). This reduction results in smallermagnitude anomalies appearing as a greater color contrast.

As listed in Table 1, the majority of the magnetic anomalies detected in Area 1 are caused by metallic debris visible at the surface. Other anomalies scattered throughout Area 1 are caused by unknown, buried sources. 
TABLE 1 Location and Description of Magnetic Anomalies Detected in the Kings Creek Study Area

\begin{tabular}{|c|c|c|c|}
\hline \multirow[b]{2}{*}{ Area } & \multicolumn{2}{|c|}{ Coordinates } & \multirow[b]{2}{*}{ Anomaly Description } \\
\hline & North & East & \\
\hline \multirow[t]{15}{*}{1} & 690 & 0 & Steam heat radiator and other metallic debris \\
\hline & 610 & 50 & Cyclone fencing \\
\hline & 370 & 150 & Gravel fill and metal culvert \\
\hline & 330 & 0 & Source unknown \\
\hline & 300 & -35 & Source unknown \\
\hline & 385 & -250 & Metal canister \\
\hline & 500 & $-300+-390$ & Two anomalies, source unknown \\
\hline & 270 & 150 & Metal canister \\
\hline & 50 & -345 & Steel cable \\
\hline & 400 & -125 & Metal pipe \\
\hline & 300 & -5 & Source unknown \\
\hline & 400 & 30 & Metal fragments \\
\hline & 420 & 50 & Metal fragments \\
\hline & 365 & 50 & Metal gas canister \\
\hline & 295 & 150 & Source unknown \\
\hline \multirow[t]{26}{*}{2} & 180 & 0 & Push-out mound \\
\hline & 150 to 190 & -50 & Burn pit and push-out with metal fragments \\
\hline & 110 to 120 & -100 & Burn pit push-out \\
\hline & 80 & -90 & Mound with metal drum fragments \\
\hline & 75 to 80 & -110 & Round metal objects (fuses?) \\
\hline & 50 & -70 & Source unknown, push-out area \\
\hline & 10 to 50 & -80 to -50 & $\begin{array}{l}\text { NE/SW-trending area of buried metal cylinders with } \\
\text { tops at surface }\end{array}$ \\
\hline & 60 & -30 & Mound of rusted cylinder and drum parts \\
\hline & 50 & -70 & Source unknown, push-out area \\
\hline & 60 & 5 & Metal fragments, push-out area \\
\hline & 45 & 0 & Source unknown, push-out area \\
\hline & 30 & $30+40$ & Two anomalies, source unknown, push-out area \\
\hline & 10 to 20 & 15 to 30 & $\begin{array}{l}\text { Source unknown, mound with pine trees surrounded by } \\
\text { non-vegetated area }\end{array}$ \\
\hline & -35 to -10 & 20 to 50 & Area covered with rusted metal fragments \\
\hline & -5 to 15 & -20 to -10 & Area covered with rusted metal fragments \\
\hline & -20 & -60 & Metal on surface \\
\hline & -60 & 0 & Source unknown \\
\hline & -50 & 90 & Source unknown, shoreline \\
\hline & -35 & 100 & Source unknown \\
\hline & -10 & $90+100$ & Two anomalies, metal debris, push-out \\
\hline & 25 to 45 & 125 to 135 & Pin flags and push-out mound \\
\hline & -30 & 140 & Metal debris \\
\hline & 0 & 150 & Metal cylinder \\
\hline & 0 & 170 & Metal debris \\
\hline & -20 & 170 & Source unknown, near shoreline \\
\hline & -10 & 190 & Source unknown, near shoreline \\
\hline
\end{tabular}


TABLE 1 (Cont.)

\begin{tabular}{|c|c|c|c|}
\hline \multirow[b]{2}{*}{ Area } & \multicolumn{2}{|c|}{ Coordinates } & \multirow[b]{2}{*}{ Anomaly Description } \\
\hline & North & East & \\
\hline & 5 to 40 & 180 to 190 & Two railroad rails, possibly other buried materiel \\
\hline & 110 & 170 & Source(s) unknown, location of GPR anomaly \\
\hline & 130 & 175 & Source unknown \\
\hline & 140 & 95 & Source unknown \\
\hline & 100 & $80+95$ & Two anomalies, source unknown \\
\hline & 100 & 40 & Source unknown, push-out \\
\hline & 100 & 20 & Metal debris \\
\hline & 115 to 135 & 20 to 40 & Source unknown, push-out area \\
\hline & 140 & 0 to 15 & Source unknown, push-out area \\
\hline \multirow[t]{12}{*}{3} & 40 & 215 & Source unknown \\
\hline & 10 to 30 & 220 to 240 & Metal debris, probable buried fill \\
\hline & 0 & 250 & Metal debris \\
\hline & -10 & 260 & Source unknown, shoreline \\
\hline & 40 & 300 & Source unknown, edge of phragmites \\
\hline & 120 & 230 & Source unknown, small mound \\
\hline & 180 & 210 & Metal debris, small mound \\
\hline & 165 & 445 & Metal debris at edge of survey \\
\hline & 250 & 350 & Gravel pile \\
\hline & 250 & 335 & Argonne trailer \\
\hline & 0 to 250 & 240 to 280 & $\begin{array}{l}\text { Linear anomalous area with some metal debris visible, } \\
\text { approximate western edge of landfill }\end{array}$ \\
\hline & 50 to 250 & 280 to 450 & $\begin{array}{l}\text { Anomalous probable fill area, no visible metal, may } \\
\text { extend farther south into phragmites }\end{array}$ \\
\hline \multirow[t]{5}{*}{4} & -300 & 700 & Source unknown \\
\hline & 50 & 740 & Metal fencing \\
\hline & 150 & 725 & Metal fencing \\
\hline & 150 & 740 & Metal fencing \\
\hline & 200 & 730 & Source unknown \\
\hline
\end{tabular}




\subsubsection{Area 2}

Area 2 is a partially wooded location containing the former Kings Creek Disposal Site and associated push-out mounds of soil and debris. Stressed vegetation and bare ground are associated with previous activities at the site. The majority of this section was surveyed on a 10 -ft grid spacing.

Figure 8 presents the total field magnetic data for Area 2. The southwestern portion of the area contains surficial metallic debris, including dismantled cylinders, fuses, and rusted metal chips. The southeastern portion of Area 2 contains surficial and buried metal objects and is probably the boundary of the 30th Street Landfill. Table 1 reveals that isolated anomalies, caused by unknown buried objects, are located throughout Area 2. One unknown anomaly, located at $110 \mathrm{~N} / 170 \mathrm{E}$ of the survey grid (\#1, Figure 8), corresponds to the location of an anomaly detected during the GPR survey and may represent a small buried tank or drum.

\subsubsection{Area 3}

Area 3 (30th Street Landfill) is an open, brushy area bounded by low-lying cattail and phragmite wetlands to the east and south. The treeline to the west (approximately 250E on the survey grid) is the approximate boundary of the landfill. This section was surveyed on a 10-ft grid spacing.

The majority of Area 3 is magnetically anomalous (Figure 9). The eastern boundary of this section, with 3-4 ft of relief above sea level, likely represents the eastern edge of landfilling. Filling probably extended farther south into an area where heavy phragmite cover prevented surveying. The central portion of the landfill is covered with soil and vegetation. Some metallic objects are visible along the eastern boundary and, especially, the western boundary of Area 3 , where cover soil has been removed or collapsed into cavities, creating holes $2-3 \mathrm{ft}$ deep. Table 1 provides a description of the anomalies detected in Area 3.

\subsubsection{Area 4}

Area 4 is east of the 30th Street Landfill, separated from the landfill by wetland. This heavily vegetated section is divided by three arms of the wetland extending toward the east (Figure 5). Area 4 was surveyed on a grid spacing of $50 \mathrm{ft}$ to determine whether additional landfilling occurred at this location. The grid orientation of Area 4 is slightly different from that in the other three sections to account for the section's irregular shape (see Figure 5). A magnetic map of Area 4 is presented in Figure 10; magnetic anomalies are listed in Table 1. The contour interval for Figure 10 is reduced in comparison to Figures 6, 8, and 9, resulting in smallermagnitude anomalies appearing with a greater color change. 
Five anomalies were detected during the total field magnetic survey in Area 4. Partially buried fencing (located at 150N/725E, 150N/740E, and 50N/740E) resulted in three anomalies $(\# 2$, \#3, and \#4, respectively, Figure 10). Two anomalies of unknown source at $-300 \mathrm{~N} / 700 \mathrm{E}$ and 200N/730E (\#5 and \#6, respectively, Figure 10) may also be associated with fencing material. The color contour change in the north-central portion of Area 4 (\#7, Figure 10) is an artifact of the contouring program. As indicated by the profile lines, no data were collected in this area, which is marsh.

\subsection{Magnetic Gradiometer Survey}

A magnetic gradiometer was used during the study to clear areas prior to placement of survey stakes and geophones. The gradiometer was also used between survey profiles in areas surveyed on a 50 -ft grid spacing (primarily Areas 1 and 4). Fine-grid (10-ft) total field magnetic surveys were not conducted in Areas 1 and 4 because of the heavy vegetation cover and the relative lack of magnetic features detected during the 50 -ft grid surveys. The instrument used for the magnetic gradiometer survey produces an audible signal that changes pitch over anomalous areas. The locations of anomalies detected during the gradiometer survey are overlaid onto magnetic maps in Figures 11 and 12.

Numerous small magnetic anomalies are scattered throughout the section north of the former Kings Creek Disposal Site. The black outlines on Figure 11 represent areas where the density of anomalies was too high for individual identification. Metallic debris, including fencing and construction debris as well as amphibolite gravel, is visible near the fenceline to the east. The larger features to the southwest are associated with metallic debris pushed out of the former burn pits. The origin of the northeast-to-southwest-trending anomalous area is unknown, but the feature may represent a former road leading to the Kings Creek Disposal Site.

Area 4 also contains numerous small magnetic anomalies (Figure 12). The majority of the anomalies are located near the current fenceline and represent old fencing material. The origin of other scattered anomalies, located away from the fenceline, is unknown. 


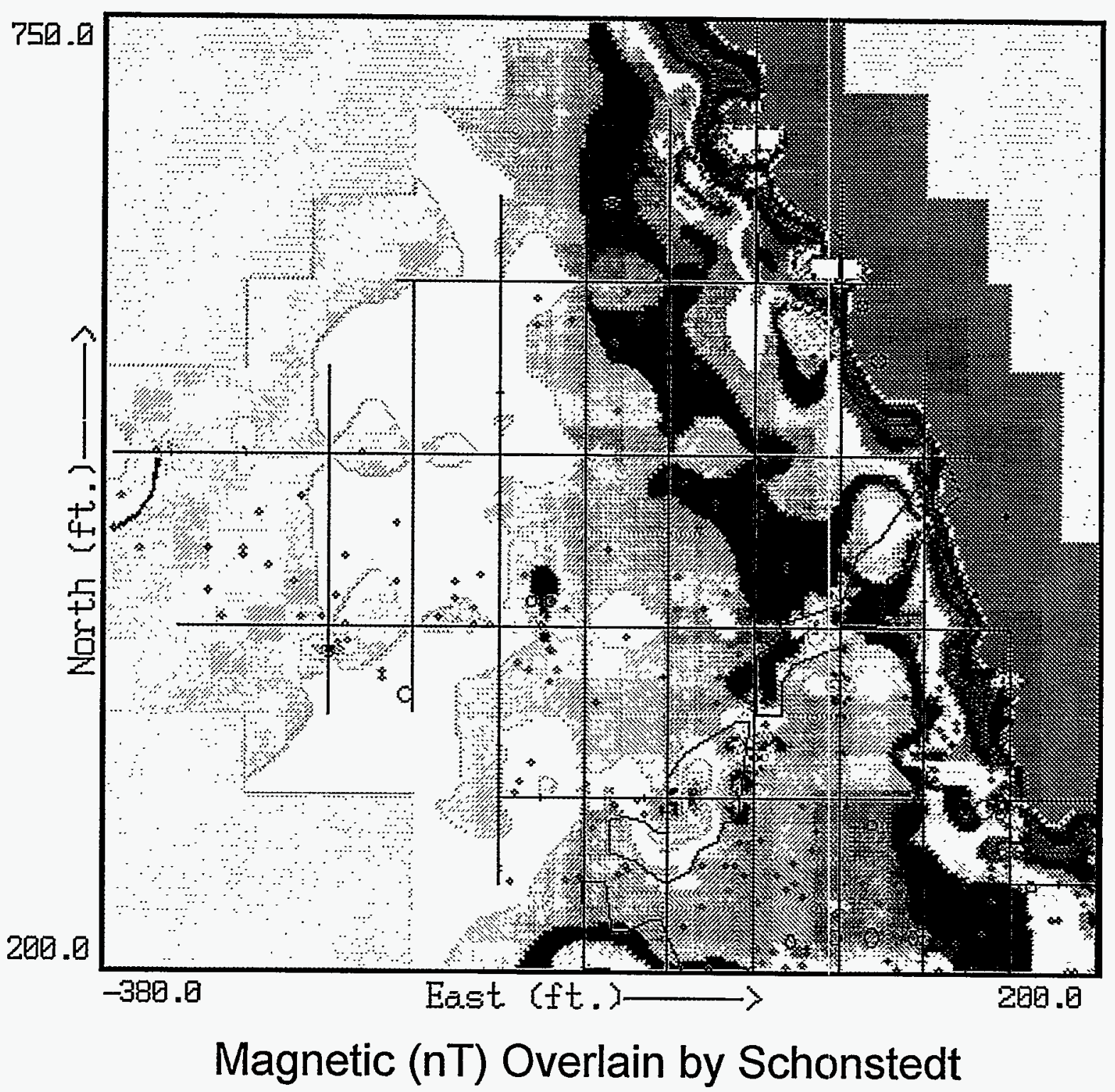

Color Scale

$53,600 \mathrm{nT}$

$54,300 \mathrm{nT}$

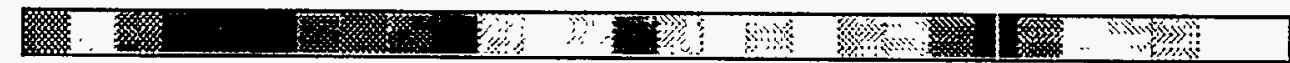

FIGURE 11 Total Field Magnetics Map Overlain by Magnetic Gradiometer Anomalies, North of Former Kings Creek Disposal Site 

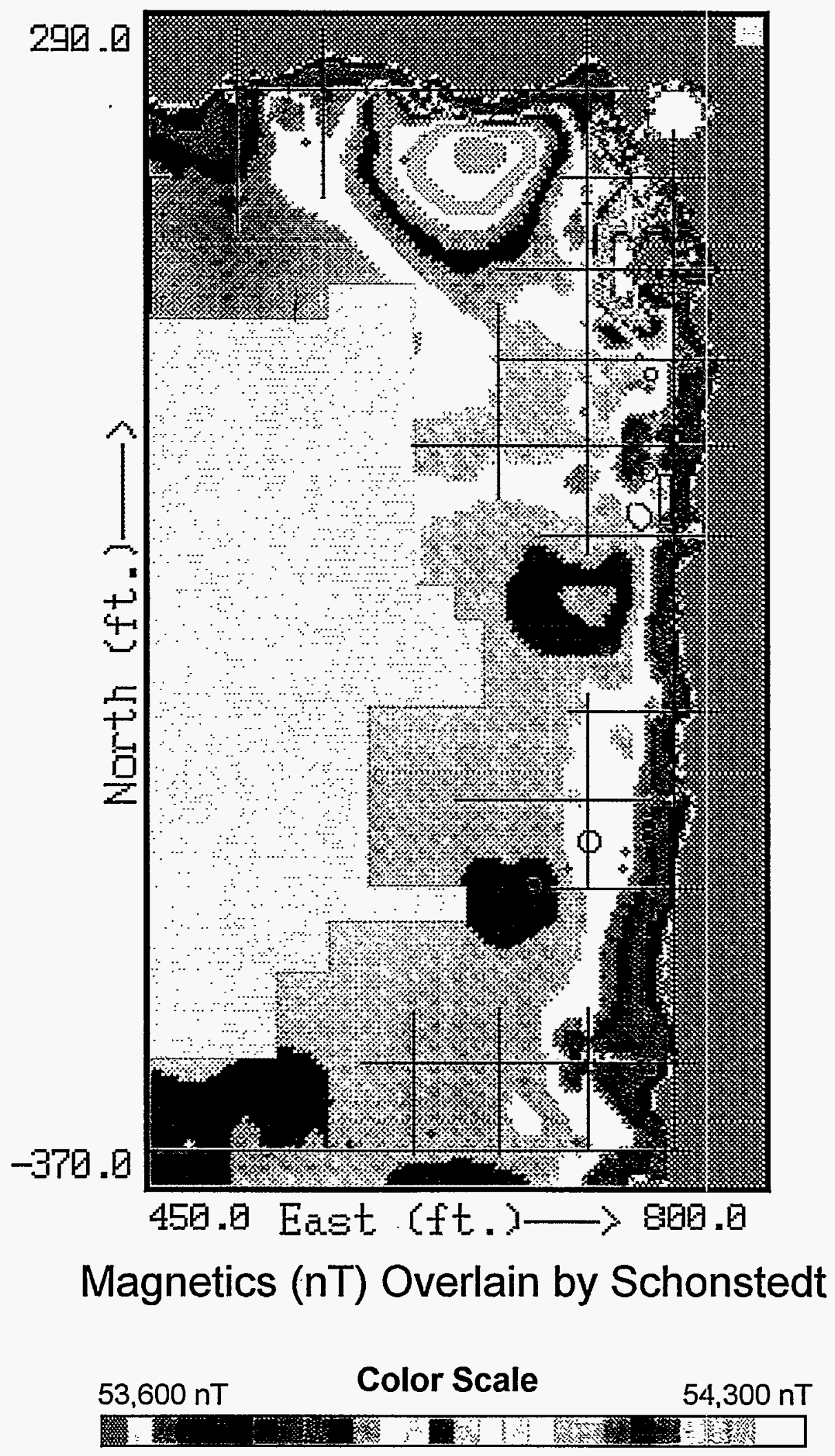

FIGURE 12 Total Field Magnetics Map Overlain by Magnetic Gradiometer Anomalies, East of 30th Street Landfill 


\section{Electrical Conductivity Survey}

Horizontal conductivity measurements were obtained by using a Geonics EM-31, an electromagnetic induction instrument that provides mean values of apparent conductivity in the subsurface. Data were collected on $50-\mathrm{ft}$ and $10-\mathrm{ft}$ transects similar to those used for the total field magnetic survey (Figure 5). Data were acquired every $0.5 \mathrm{~s}$, resulting in data points spaced $1.0-1.5 \mathrm{ft}$ apart, depending on traverse rate. Fiducial marks were placed every $50 \mathrm{ft}$ to correctly position the data within each profile. Figure 13 is a color contour map of the conductivity values of the entire study area.

The EM-31 instrument measures the apparent subsurface conductivity from just beneath the land surface to a depth of approximately $18 \mathrm{ft}$. Factors affecting subsurface conductivity include the following: depth to groundwater, chemical composition of groundwater, presence of clay minerals, type of clay minerals, presence of metals, and presence of amphibolitic roadfill. The EM-31 data were interpreted in conjunction with the magnetic, GPR, topographic, and boring data for the Kings Creek study area. These other data were used to help identify the potentially conflicting factors affecting the measured apparent conductivity.

The EM-31 survey area was divided into the same four sections used for the magnetic data survey (Figures 14 through 17). Apparent conductivities shown on the maps range from approximately -60 to $380 \mathrm{mS} / \mathrm{m}$; the greatest conductivity ranges were observed near the 30th Street Landfill and near large surficial metallic objects (fences and debris). Although metals are good conductors, their shape and orientation in relation to the EM-31 instrument can result in an electromagnetic field in which the apparent conductivity, as read by the EM-31, is negative. Negative conductivities are an artifact of crossing high-conductivity gradients with the EM-31 boom. When crossed at right angles by the EM-31, an elongated piece of metal (such as a buried pipe) will produce three banded anomaly lineaments. The lineaments will consist of a central minimum bounded by two maxima (Geonics Limited 1992). This EM-31 signature for buried pipes has previously been observed at Beach Point in APG (see McGinnis et al. 1994a). The EM-31 contour interval in the figures representing Areas 1 and 4 (Figures 14 and 17) has been reduced from that presented in Figure 13, which represents the entire study area, to illustrate the more subtle conductivity changes in these less disturbed areas.

EM-31 measurements were also collected during an offshore geophysical survey performed by ANL. The surveyed area included the near shore adjacent to the Kings Creek study area. A portion of the offshore EM-31 survey data is discussed in conjunction with the onshore data from Area 3.

\subsection{Area 1}

Conductivity values for Area 1 are shown in Figure 14. Two low-conductivity anomalies, located in the northern portion of Area 1 at approximately 690N/00E and 650N/30E (\#8 and \#9, respectively, Figure 14), are associated with metallic debris. A conductivity high was found at 

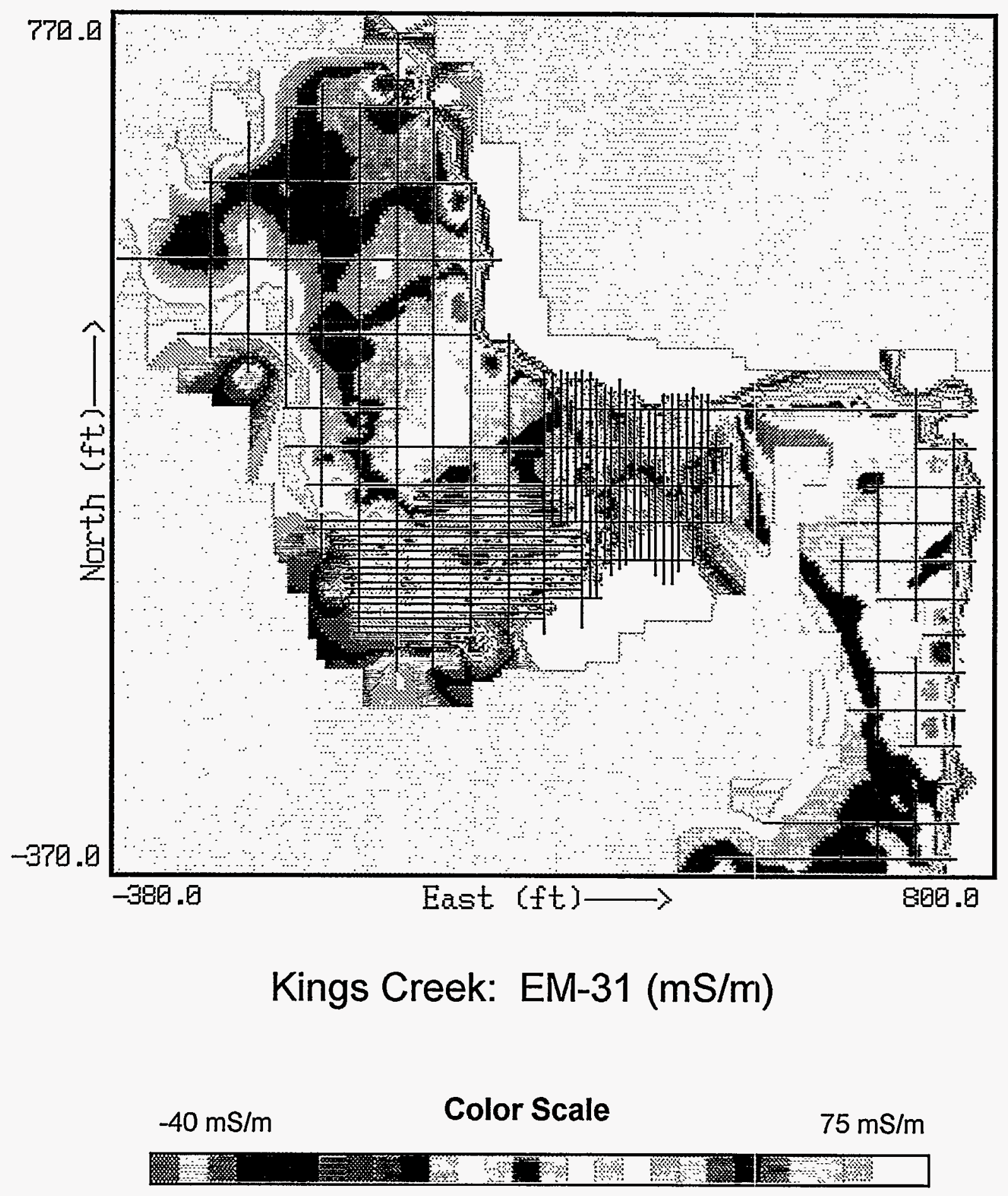

FIGURE 13 Kings Creek Study Area, EM-31 Electromagnetics Map 


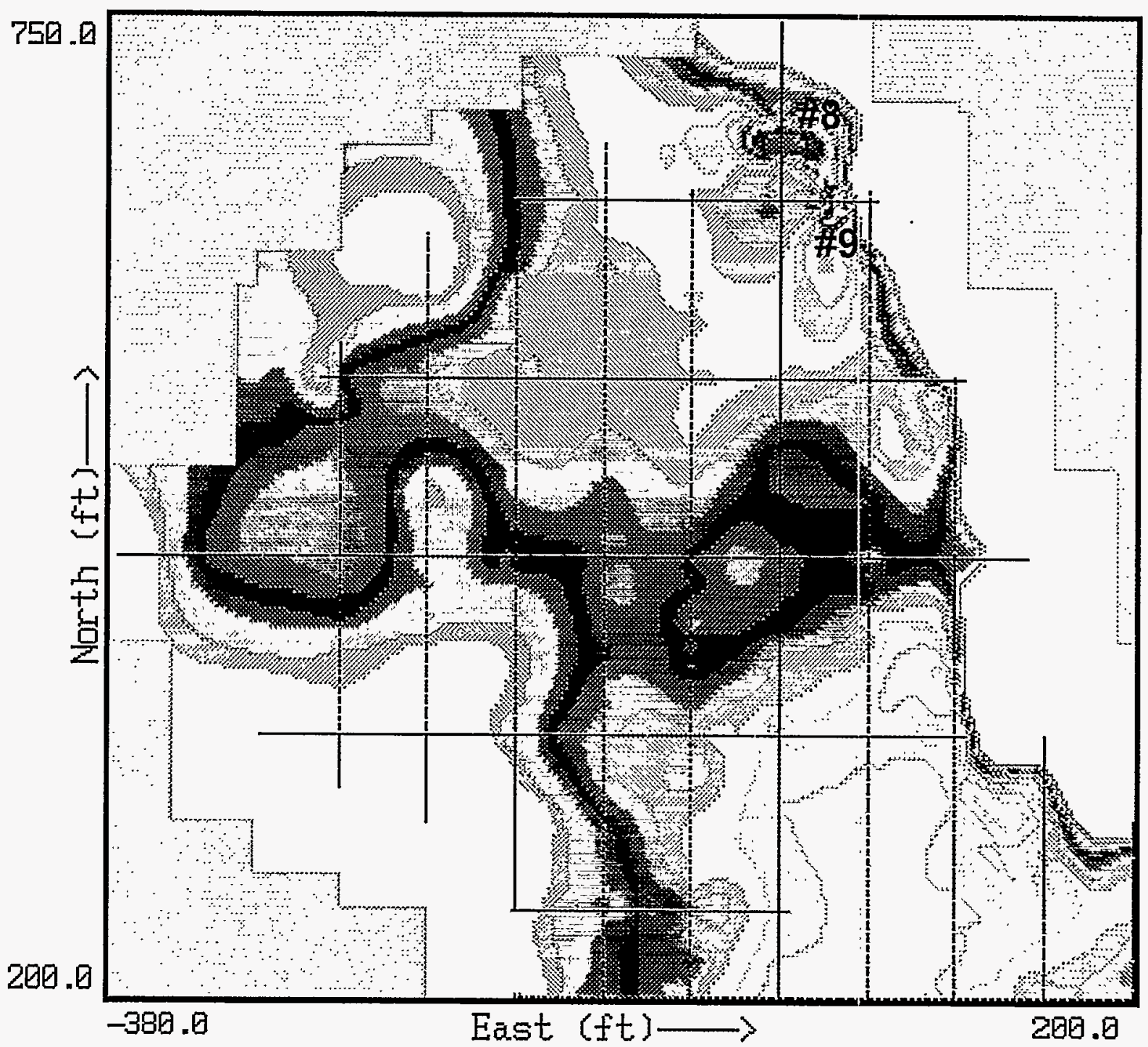

Kings Creek: Area 1 EM-31 (mS/m)

\begin{tabular}{|c|c|c|}
\hline$-20 \mathrm{mS} / \mathrm{m}$ & Color Scale & $30 \mathrm{mS} / \mathrm{m}$ \\
\hline . & 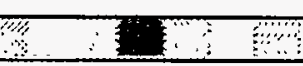 & ris \\
\hline
\end{tabular}

FIGURE 14 Area 1, EM-31 Electromagnetics Map 


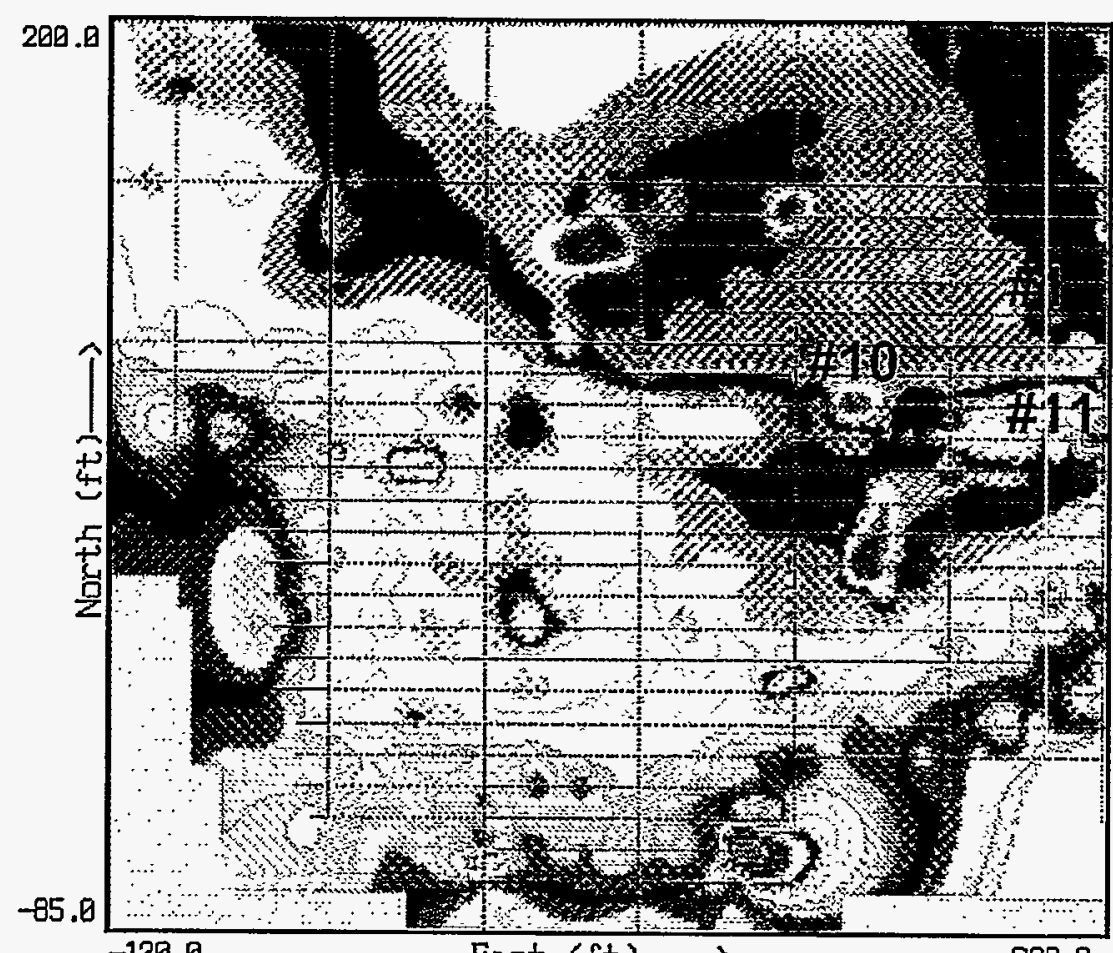

$\mathbf{A}$

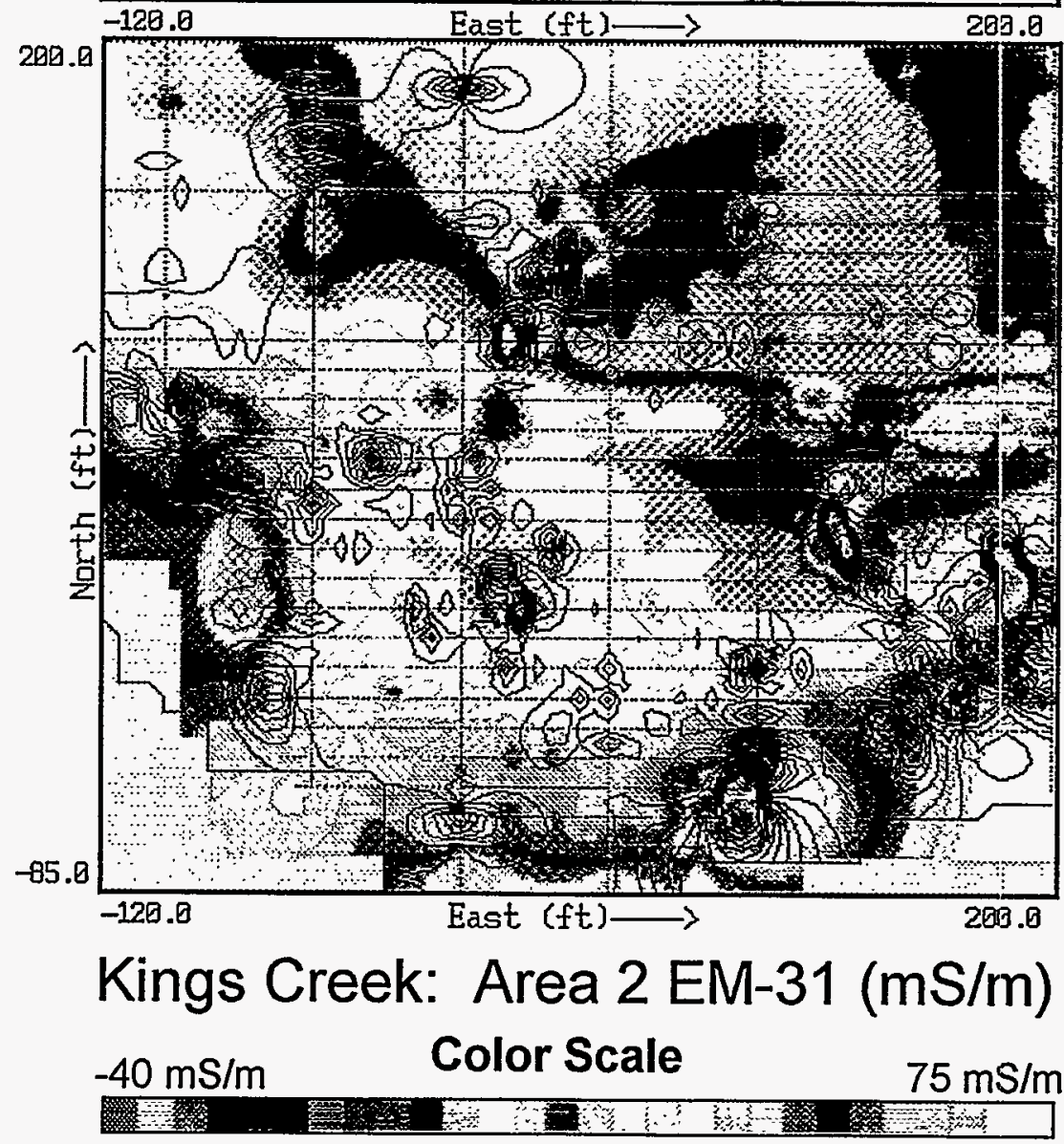

FIGURE 15 A: Area 2, EM-31 Electromagnetics Map; B: Area 2, EM-31 Overlain by Magnetic Contours 

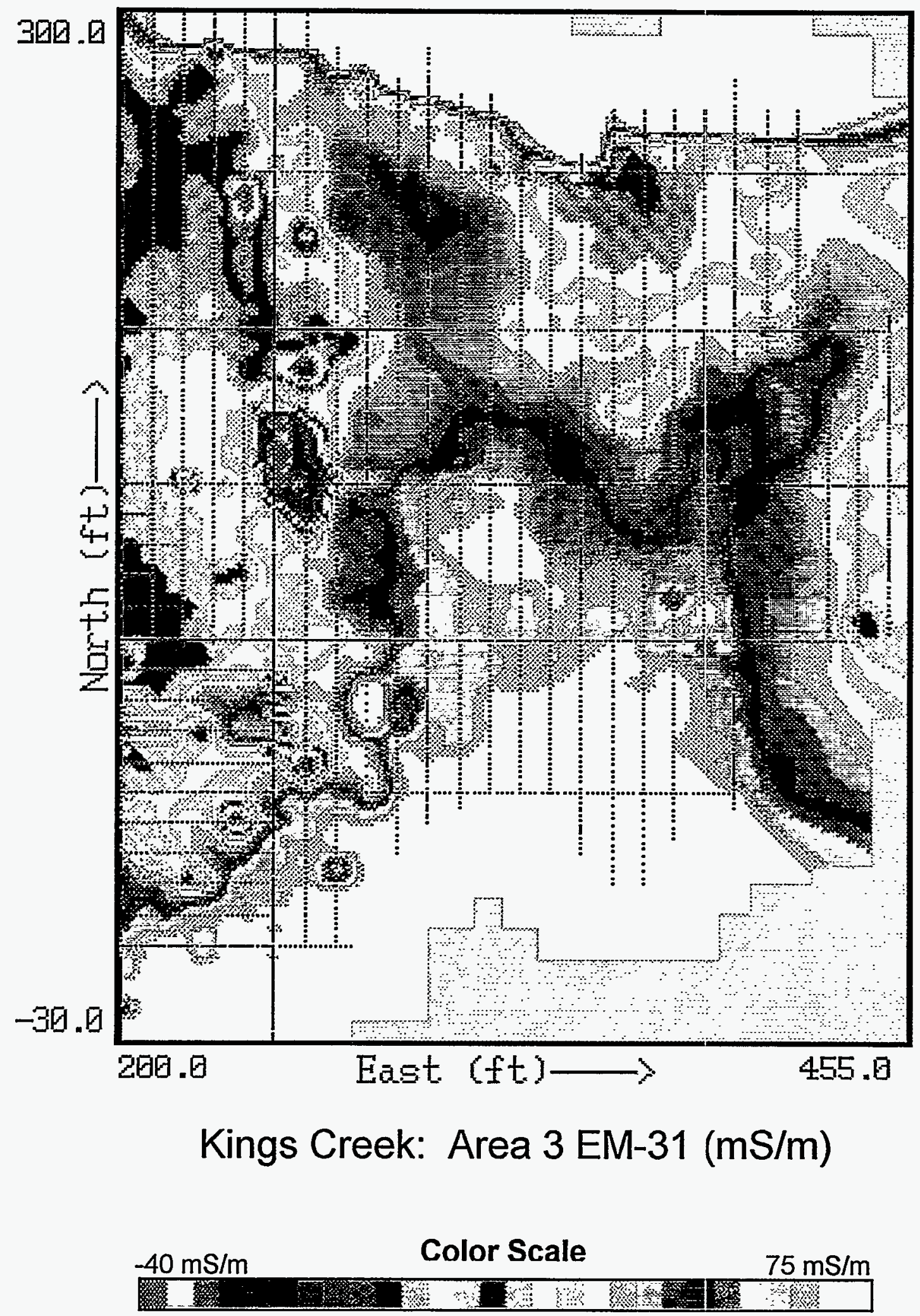

FIGURE 16 Area 3, EM-31 Electromagnetics Map 


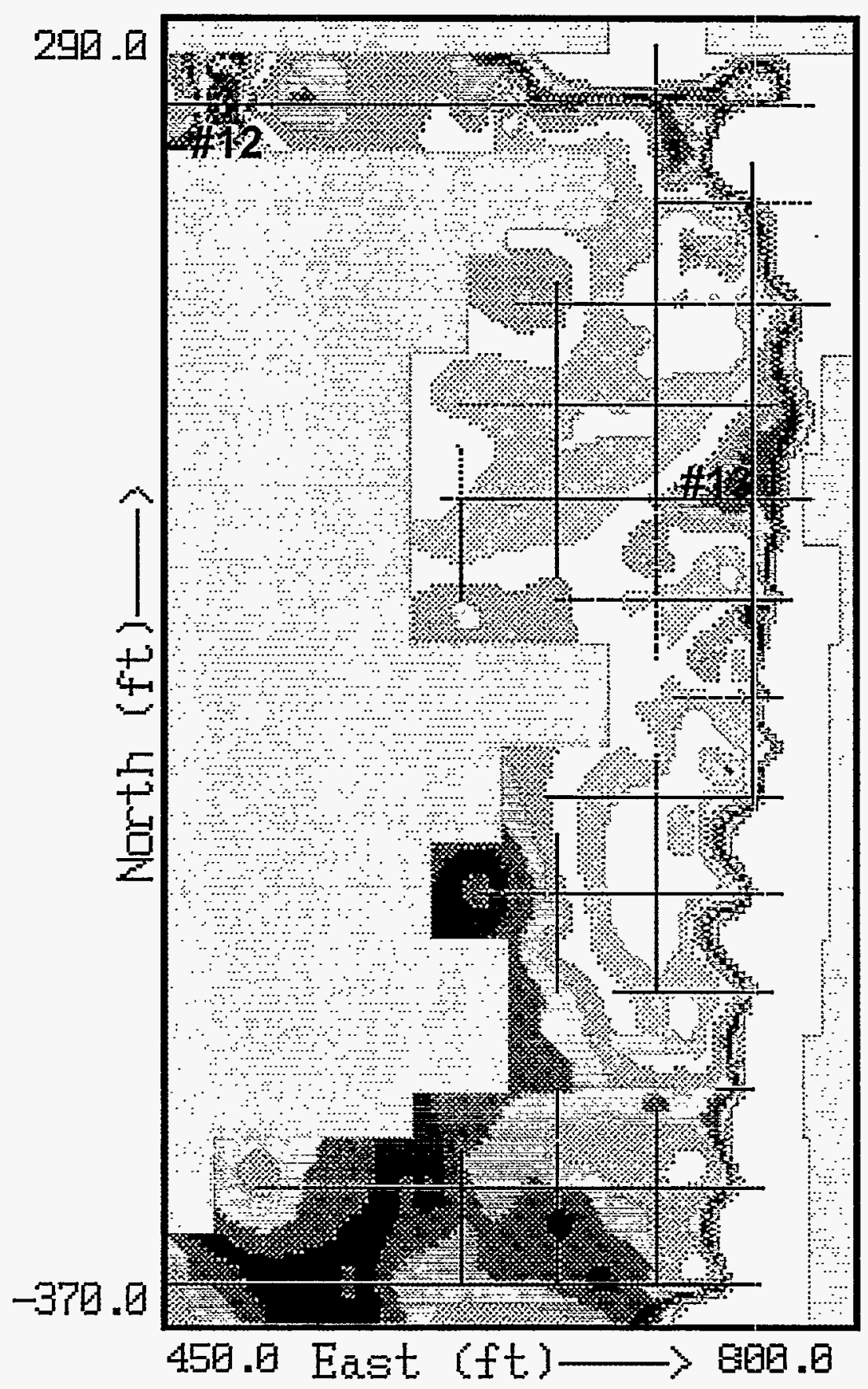

Kings Creek: Area 4 EM-31 (mS/m)

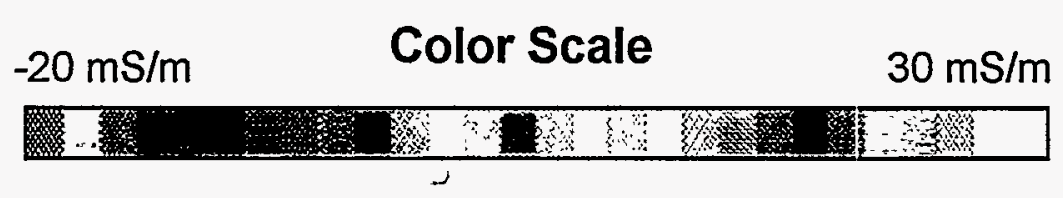

FIGURE 17 Area 4, EM-31 Electromagnetics Map 
the fenceline along the eastern boundary of Area 1. Metallic objects can provide either a high or low conductivity anomaly depending upon their size, shape, and orientation. Other highs along the northwest, west, and southwest edges of the section are likely caused by the surface water in Kings Creek.

The northeast/southwest-trending, relatively higher-conductivity feature detected in the central portion of Area 1 is likely caused by the site topography (Figure 2). Generally, the depth to the water table in lower topographic areas will be shallower, resulting in a higher average conductivity for the relatively shallow depths measured by the EM-31 (i.e., the upper $18 \mathrm{ft}$ ). Lithology may also be a factor; if more clays are present in the shallow subsurface, slightly higher conductivities will result.

\subsection{Area 2}

Conductivity values for Area 2, the approximate location of the former Kings Creek Disposal Site, are shown in Figure 15A. The figure shows several isolated areas of low conductivity, indicated by the colder colors. Most of these low-conductivity zones correspond to buried or surficial magnetic anomalies. Figure 15B shows the EM-31 conductivity contours (in color) overlain by the black line magnetic contours. Two low-conductivity anomalies detected by the EM-31 at $80 \mathrm{~N} / 120 \mathrm{E}$ and $70 \mathrm{~N} / 180 \mathrm{E}$ (\#10 and \#11, respectively, Figure 15A) do not correspond to magnetic anomalies. This finding may result from a positioning error during the magnetic survey caused by the thick vegetative undergrowth in these areas. Another lowconductivity anomaly, located at 110N/170E (\#1, Figure 15A), was detected during both the magnetic and GPR surveys.

In general, no features indicative of lithologic change or buried paleochannels are revealed by the EM-31 data for Area 2. Conductivities gradually increase toward Kings Creek, which would be expected based on the presence of surface water and metallic debris at some locations (Figures 15A and 15B). No large-scale buried features were detected by the EM-31 survey in the former Kings Creek Disposal Site.

\subsection{Area 3}

Conductivity values for Area 3, the approximate area of the 30th Street Landfill, are shown in Figure 16A. The complex patterns of EM-31 anomalies, located along the western and southwestern boundaries of the 30th Street Landfill, likely represent buried and surficial metallic debris.

The conductivity feature of most interest in Area 3 is the centrally located zone of relatively higher conductivity. This feature is believed to represent the site of a former estuary that was later used as a landfill. The EM-31 data correspond to the location of the former estuary, with upstream 
lobes extending toward the northwest and northeast. Additional evidence of a deeper paleochannel at this location, both onshore and offshore, is presented with the discussion of the GPR surveys in Section 5.

EM-31 data were also collected in the offshore portion of the embayment adjacent to Area 3. The location of this portion of the offshore survey is shown in Figure 18. The electromagnetic data reveal relatively higher conductivities $200 \mathrm{ft}$ into Kings Creek (Figure 19). These higher conductivities indicate the presence of clayey estuarine sediments and groundwater with relatively higher conductivity. A more detailed evaluation of the offshore geophysical study will be presented in a separate report.

\subsection{Area 4}

Conductivity values for Area 4, east of the landfill/disposal areas, are shown in Figure 17. One low-conductivity anomaly, located at 250N/490E (\#12, Figure 17), represents a steel culvert beneath the roadway. As described in the beginning of this section, the shape and orientation of

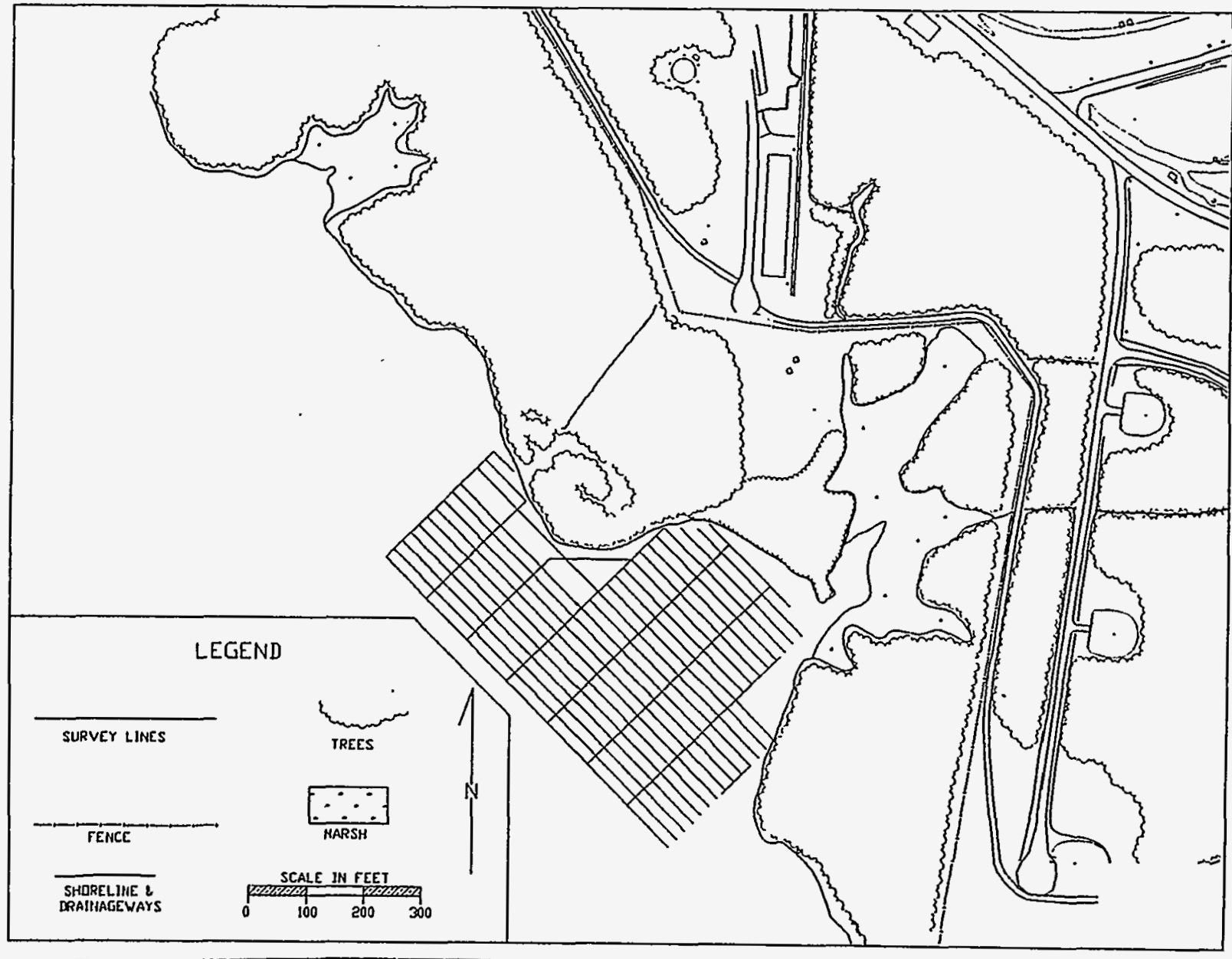

FIGURE 18 Location of EM-31 Offshore Profiles 

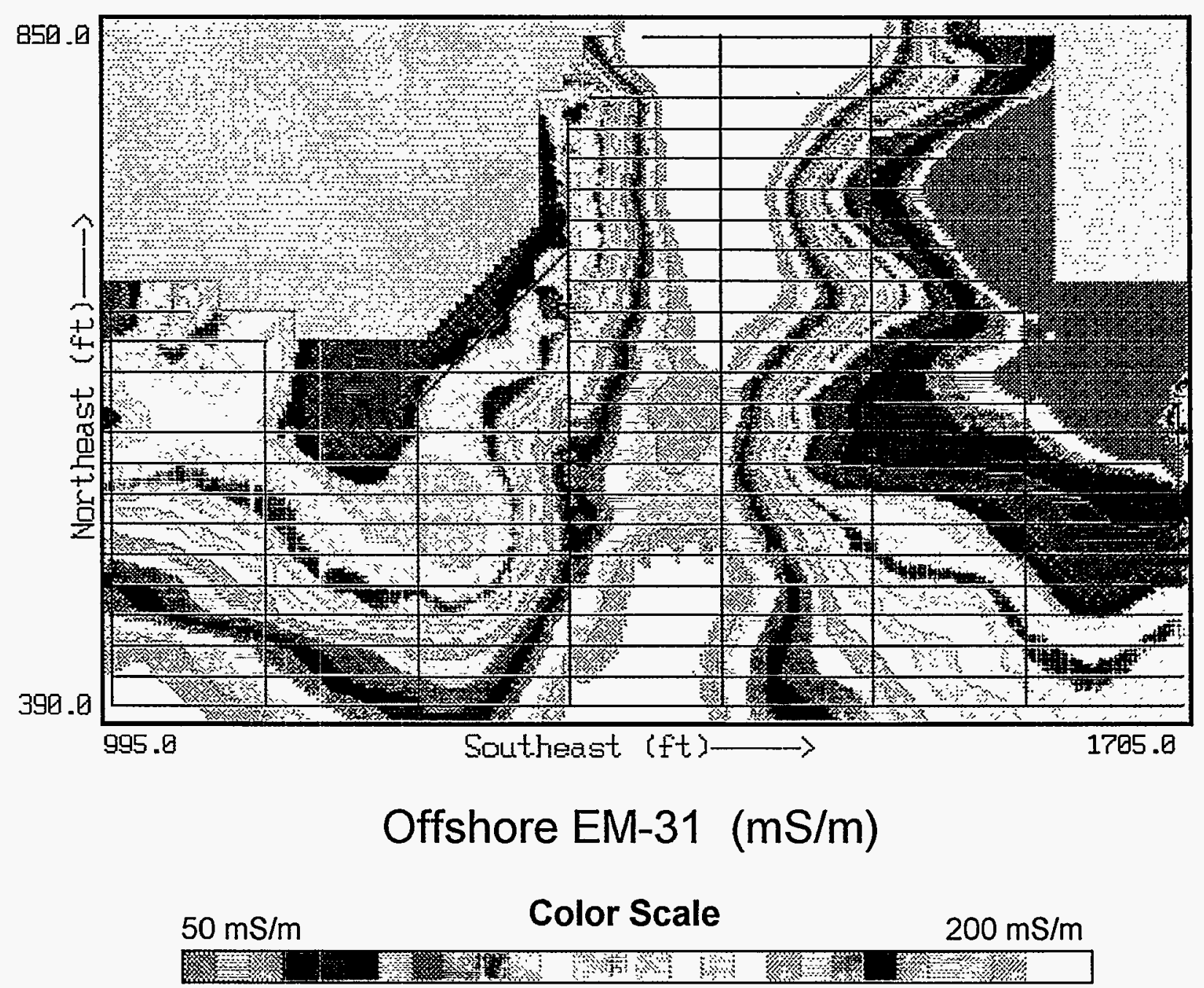

FIGURE 19 Kings Creek Offshore EM-31 Electromagnetics Map

the metal culvert can produce an apparent conductivity low. High-conductivity anomalies, caused by the fenceline and the amphibolite roadfill material, were found in the northern portion and along the eastern edge of Area 4. Also, partially buried fencing material, located at approximately $50 N / 730 E$ (\#13, Figure 17), may create the conductivity high extending westward at this location.

The data presented in Figure 17 were plotted using a smaller contour interval than that used for Areas 2 and 3 to highlight the more subtle conductivity changes in this relatively quiet area. Slightly higher conductivities in the southern portion of Area 4 likely represent a greater clay content in the upper $18 \mathrm{ft}$ of sediment. A recently installed soil boring (WBR-27) in this area (approximate location shown in Figure 20) exhibited predominantly clayey sediments to $19 \mathrm{ft}$ below surface, with a sand zone between 9.0 and $13.6 \mathrm{ft}$. Farther north in Area 4, conductivities were lower because of greater amounts of sand in the subsurface. The lithology found in recently installed soil boring WBR-23 (Figure 20) was predominantly sands and silty sands to 


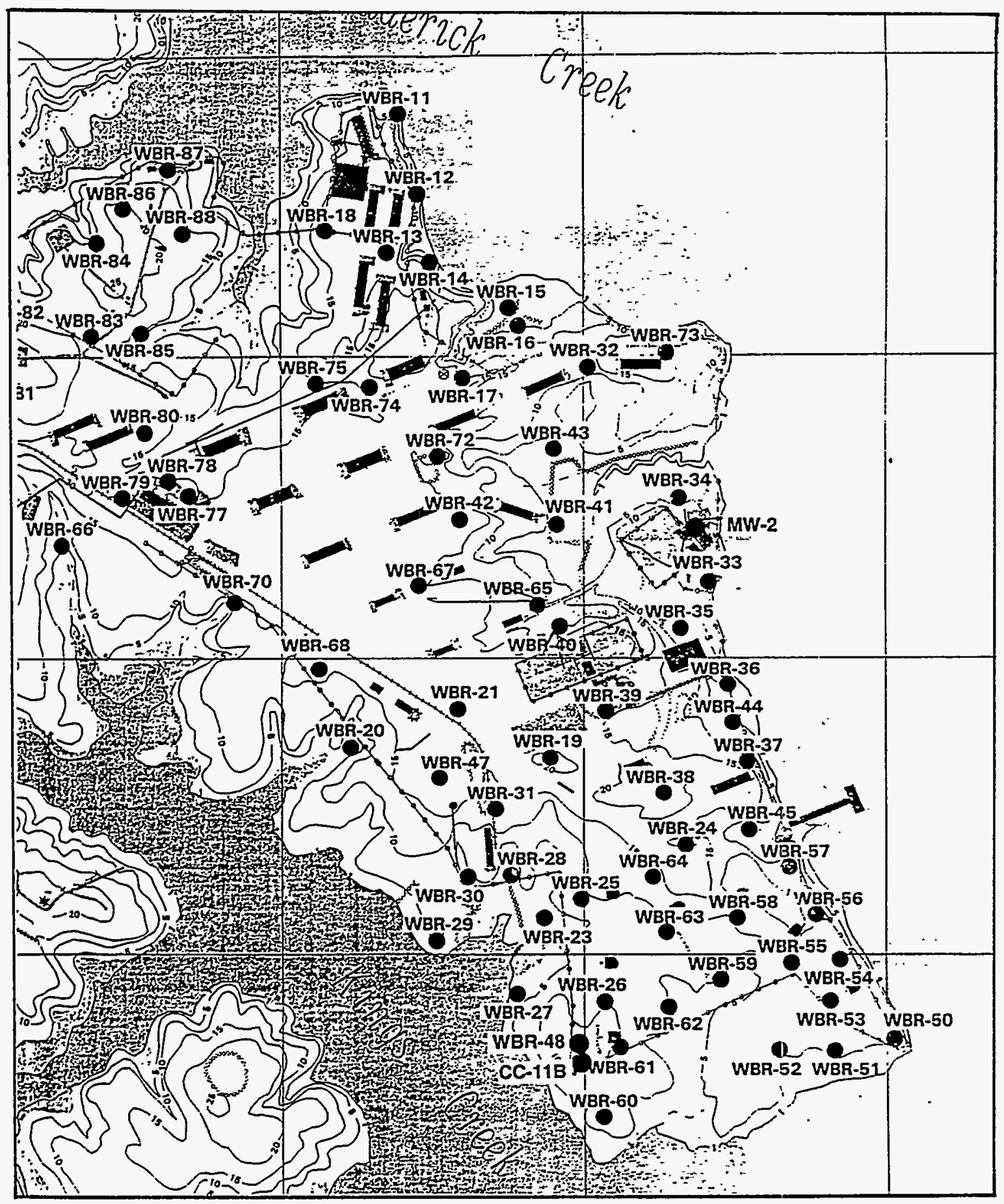

FIGURE 20 Monitor Well Location Map, Bush River Peninsula (adapted from U.S. Army Corps of Engineers 1994)

approximately $41 \mathrm{ft}$ below land surface. Conductivity, soil boring, and GPR data (see Sections 4 and 5) indicate that a paleochannel, trending east-west, is present at this location. Boring logs are included as Appendix A. 


\section{Geophysical Well Logging}

Downhole natural gamma and electromagnetic induction (conductivity/resistivity) well logging were performed on eight monitor wells installed in 1994 (WBR-19, WBR-20, WBR-23, WBR-35, WBR-38, WBR-42, WBR-43, and WBR-47) and two previously installed site monitor wells (CC-11B and MW-2) on the Bush River Peninsula (Figure 20). The natural gamma and conductivity/resistivity well logs are presented in Appendix B. Four of the logged wells (WBR-19, WBR-20, WBR-23 and WBR-47) are located in the vicinity of the Kings Creek study area. Following the Kings Creek geophysical surveys, monitor well WBR-48 was installed adjacent to monitor well CC-11B. Boring logs for these five wells are included in Appendix A. In addition to the natural gamma and electromagnetic induction downhole geophysical techniques, downhole seismic logging was performed on monitor well $\mathrm{CC}-11 \mathrm{~B}$; the results of the downhole seismic logging are presented in Section 6.2.

Prior to the insertion of the downhole well logging equipment, the headspace of the monitor well was checked with a photoionization detector and a Geiger-Mueller counter. The downhole probes and cable were decontaminated following logging at each well by washing with a nonphosphate detergent and double rinsing with distilled water. Paper towels used to wipe the probe and cables were also surveyed by using the Geiger-Mueller counter.

A logging speed of $10 \mathrm{ft}$ per minute was employed with each method. Data were collected going both up and down the wells to check for repeatability. All data were stored on the field computer used to operate the logging programs.

The natural gamma logging technique measures naturally occurring gamma radiation in the subsurface. In general, higher gamma activity is found within clayey sediments than within sands. Electromagnetic induction data indicate the subsurface conductivity, which is primarily a function of the pore water chemistry below the water table. Natural gamma, conductivity, and resistivity (which is the inverse of conductivity) logs are presented in Appendix B. Soil boring logs for monitor wells WBR-19, WBR-20, WBR-23 and WBR-47, located near the Kings Creek study area (Figure 20), were available to compare the downhole geophysical data with the actual lithology found in these boreholes. A column presenting the lithology, as obtained from the soil boring logs, has been added to the natural gamma and conductivity/resistivity logs for these four wells (Appendix B). A column presenting the lithology obtained from the soil boring log for monitor well WBR-48 (recently installed adjacent to monitor well CC-11B) has been added to the natural gamma and conductivity/resistivity logs for monitor well CC-11B. A good correlation between the geophysical logs and the soil boring logs for these four wells is evident. 


\section{Ground-Penetrating Radar Surveys}

The primary objective of the GPR surveys was to provide a better understanding of the shallow stratigraphy in and around the King's Creek Disposal Site and the 30th Street Landfill. GPR was also used to help locate buried anthropogenic anomalies. Because of the dense vegetation within most of the study area, GPR surveying was limited. Profiles were collected along the fence line, paths, and abandoned roads in the woods, and in an open grassy area near the survey center. GPR profiling was also performed offshore from the study area. The GPR profile locations are shown in Figure 21.

Both the 100- and 300-MHz antennas, in a bistatic configuration, were used along the GPR profiles. The antennas were separated by a fixed distance of $4.5 \mathrm{ft}$. Onshore profiles were collected in a continuous mode using an all-terrain vehicle to tow the antennas. The offshore data were collected by using a small bass boat as the towing vehicle; the antennas were placed on the bottom of an inflatable rubber raft towed behind the boat. Range settings between 100 and 600 nanoseconds (ns) were used to collect the GPR profiles. The profiles collected with the $300-\mathrm{MHz}$ antennas at a range setting of $300 \mathrm{~ns}$ provided the best data in most onshore locations. The $100-\mathrm{MHz}$ antennas were more effective over water, with a range of $500 \mathrm{~ns}$. All of the profiles shown have been computer-processed with a boxcar filter. Adjustments in the gains have been made for some of the profiles to help remove high-frequency noise and enhance structure at depth. The approximate depth given for the profiles is based on a two-way travel time of $9 \mathrm{~ns} / \mathrm{ft}$ for the soils and $18 \mathrm{~ns} / \mathrm{ft}$ for the offshore water column. The two-way travel times for the soils and water are estimates based on velocities given by the manufacturer (GSSI 1987). GSSI estimates the two-way travel time for "average soil" at between 7 and $9 \mathrm{~ns} / \mathrm{ft}$. The slower velocity of $9 \mathrm{~ns} / \mathrm{ft}$ was used because of the shallow water table and saturated soils.

\subsection{Offshore GPR Surveys}

Figures 22A and 22B illustrate a GPR profile collected approximately $30-40 \mathrm{ft}$ offshore from the Kings Creek study area. The location of this profile is shown in Figure 21 (profile \#16). The profile was collected by using the $100-\mathrm{MHz}$ bistatic configuration with an antenna separation of $4 \mathrm{ft}$ and a range setting of $500 \mathrm{~ns}$. Figure $22 \mathrm{~A}$ is shown without the interpretation; Figure 22B shows the interpreted structures. This profile reveals southeast- and northwestdipping structures that are likely the sides of a paleochannel. The paleochannel measures over $500 \mathrm{ft}$ wide and the thalweg extends below the depth of penetration. The depth of penetration is inferred to be approximately $45 \mathrm{ft}$ below the creek bottom. The water depth is between $2-3 \mathrm{ft}$. The upper $10 \mathrm{ft}$ of sediment is composed of very soft silts and clays. The loss of signal over the middle portion of this paleochannel suggests that the channel may be filled with more clayey, saturated sediments that are difficult to penetrate with GPR. The profile also shows what may be old terraces on each side of the channel. The GPR data collected offshore will be presented in a future report. 


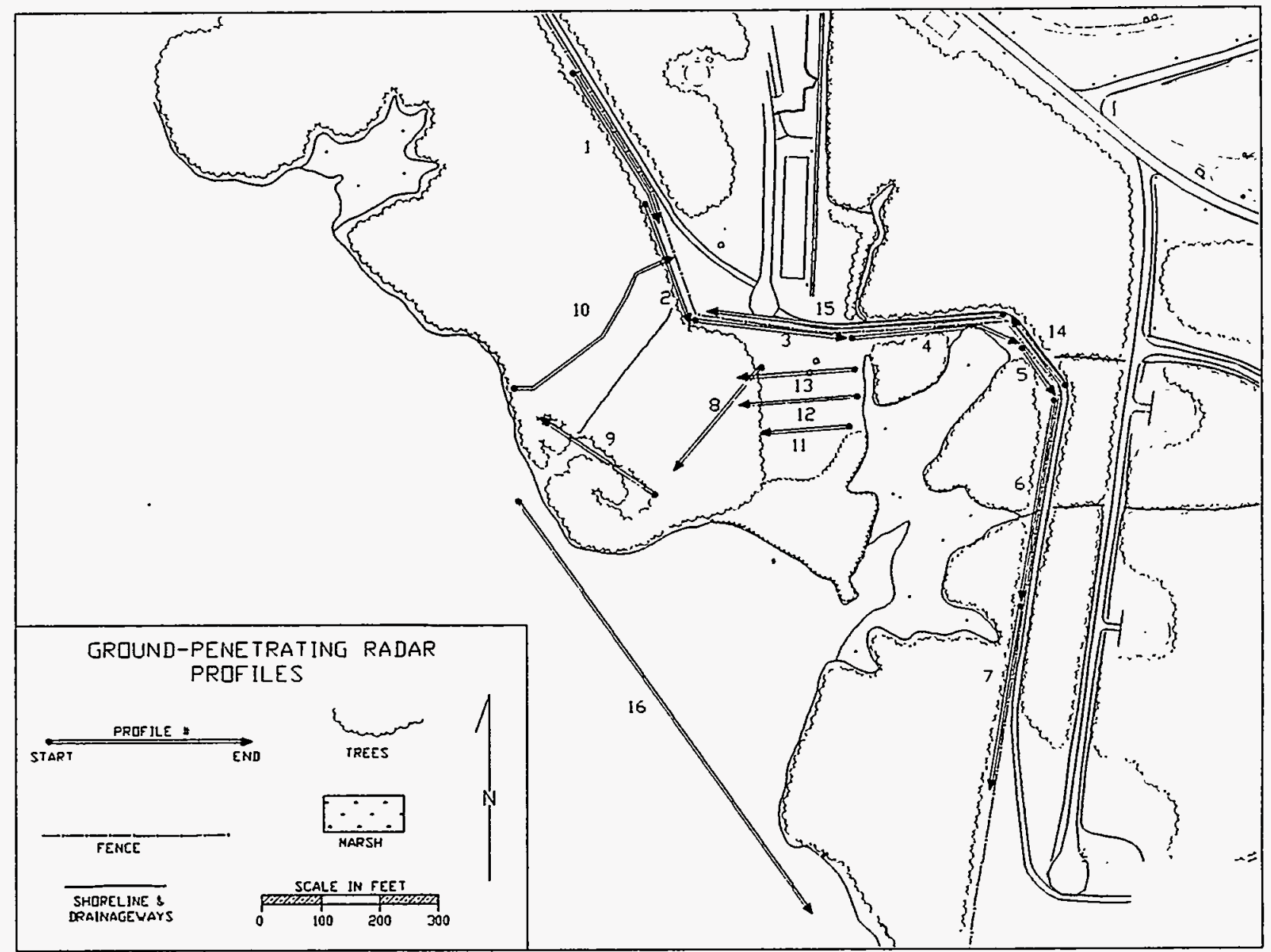

FIGURE 21 Ground-Penetrating Radar Profile Locations

\subsection{Onshore GPR Surveys}

The onshore GPR data also reveal dipping structures that may be associated with paleochannels. Figures $23 \mathrm{~A}$ and $23 \mathrm{~B}$ show a portion of what may be a paleochannel beneath the former location of the 30th Street Landfill. The profile shown in Figures 23A and 23B was collected from east to west along the $150 \mathrm{~N}$ grid line. The location of this profile is shown in Figure 21 (profile \#12). The east-dipping structure may be the west side of a paleochannel. This profile also shows some buried debris approximately 6-7 ft below the ground surface from $400 \mathrm{E}$ to $380 \mathrm{E}$. Near-surface debris can be seen over the last $25 \mathrm{ft}$ of the profile.

Figures $24 \mathrm{~A}$ and $24 \mathrm{~B}$, which illustrate a profile collected from east to west along grid line $200 \mathrm{~N}$ (profile \#13 on Figure 21), show both sides of a paleochannel with the thalweg at approximately $350 \mathrm{E}$. The bottom of the channel is approximately $35 \mathrm{ft}$ below the ground surface. This profile also shows an undulating surface between 5 and $15 \mathrm{ft}$ below the ground surface, which likely represents two shallow paleochannels superimposed over the deeper, older paleochannel. On the basis of the current water depth in Kings Creek, which is $5 \mathrm{ft}$ or less, this undulating reflector cannot represent pre-fill topography. The paleochannel system developed in 
the Kings Creek estuary during the Pleistocene Epoch was subsequently filled with Holocene sediments. Some buried debris, located within the upper few feet, is also evident in the profile.

The GPR profile presented in Figures 25A and 25B (profile \#15 on Figure 21) also shows two possible paleochannels. This profile was collected from east to west inside the security fence with the $100-\mathrm{MHz}$ bistatic antenna configuration at a range setting of $400 \mathrm{~ns}$. During collection of this profile, there was likely an intermittent loose antenna connection that appears as a strong flat ring down the entire profile or as sharp breaks in the signal. The paleochannel on the east end measures approximately $175 \mathrm{ft}$ wide, with the thalweg at a depth of approximately $22 \mathrm{ft}$ below ground surface. The deeper channel on the west end is over $250 \mathrm{ft}$ wide and roughly $33 \mathrm{ft}$ deep. Channel fill materials can also be seen on this profile as flat-lying reflectors.

Profile \#14 (Figures 26A and 26B) was collected from southeast to northwest inside the security fence with the $100-\mathrm{MHz}$ bistatic antenna at a range setting of $400 \mathrm{~ns}$. The northwest end of profile \#14 joins the east end of profile \#15 (Figure 21). A west-dipping structure in the northwestern portion of this short profile likely represents a continuation of the shallow paleochannel structures visible on the east side of profile \#15 (Figures 25A and 25B).

Figures 27A and 27B show another paleochannel that is much smaller and shallower than the other subsurface features detected using GPR methods. This profile (profile \#6 in Figure 21) was collected along the eastern edge of the survey area. The paleochannel corresponds to an existing drainageway at grid coordinates $-30 \mathrm{~N} / 770 \mathrm{E}$. The thalweg of this channel is approximately $7 \mathrm{ft}$ below the ground surface and the channel width is roughly $30 \mathrm{ft}$. On the basis of well log data and, potentially, EM-31 electromagnetic data (Figure 17), another paleochannel is suspected at approximately $100 \mathrm{~N}$ along this profile. Poor signal penetration is the result of ground surface conditions in this area.

Some anthropogenic anomalies are shown in Figure 28. This figure shows the last $75 \mathrm{ft}$ of profile \#8 (Figure 21) within the former Kings Creek Disposal Site. The anomaly centered at grid coordinates $110 \mathrm{~N} / 170 \mathrm{E}$ is most likely a cylindrical object, based on its hyperbolic shape. The object is buried about $1 \mathrm{ft}$ below the ground surface. The debris shown at the end of the profile is also buried in the upper $1 \mathrm{ft}$ of the subsurface.

The profile presented in Figures 29A and 29B was collected roughly parallel to the shoreline from southeast to northwest across the area, which is void of vegetation. The location of this profile is shown in Figure 21 as profile \#9. A small, shallow paleochannel is apparent at the beginning of the profile. The former burn pit is also evident. The burn pit measures roughly $25 \mathrm{ft}$ across. The depth to the bottom of the pit is difficult to identify because of the ringing reflectors, but is probably less than $3 \mathrm{ft}$, which is the approximate depth to the water table inferred from the site topography. 

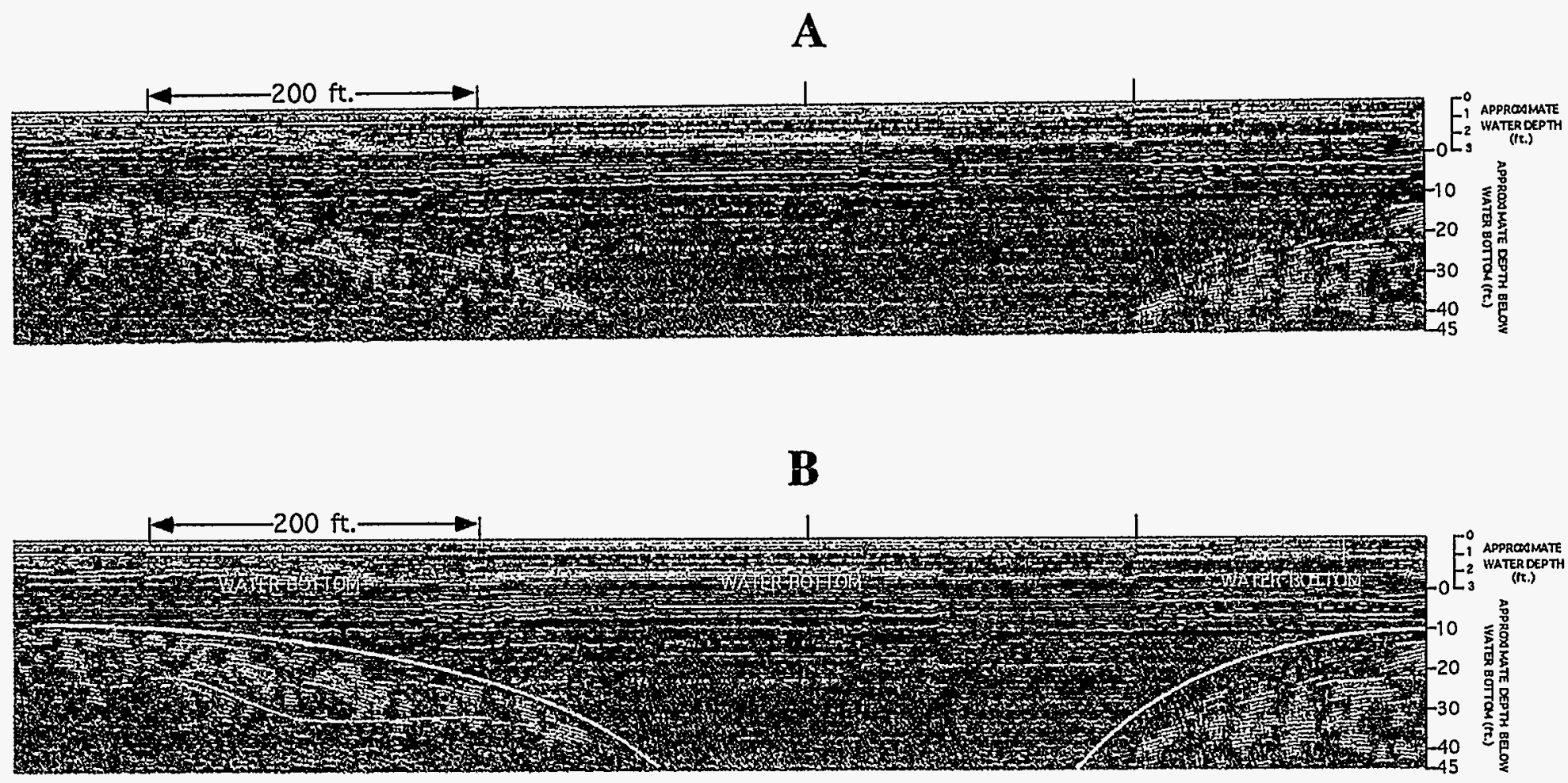

FIGURE 22 A: GPR Profile \#16 (Offshore); B: GPR Profile \#16 with Interpretation 

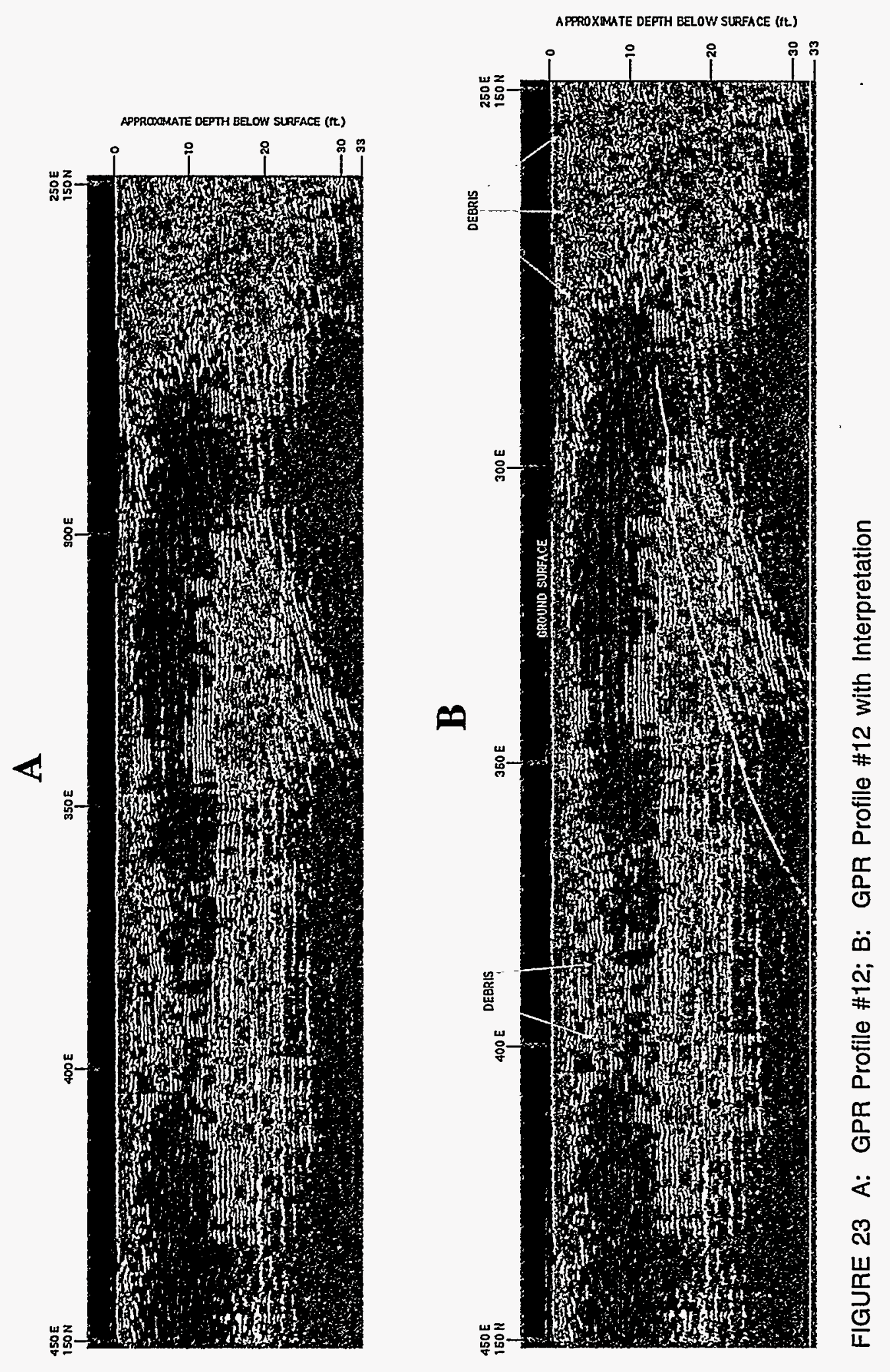

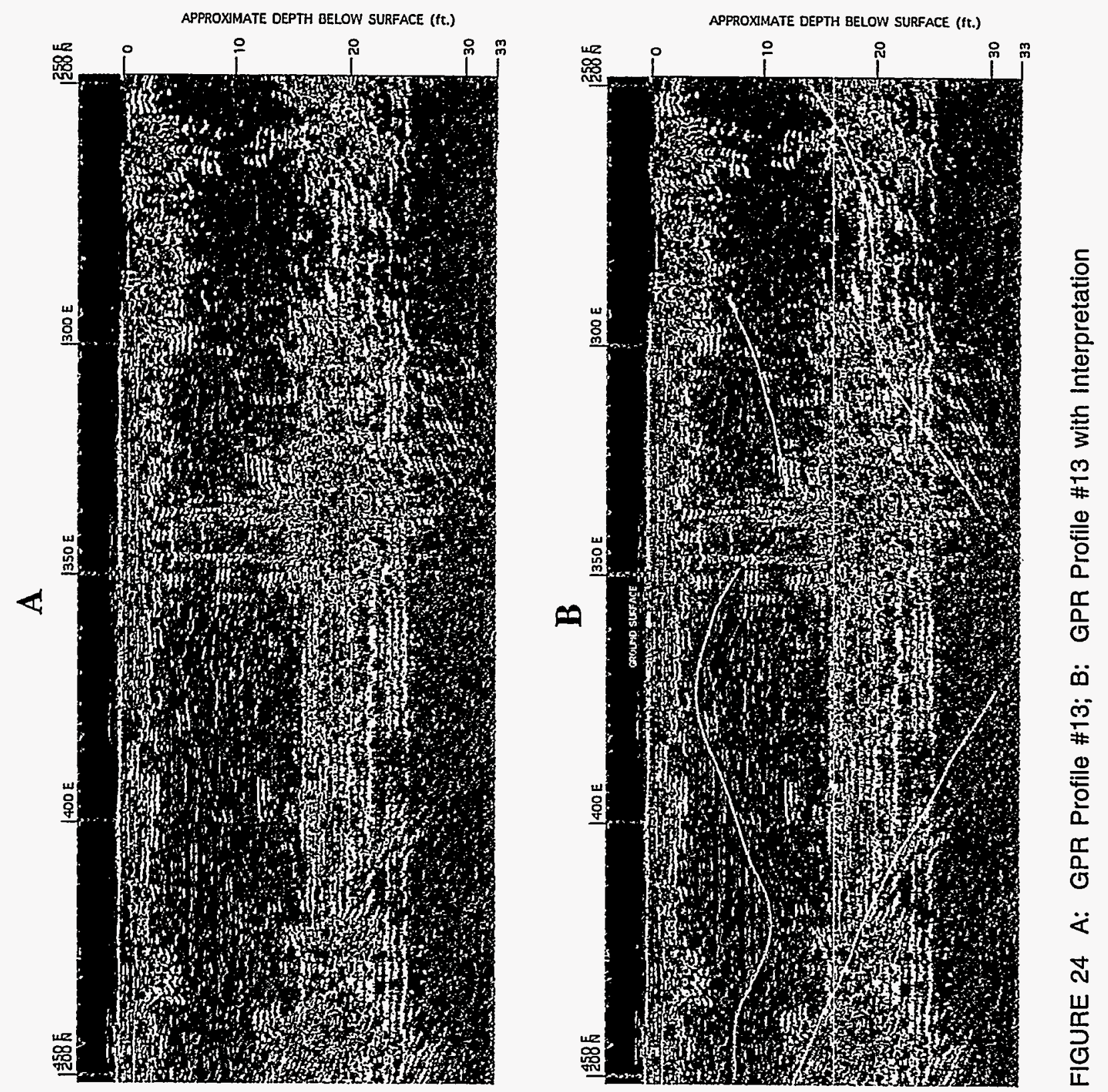


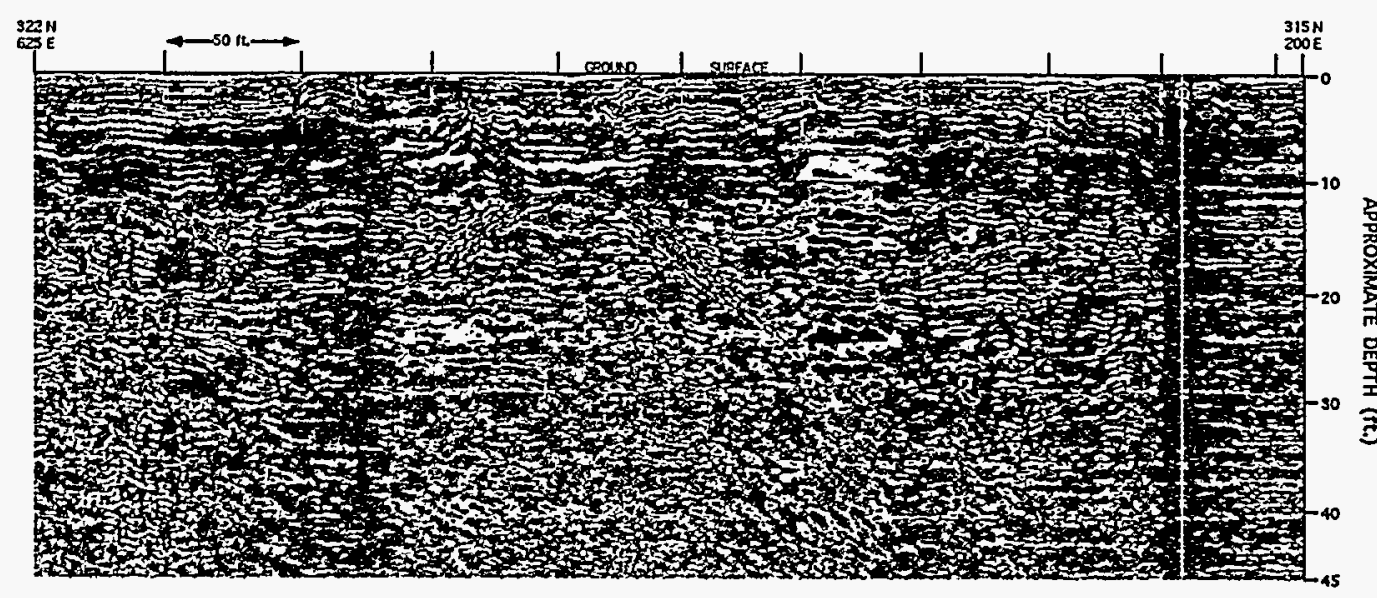

A

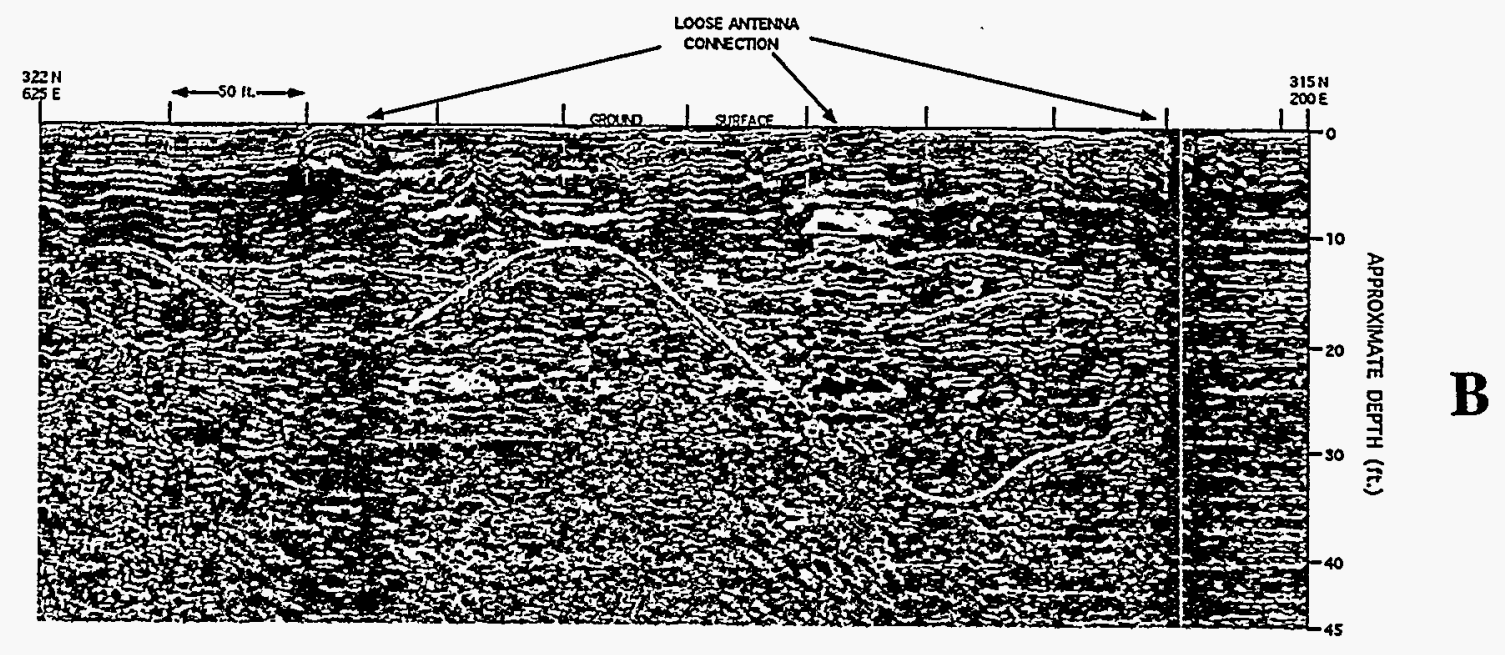

FIGURE 25 A: GPR Profile \#15; B: GPR Profile \#15 with Interpretation 

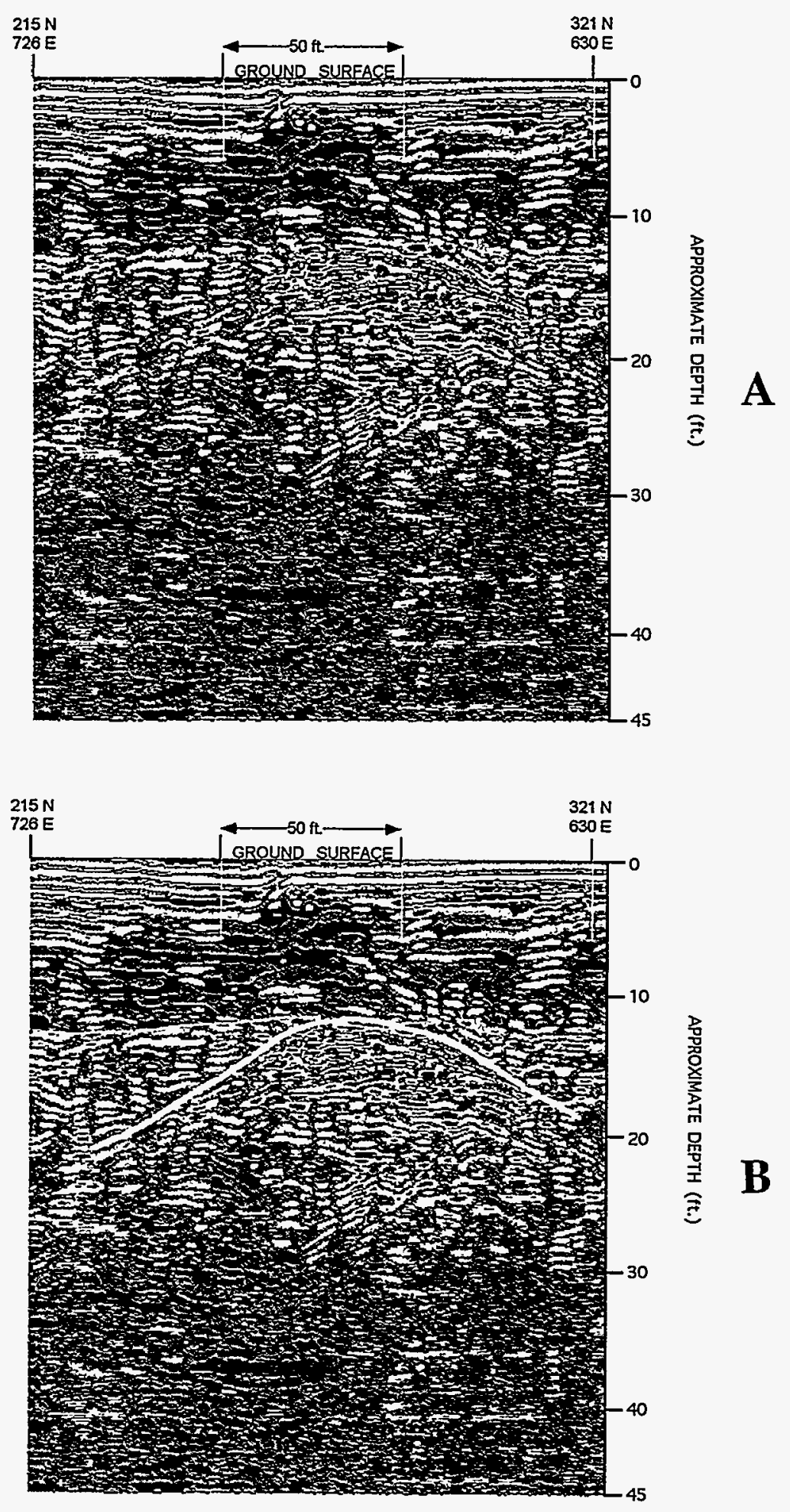

FIGURE 26 A: GPR Profile \#14; B: GPR

Profile \#14 with Interpretation 

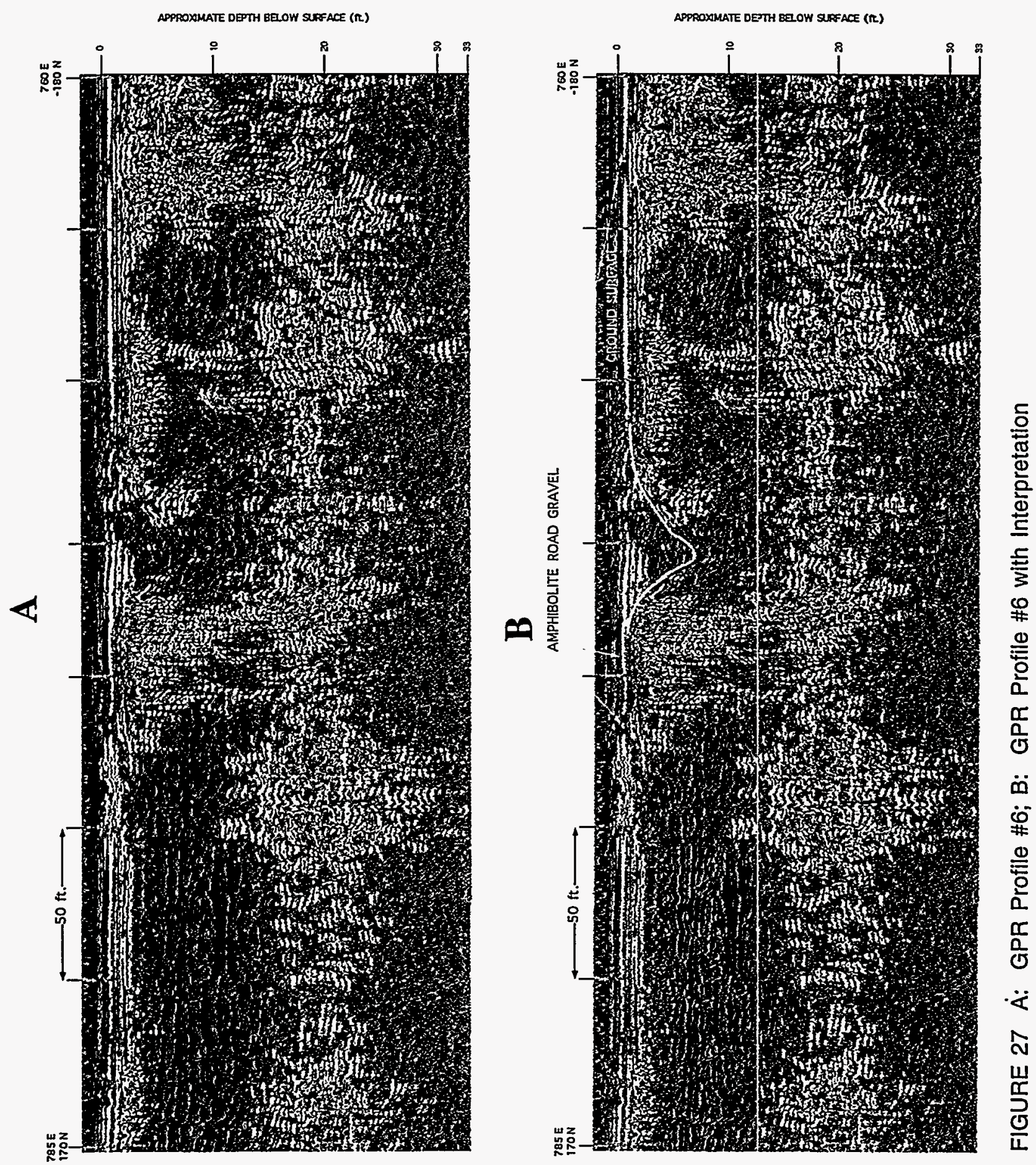
APPROXIMATE DEPTH BELOW SURFACE (ft.)

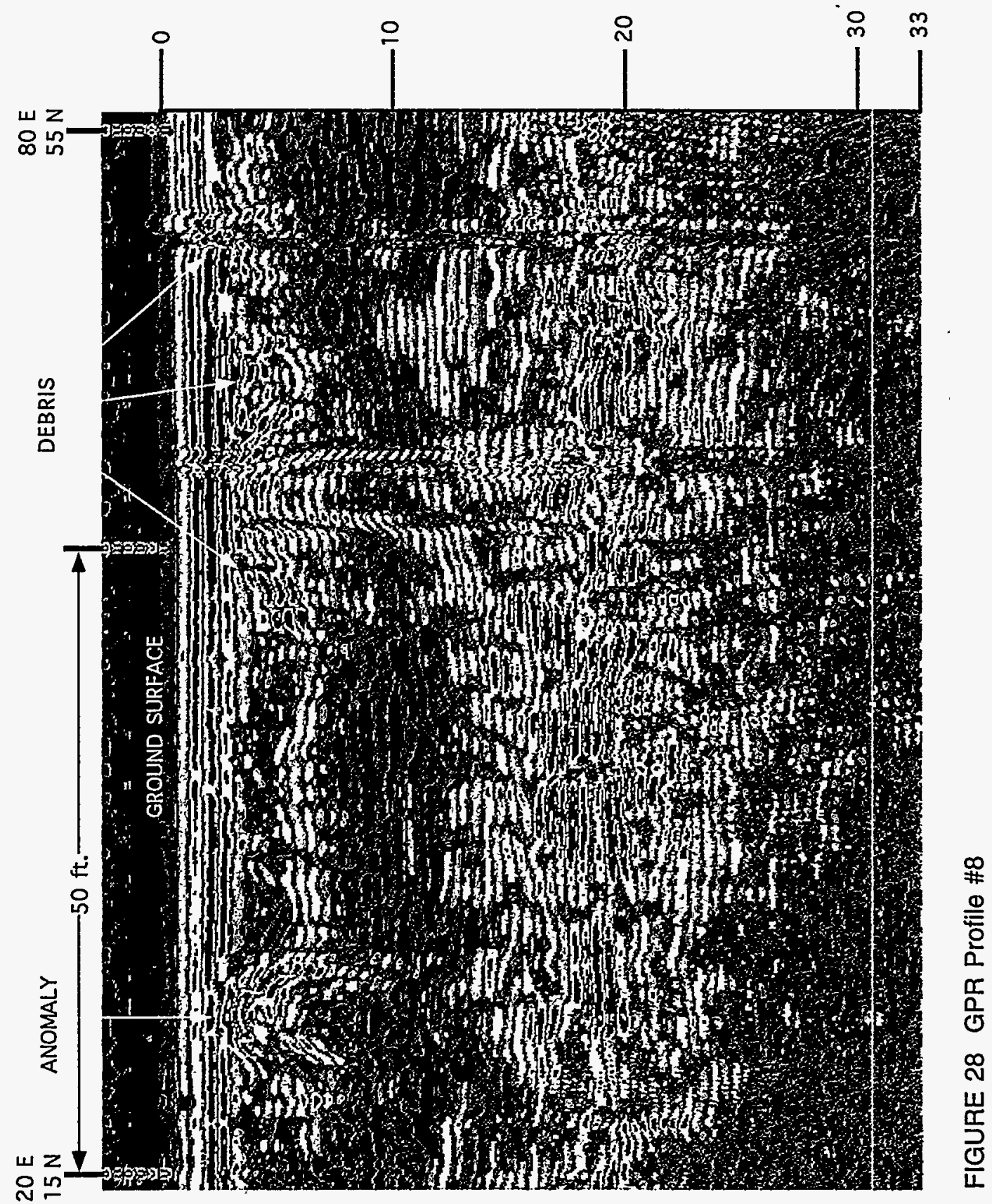



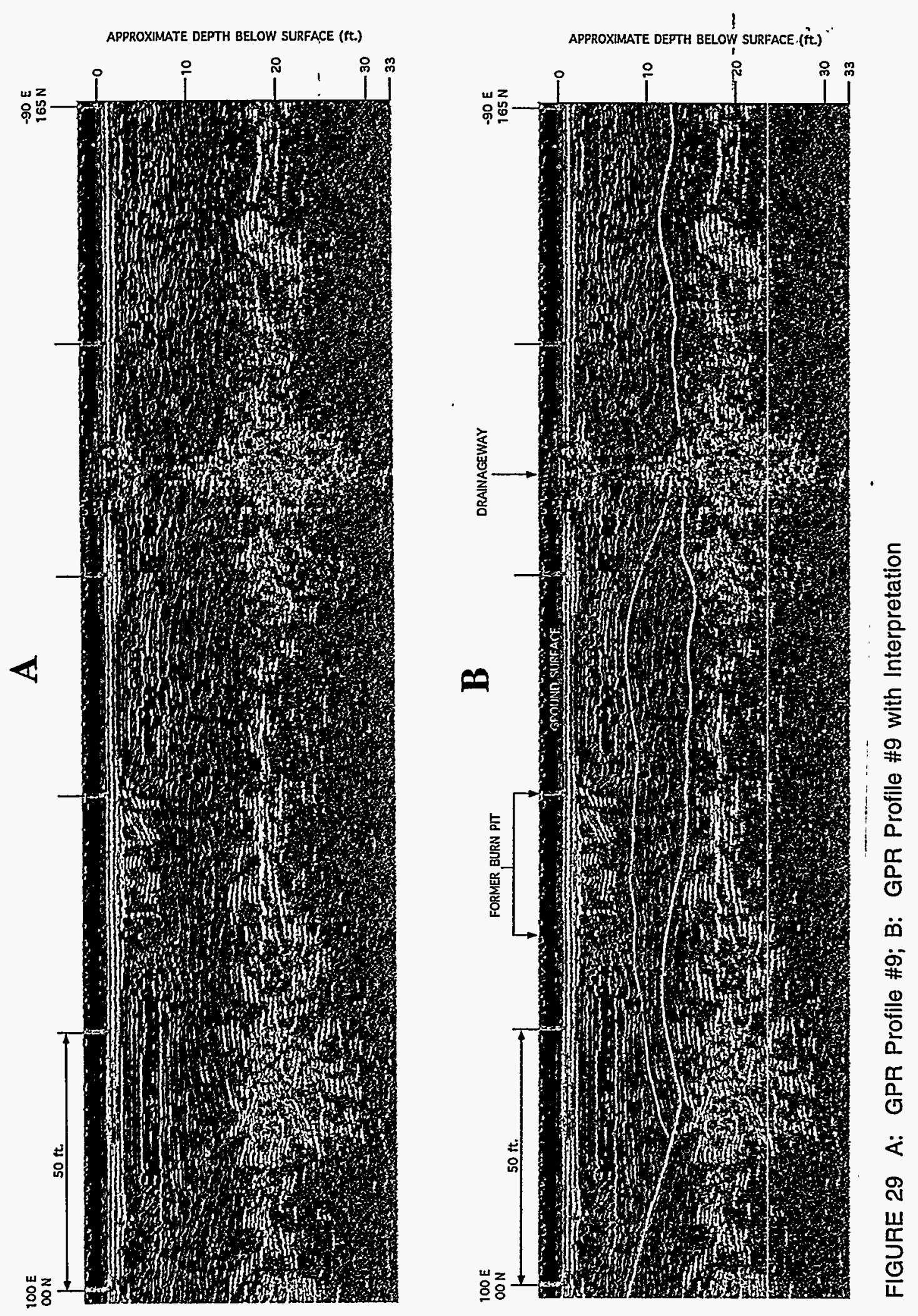


\section{Seismic Surveys}

Three seismic refraction and three seismic reflection profiles were recorded in the Kings Creek study area. The seismic surveys were conducted to provide geophysical information on lithologic units below the depth ranges reached by electromagnetic and GPR methods. Also, surface-to-borehole average velocity measurements were conducted at monitor well CC-11B to provide additional depth control for the seismic models. The locations of all seismic profiles, including refraction, reflection, and borehole surveys, are shown in Figure 30.

\subsection{Seismic Refraction Surveys}

One deep and two shallow refraction profiles were conducted to provide seismic velocity and depth information for strata from the ground surface to crystalline bedrock. Refraction survey parameters are summarized in Table 2. The deep refraction profile, line BRP-1, was used to obtain layer-velocity information to depths below $400 \mathrm{ft}$; the shallow refraction profiles, BRP-2 and BRP-3, were conducted to provide seismic velocity information for the near-surface sediment.

Conversion of the time-distance data into a velocity-depth model was performed using the SIPT2 processing software developed by RIMROCK Geophysics, Inc. (1992). Average velocities obtained from a borehole check-shot were also used to help constrain this model.

Refraction data are useful for determining interval velocities for stratigraphic and nonstratigraphic units when the velocity increases with depth. Lithologic units that have similar or lower velocities than overlying units do not refract energy back to the surface, and thus, are not detected by the refraction method. In addition, thin, high-speed layers may not be detected if their thickness is less than the wavelength of the seismic energy for that particular refraction survey. This limiting thickness is generally on the order of "tens of feet" for seismic refraction prospecting. In short, the velocity-depth model derived only from seismic refraction analysis may be incomplete. Velocity information for layers transparent to the refraction data is provided by a borehole check-shot (discussed in Section 6.2).

Interpretation of shallow refraction lines BRP-2 and BRP-3 results in a two-layer model consisting of unsaturated sediment above the water table and saturated sediment below (Figures 31A and 31B). A velocity of $1,154 \mathrm{ft} / \mathrm{s}$ was computed for Layer 1; a velocity of $5,761 \mathrm{ft} / \mathrm{s}$ was determined for the saturated sediment (Layer 2). The shallow refraction data also show that lateral velocity variations exist in the Layer 1 material. These variations probably arise from differences in saturation, compaction, and composition of these sediments. The shallow seismic data demonstrate that (1) lateral variations in seismic velocity are significant near the surface, and (2) static corrections in seismic reflection data are to be expected. A depth of 8-13 ft and a seismic velocity of $5,761 \mathrm{ft} / \mathrm{s}$ were computed for Layer 2 , which is interpreted to comprise saturated sediments at or below the water table. 


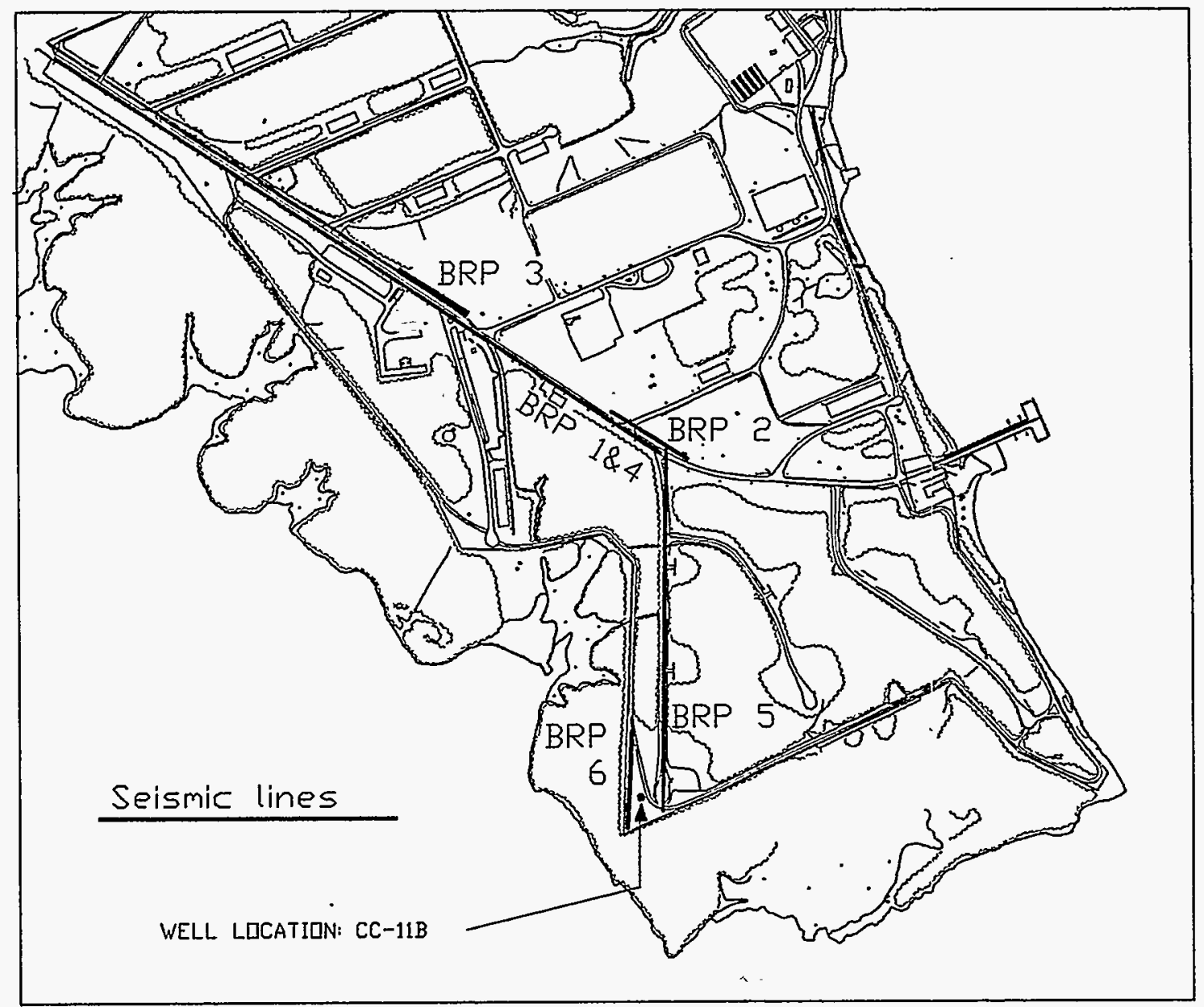

FIGURE 30 Seismic Profile Locations

TABLE 2 Seismic Refraction Profiles near the Kings Creek Study Area

\begin{tabular}{lccc}
\hline & \multicolumn{3}{c}{ Line Identification Number } \\
\cline { 2 - 4 } \multicolumn{1}{c}{ Parameters } & BRP-1 & BRP-2 & BRP-3 \\
& & & \\
& & & \\
Seismic source & EWG & Hammer & Hammer \\
Geophone interval (ft) & 30 & 5 & 5 \\
Geophones per spread & 23 & 12 & 12 \\
Number of spreads & 3 & 1 & 1 \\
Total length of spreads (ft) & 2,040 & 55 & 55 \\
Number of shots & 18 & 9 & 9 \\
Maximum shot-to-phone distance (ft) & 2,650 & 210 & 185 \\
& & & \\
\hline
\end{tabular}


A: First Arrivals for Line BRP1B

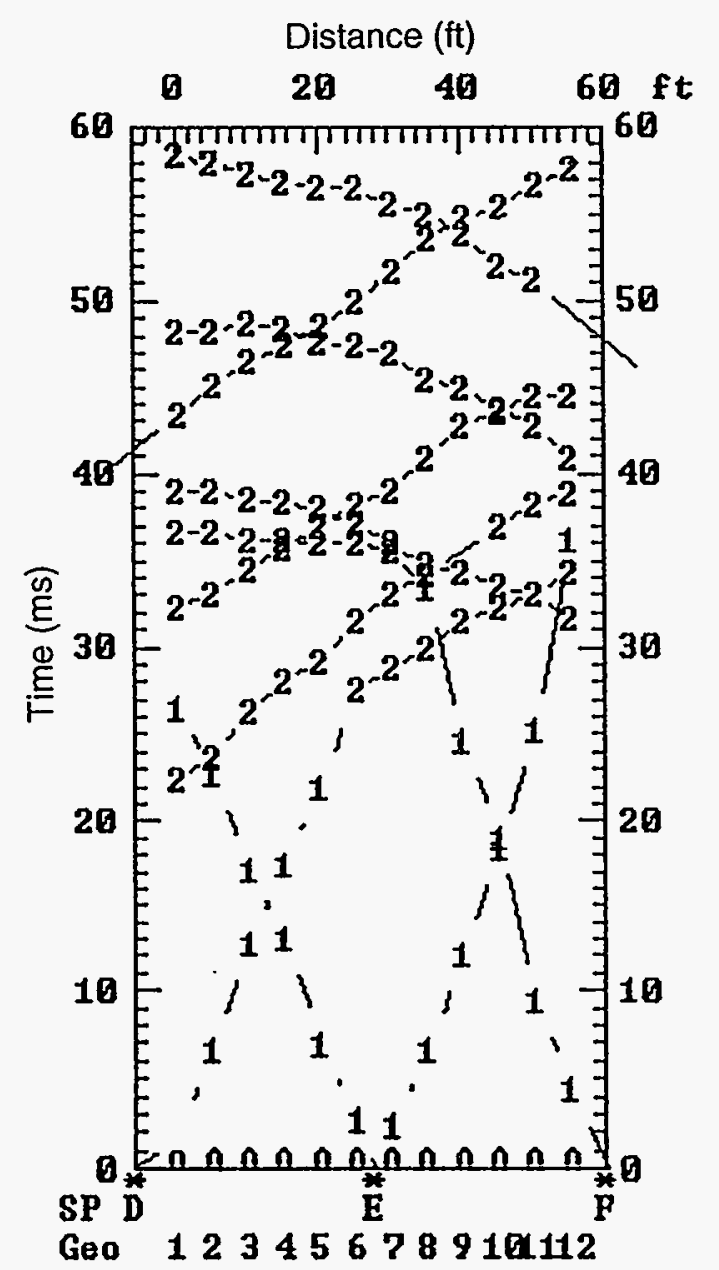

B: First Arrivals for Line BRP1C

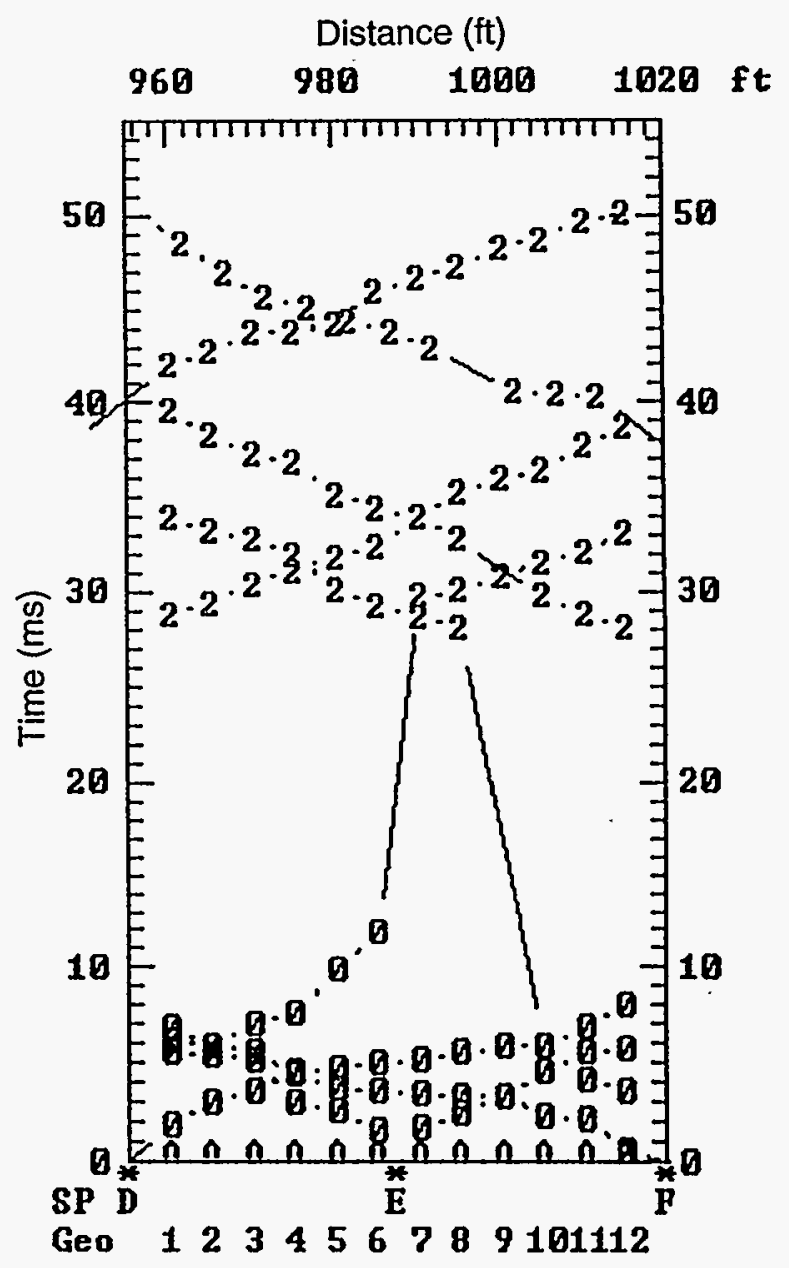

FIGURE 31 First Arrival Time versus Distance Data from Seismic Refraction Lines BRP-2 (A) and BRP-3 (B)

The deepest and highest-velocity layer, identified as Layer 3 on the time-distance plot for seismic refraction profile BRP-1 (Figure 32), has a seismic velocity of $16,790 \mathrm{ft} / \mathrm{s}$. Layer 3, at a depth ranging between 420 and $440 \mathrm{ft}$, represents Precambrian crystalline rock that underlies Cretaceous sediment.

Figure 33 shows the relationship between seismic velocity and depth, based on both refraction and borehole data. The interval velocity curve derived from refraction data is based on the inversion of both shallow and deep refraction time picks. The figure also illustrates a curve for average velocity versus depth, showing the weighted average of all interval velocities between the surface and the corresponding depth. The average-velocity-versus-depth information is used to generate a depth scale for seismic reflection data. Interval velocities from both refraction and borehole techniques were used in the average velocity calculations. 


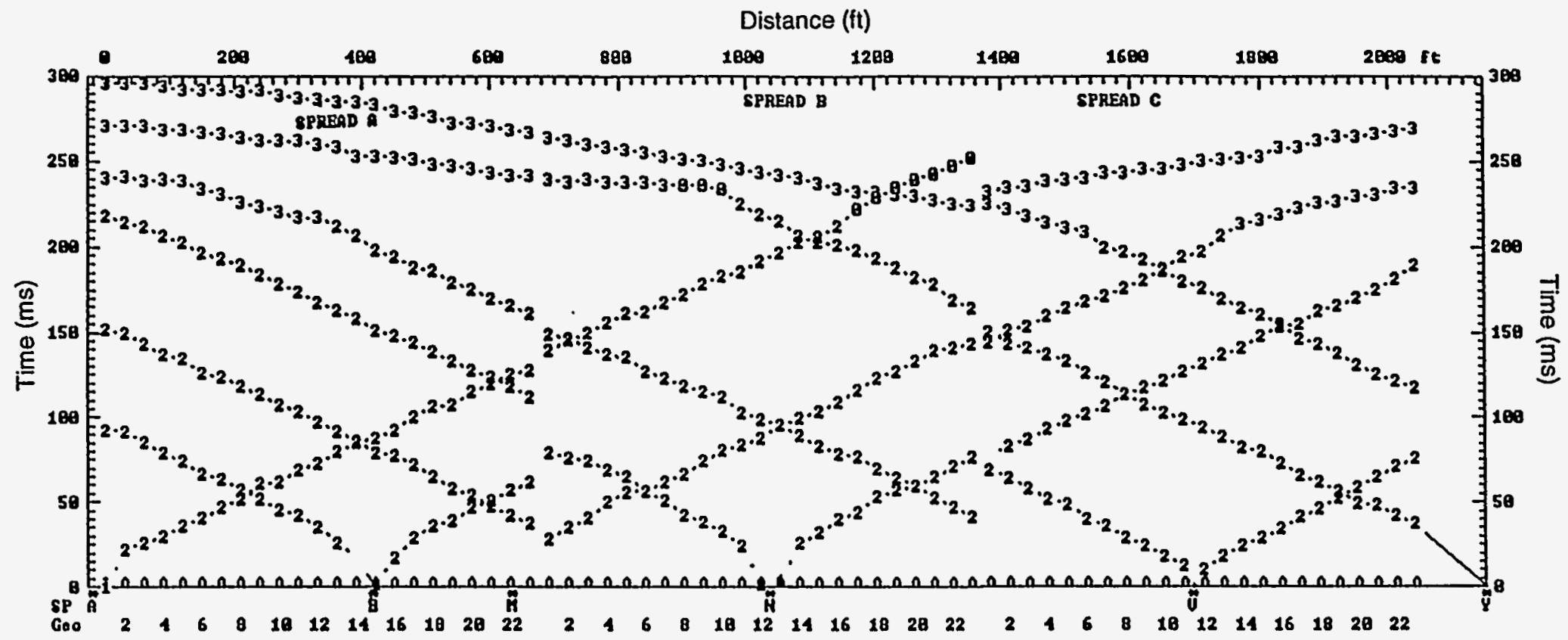

FIGURE 32 First Arrival Time versus Distance Data from Seismic Refraction Line BRP-1 


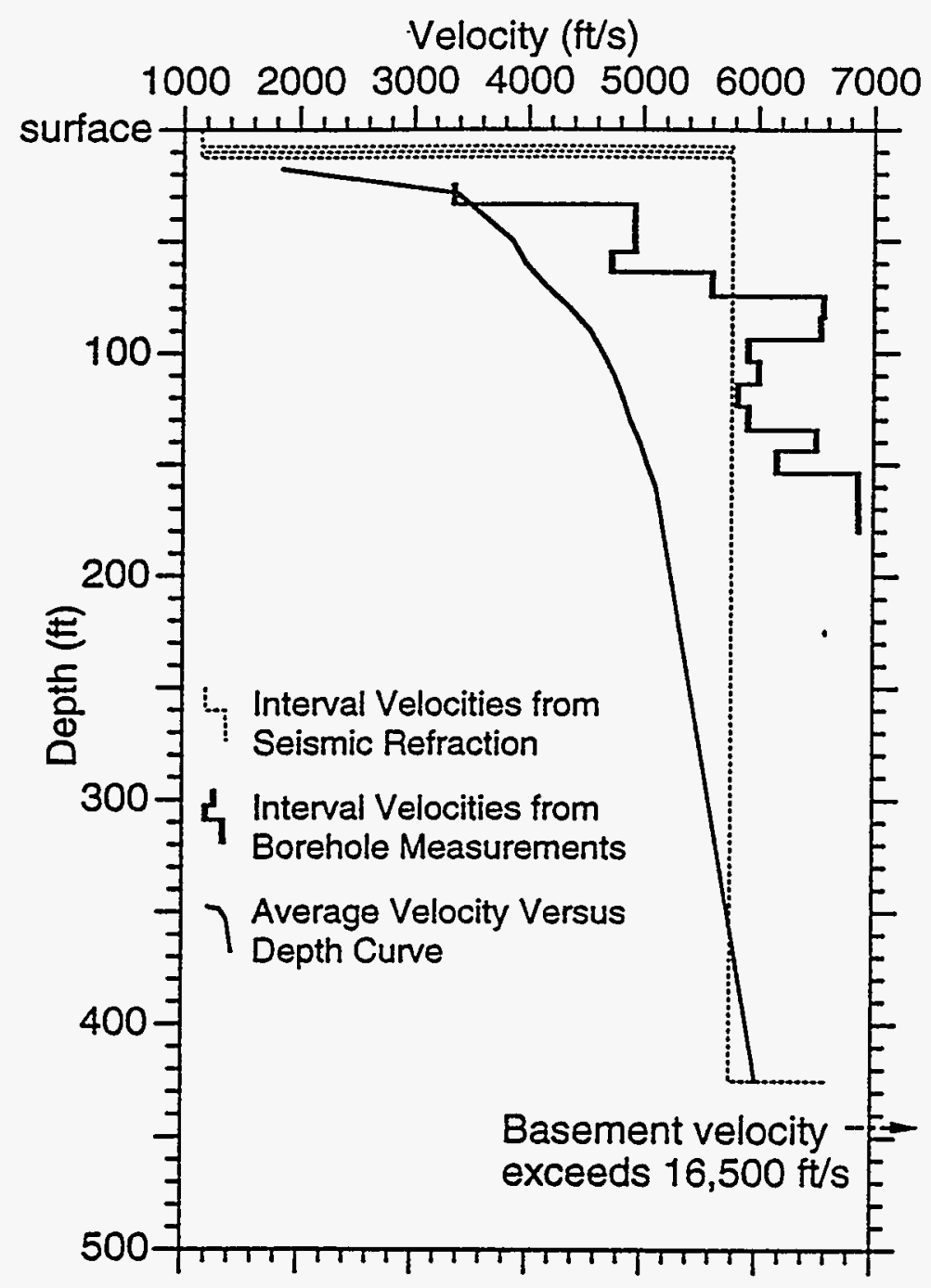

FIGURE 33 Velocity-Depth Model Obtained by Inverting Seismic Refraction Data and Borehole Seismic Data

The velocity-depth model in Figure 33 does not account for lateral velocity variations over the Bush River Peninsula, but is useful in obtaining approximate depth calculations for reflectors in the seismic reflection data presented in Section 6.3. The depth estimates, however, must be used cautiously. The depth of the low-velocity layer near the surface, which was set at $4.0 \mathrm{ft}$ in the model, is known to vary from 0 to at least $10 \mathrm{ft}$ based on the two shallow refraction profiles. The lateral velocity variations near the surface can cause an error of several percentage points in the depth estimation.

\subsection{Downhole Seismic Velocity Measurements}

Surface-to-borehole average velocity measurements were conducted at monitor well CC-11B (Figure 30). The survey was conducted by lowering a down-hole geophone to a known 
depth and recording the travel time for signals produced from a sledgehammer source located at various distances from the borehole. Sets of measurements were collected with the geophone at $10-\mathrm{ft}$ intervals within the monitor well, starting at $160 \mathrm{ft}$ below the top of casing and proceeding to $50 \mathrm{ft}$ below the top of casing (which was $3.0 \mathrm{ft}$ above land surface). An additional set of measurements was taken with the geophone at $29 \mathrm{ft}$ below the top of casing. Shallower measurements were not recorded because of poor signal quality near the surface. Horizontal source offset distances of $25,50,75$, and $100 \mathrm{ft}$ northwest of monitor well CC-11B were used for each set of measurements.

Average velocities were obtained by dividing the slant distance between each sourcelocation/receiver-location pair by the travel time. Interval velocities were calculated by using differences in both slant distance and travel time between the current reading and the reading at the adjacent shallower depth. Velocity calculations were repeated for each horizontal offset and compared. Using slant distance in the velocity calculations caused some systematic error, which resulted in artificially high velocity calculations. The error, which was greater at greater offsets, resulted from refracted first arrivals. In creating the velocity-depth model, preference was given to shorter offsets to minimize this error. Lateral variations were assumed to be relatively minor compared with vertical variations in the velocity calculations.

The relationship between seismic velocity and depth based on both refraction and borehole data is shown in Figure 33. Velocity information obtained from the borehole survey is more detailed than data from the refraction surveys. Unlike the refraction method, the borehole technique is not adversely affected by low-velocity layers and can detect thin layers of relatively low velocity.

The interval velocity model presented in Figure 33 (based on borehole measurements) shows an increase in velocity between about 60 and $70 \mathrm{ft}$, followed by a decrease at approximately $90 \mathrm{ft}$, and another increase at about 130-150 ft. The gamma and conductivity logs for borehole CC-11B both show relatively higher readings for the 50- to 120-ft depth range (see Appendix B). Following the downhole geophysical measurements conducted on monitor well CC-11B, monitor well WBR-48 was installed to a depth of $133 \mathrm{ft}$ below surface adjacent to well CC-11B. The boring log for well WBR-48 is included in Appendix A; the lithology for this well is plotted on the gamma and conductivity/resistivity logs for well CC-11B. A high clay content was observed between 47.5 and $101 \mathrm{ft}$, which closely corresponds to the geophysical logs and generally agrees with the seismic velocity model.

\subsection{Seismic Reflection Surveys}

Three seismic reflection profiles, two deep and one shallow, were conducted to record variations in stratigraphy for strata from the ground surface to the crystalline basement in the vicinity of the Kings Creek study area. Survey parameters are summarized in Table 3. The profile locations are shown in Figure 30. 
TABLE 3 Seismic Reflection Profiles near the Kings Creek Study Area

\begin{tabular}{lrrr}
\hline & \multicolumn{3}{c}{ Line Identification Number } \\
\cline { 2 - 4 } \multicolumn{1}{c}{ Parameters } & BRP-4 & BRP-5 & BRP-6 \\
& & & \\
\hline & & & \\
Type & Deep & Deep & Shallow \\
Seismic source & EWG & EWG & Hammer \\
Offset (ft) & 90 & 90 & 18 \\
Geophone interval (ft) & 6 & 6 & 3 \\
Number of shots & 428 & 202 & 77 \\
Number of 24-channel spreads & 408 & 192 & 72 \\
Total length of survey (ft) & 2,442 & 1,146 & 213 \\
& & & \\
\hline
\end{tabular}

Two deep reflection lines (BRP-4 and BRP-5) are located adjacent to the north and the east sides of the Kings Creek study area, respectively (Figure 30). Processed seismic sections for lines BRP-4 and BRP-5 are shown in Figures 34 and 35. The deep seismic reflection data were processed using EAVESDROPPER software developed at the Kansas Geological Survey (1993). Processing steps included trace editing and muting, bandpass filtering, velocity analysis, and CDP sorting and stacking. Seismic arrivals prior to 65 milliseconds (ms) were muted to remove firstarrival refracted energy from the seismic data.

Figures 34 and 35 show stacked seismic sections extending from north (left) to south (right). The north extent of line BRP-5 (left edge of Figure 35) begins approximately where the south extent of line BRP-4 ends (right edge of Figure 34). The stick diagrams at the bottom of both figures show the major reflections.

The crystalline bedrock is observed in both lines at a depth of approximately $450 \mathrm{ft}$ in the north (Figure 34) and dipping to nearly $550 \mathrm{ft}$ in the south (Figure 35). The estimated basement depth reported in the literature for the APG area ranges from $350 \mathrm{ft}$ (Southwick, Owens, and Edwards 1969) to $800 \mathrm{ft}$ (Otton and Mandle 1984). The bedrock depth interpreted from seismic data reported for the Beach Point Peninsula, located a few thousand feet south of the Bush River Peninsula (Figure 1), is about $560 \mathrm{ft}$ (McGinnis et al. 1994a). The crystalline basement generally dips to the southeast at an angle of less than one degree in the vicinity of APG (Bennett and Meyer 1952; Dingman et al. 1956; Southwick, Owens, and Edwards 1969).

Another less prominent but relatively continuous reflector is observed at a depth of about $275 \mathrm{ft}$ dipping gradually to the south in both Figures 34 and 35 . The source of the reflector is below any deep boreholes at the Bush River Peninsula and the reflector has not been observed in other geophysical data sets. The continuous nature of the reflector suggests that the feature might be an important hydrogeological boundary. 

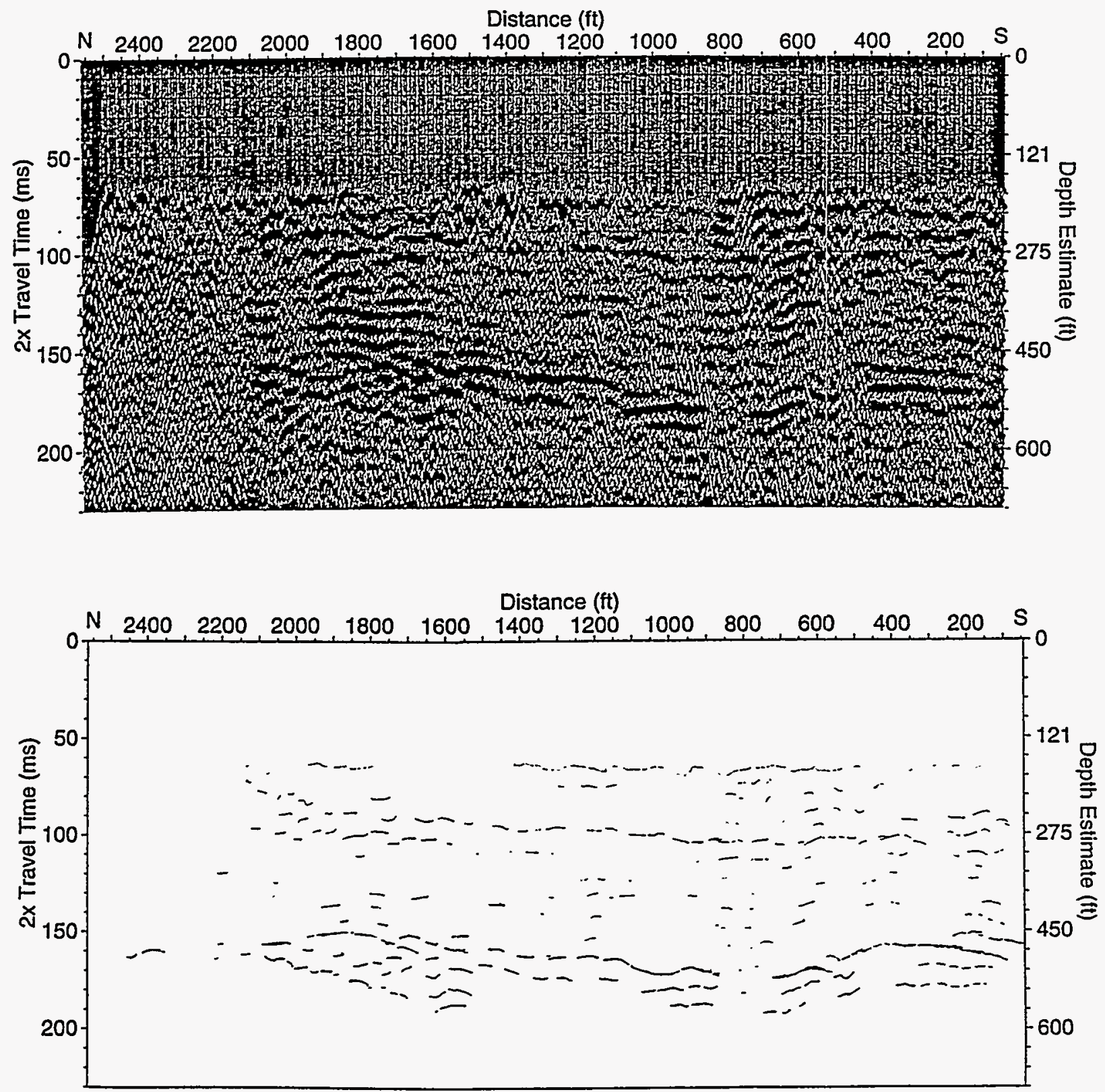

FIGURE 34 Seismic Reflection Profile for Line BRP-4 

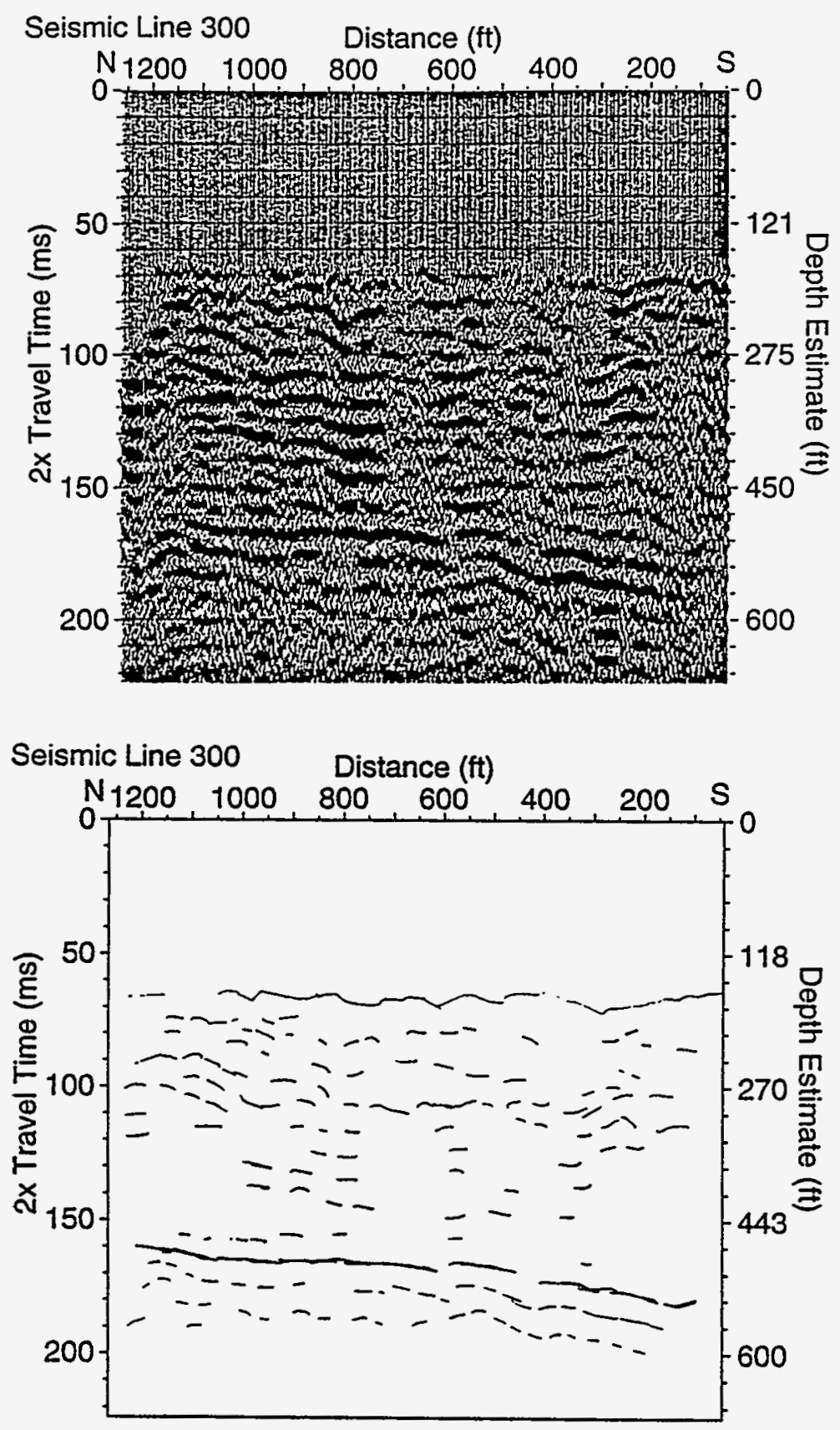

FIGURE 35 Seismic Reflection Profile for Line BRP-5 
One shallow reflection line, BRP-6, is located south of the Kings Creek study area, adjacent to monitor well CC-11B (Figure 30). A processed seismic section for line BRP-6 is presented in Figure 36. Processing steps for line BRP-6 were similar to those used for lines BRP-4 and BRP-5, except that the first-arrival mute was applied to signals prior to about $20 \mathrm{~ms}$ (versus $65 \mathrm{~ms}$ for the deeper reflection lines). The seismic section in Figure 36 extends from north (left) to south (right) and shows reflectors for depths as shallow as $35 \mathrm{ft}$. The distance scale is in feet from monitor well CC-11B. The stick diagram at the bottom shows the major reflections as interpreted from the seismic section.

A continuous reflector is observed at a depth of approximately $40-50 \mathrm{ft}$. The geophysical well logs for monitor well CC-11B show a layer of increased gamma and conductivity values beginning at about $48 \mathrm{ft}$ and extending to about $120 \mathrm{ft}$, typical for clay-rich sediments. The reflector in the shallow reflection line (Figure 36) may correspond to the top of the confining layer at the base of the surficial aquifer (Figure 4). No seismic reflection from the bottom of the clayrich layer was observed because of static noise and signal reverberation in the seismic section. 


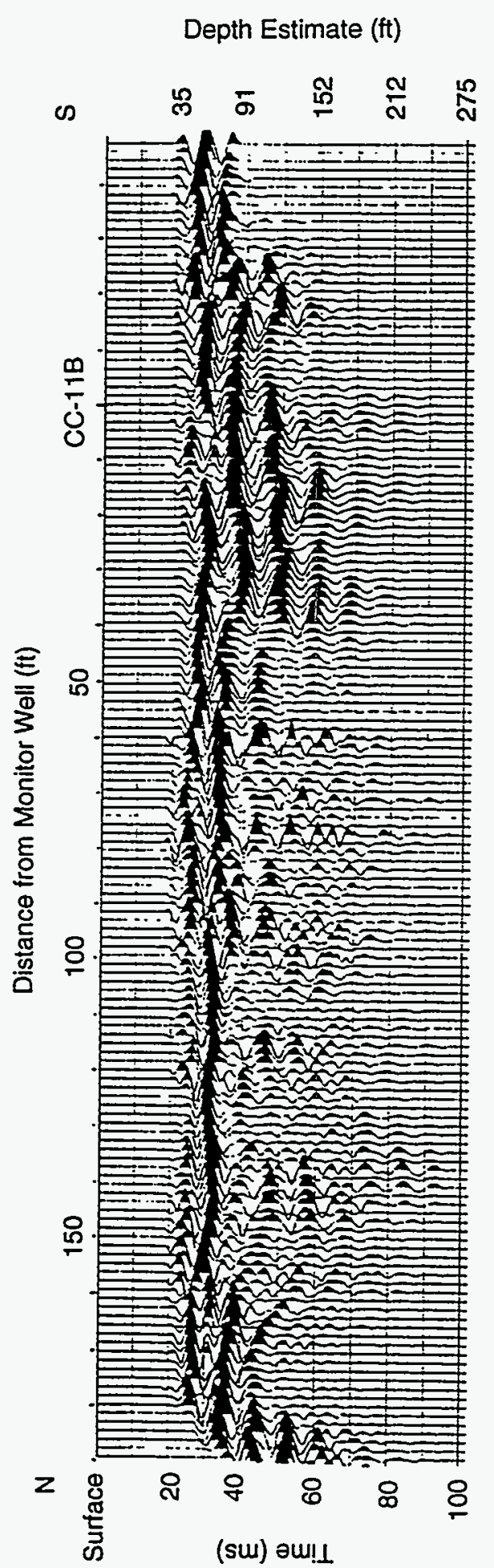

Depth Estimate (ft)

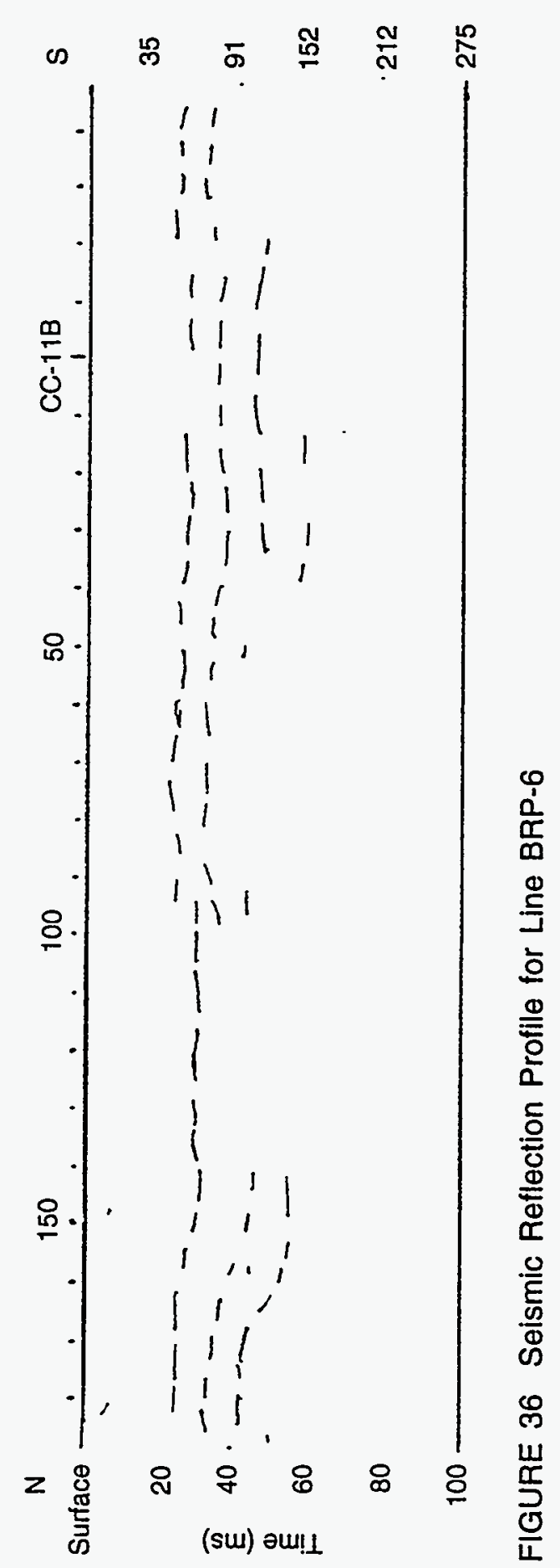




\section{Discussion}

\subsection{Areal Extent of Kings Creek Disposal Site and 30th Street Landfill}

Geophysical technologies, including magnetics, seismic reflection and refraction, borehole geophysics, electromagnetics, and GPR, have been utilized in the environmental investigation of the Kings Creek study area. These geophysical techniques, combined with visual observations, have helped define the areal extent of the former Kings Creek Disposal Site and the 30th Street Landfill.

Total field magnetics data and magnetic gradiometer surveys north of the former burn pits at the Kings Creek Disposal Site (Figure 11) indicate that metal debris is scattered throughout the area surveyed. A linear trend of magnetic anomalies is present running southwest from the northsouth-trending fenceline toward the former burn pits. The origin of this feature is unknown, but the trend may indicate remnants of a previous site access road. These anomalous zones are not believed to be large-scale (i.e., tens of feet) waste burial areas, although smaller, isolated areas of buried wastes and/or munitions cannot be ruled out.

Variations in EM-31 conductivity data for the former Kings Creek Disposal Site, including the surveyed area to the north, are produced by changes in the near-surface geology and metal debris. On the basis of the spatial association of geophysical anomalies, the extent of the former Kings Creek Disposal Site is likely confined to the areas of currently disturbed or absent vegetation and the associated berms formed by pushed-out materials from the burn pits.

Limited GPR data were obtained from the former Kings Creek Disposal Site because of the heavy vegetation covering much of the area. One anomalous feature, detected by the GPR, magnetic, and electromagnetic surveys, is located at approximately 110N/170E (\#1, Figures 8 and $15 \mathrm{~A}$ ) of the survey grid. This feature, illustrated in Figure 28, may represent a buried drum or small tank. Further characterization of this subsurface feature is recommended.

The total field magnetic survey was used to map the areal extent of the 30th Street Landfill. The western extent of the main landfill body is defined by the $240 \mathrm{E}$ north-south grid line (Figure 9). The majority of the discontinuous magnetic anomalies west of the 240E line can be explained by surficial debris, but further characterization may be necessary because buried ferrous objects may also be present at these locations. The landfill is believed to be confined by the security fence to the north, but the fence overwhelms any other magnetic and electromagnetic signals, making it impossible to pinpoint the exact northern boundary. The eastern boundary of the landfill corresponds to the western limits of the present wetland. No indication of landfilling was found farther to the east (Figures 10,12, and 17). The limits of landfilling to the south, into the current wetland, are not known. Geophysical surveys have not been conducted farther south because of the thick phragmite cover present at this location. However, geophysical surveys performed offshore from the wetland during late summer 1994 indicate that metallic debris is present near the shoreline. 
The 30th Street Landfill is located in a former wetland. GPR data indicate that the western boundary of the landfill is also the location of the western edge of a paleochannel. On the basis of GPR data (profiles \#12 and \#13, Figures 23 and 24), the total depth of fill at the 30th Street Landfill is approximately 8-10 ft. The EM-31 data presented in Figure 16A show the location of the pre-landfill wetland as a conductive high resulting from Holocene and Pleistocene clayey sediments and fill material. Offshore electromagnetic surveys have indicated that a more conductive subsurface zone is present at the location of a paleochannel that extends into Kings Creek from the 30th Street Landfill (Figure 18). The origin of this more conductive material offshore is clayey sediments deposited in the paleochannel at depths measurable with the EM-31 (upper $18 \mathrm{ft}$ ).

\subsection{Hydrogeologic Framework}

Well logs of recently installed monitor wells provide the basic subsurface geologic control for the remedial investigation/feasibility study currently being conducted in the Bush River Peninsula area (see Figure 20 and Appendix A). Geophysical methods (including GPR, EM-31, seismic reflection and refraction, and downhole gamma and induction logging) complement the basic area-wide studies conducted to define the geologic and hydrogeologic framework beneath the study area.

GPR imaging provides a detailed display of reflectors to depths up to $45 \mathrm{ft}$. The reflectors represent contacts separating recently deposited channel-fill complexes from underlying sediments. These contacts also constitute irregularities in the base of the surficial aquifer. The channel-fill complexes in the APG area are the result of multiple erosion/deposition events that occurred during the successive low sea-level stands and subsequent marine transgressions of the Pleistocene Epoch. The GPR profile presented in Figure 24 is a good example of two superimposed erosion/deposition events beneath the 30th Street Landfill. At this location, two more recent, shallow channel features are superimposed on an older, deeper paleochannel.

Seismic imaging, in conjunction with downhole logging, shows details of the shallow and deep facies beneath the study area. The top of the confining layer (at the base of the surficial aquifer) appears as a continuous reflector at a mean depth of $45 \mathrm{ft}$ below land surface (Figure 36). Downhole gamma and conductivity logs of monitor well CC-11B suggest that this confining layer extends to a depth of approximately $120 \mathrm{ft}$ below land surface. Reflectors dipping eastward at approximately $275 \mathrm{ft}$ below the surface (Figure 34) mark undifferentiated depositional sequences of Cretaceous, Atlantic Coastal Plain strata. The top and bottom of the upper confined aquifer cannot be defined on the basis of reflection data alone. The eastern-dipping Cretaceous strata rest on a crystalline bedrock ranging in depth from $450 \mathrm{ft}$ north of the Kings Creek study area (Figure 34) to nearly $550 \mathrm{ft}$ in the south (Figure 35). 


\subsection{Subsurface Paleochannel Locations}

It is important to define the paleochannel locations because their basal sediments often consist of materials of greater hydraulic conductivity (sands and gravels) that form the base of the surficial aquifer. The current drainageway and wetland locations in the Bush River Peninsula are good indicators of the locations of Pleistocene drainage systems. The Pleistocene paleochannels can be deeply incised into the underlying Cretaceous sediments; depths to the base of these features have been found to be at least $50 \mathrm{ft}$ below sea level offshore (Figure 22) and greater than $35 \mathrm{ft}$ below land surface onshore (monitor well WBR-23, Appendix A).

Preliminary subsurface data collected during the geophysical studies at Kings Creek were used to help select the locations of the recently installed site monitor wells. On the basis of the boring logs for these wells and the electromagnetic and GPR subsurface data collected, the approximate locations of major paleochannel features have been mapped and are presented in Figure 37. As the figure shows, a major paleochannel extends into Kings Creek from the wetland adjacent to, and including, the 30th Street Landfill. Multiple branches of the channel to the west,

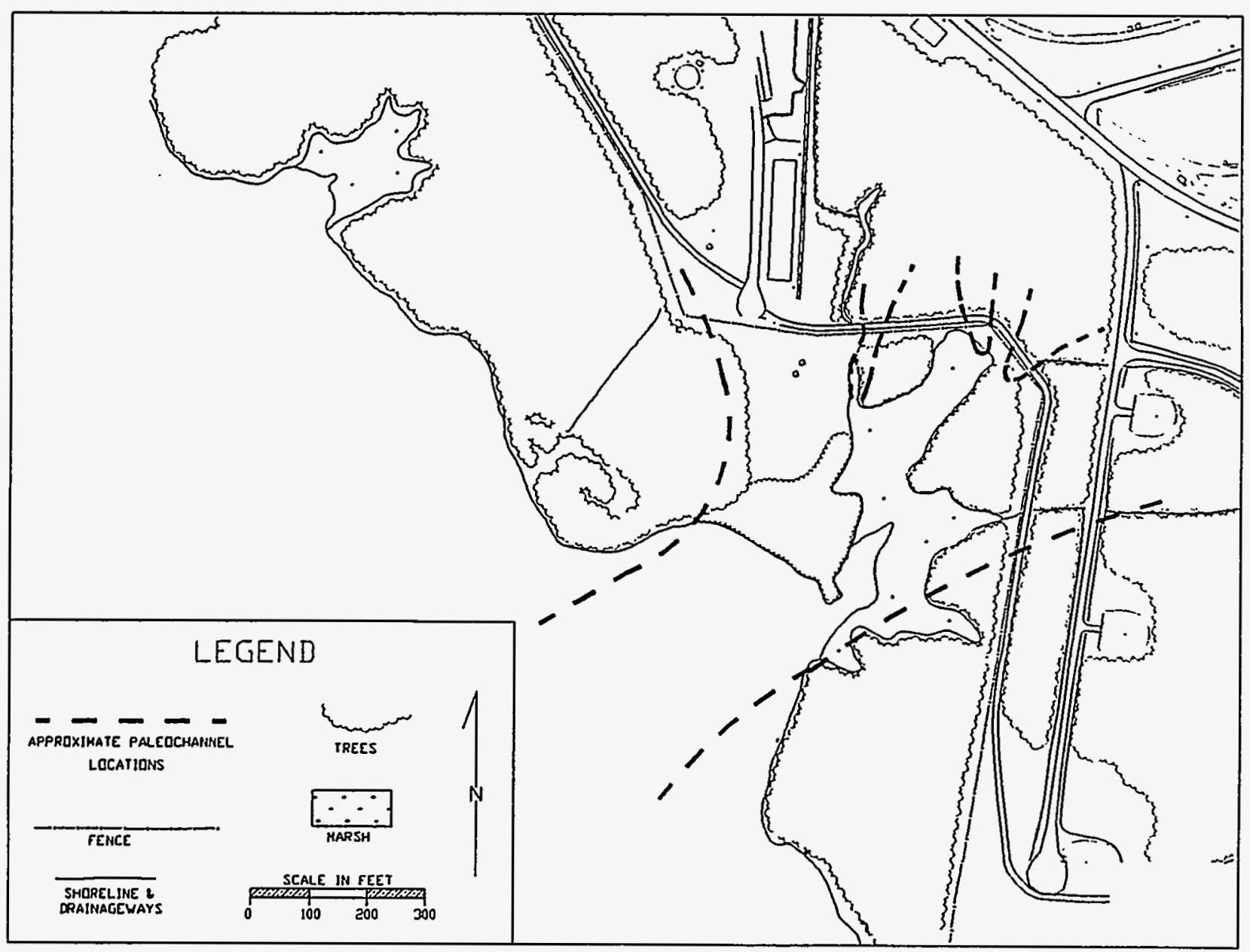

FIGURE 37 Approximate Paleochannel Locations Inferred from GPR Data 
east, and north appear to meet at this wetland location. The west channel branch extends through the 30th Street Landfill at a depth of 25 to $30 \mathrm{ft}$ below sea level. This branch is visible on GPR profiles \#12, \#13, and the western (right) side of \#15 (Figures 23 through 25). Additional, shallower features ( $8-10 \mathrm{ft}$ below ground surface), which likely represent later erosional features, are superimposed on the deeper feature in profile \#13 (Figure 24). The shallower features correspond to two EM-31 conductivity highs extending northward in the 30th Street Landfill (Figure 16B).

Another paleochannel extends eastward from the wetland area. The channel boundaries at this location are less precise because of the lack of good GPR reflectors in the eastern section of the study area. This paleochannel is defined largely from logs for monitor wells WBR-23 and WBR-25 (Appendix A).

Two shallow (approximately $20 \mathrm{ft}$ below ground surface) paleochannel branches extend toward the north. These branches are defined by GPR profiles \#14 (Figure 26) and \#15 (Figure 25) along the security fenceline north of the 30th Street Landfill (Figure 21). GPR data at these locations indicate two shallow channel features that may be superimposed over a deeper channel body, similar to those observed in the western branch. Review of the boring log for monitor well WBR-19 (Appendix A) indicates that paleochannel-type sediments are present at this location (Figure 20). Additional data collection is necessary to confirm the continuity of channel locations farther north.

Mapping the location of these potential hydraulically conductive zones is very important in understanding the hydrology of the surficial aquifer and the potential for interconnection between the surficial aquifer and the underlying upper confined aquifer (referred to as the Canal Creek aquifer on Figure 4). Five soil borings (BR-1 through BR-5, Figure 2) and recently installed monitor well WBR-48 provide depth information for the top of the Cretaceous upper confined aquifer. Monitor well WBR-48 is the closest control point to the Kings Creek study area. The top of the upper confined aquifer at the location of WBR-48 is approximately $100 \mathrm{ft}$ below land surface (approximately $90 \mathrm{ft}$ below sea level). Both sides of the offshore paleochannel are visible on GPR profile \#16 (Figure 22), but the total depth of the thalweg has not been determined due to signal loss below a depth of approximately $50 \mathrm{ft}$ below sea level. Extrapolating the slope of the two channel sides gives the depth of the thalweg at approximately $80 \mathrm{ft}$ below sea level. 


\section{Summary and Conclusions}

During the 1920s and 1930s, chemical munitions and wastes were reportedly burned at the former Kings Creek Disposal Site. Active landfilling reportedly occurred at the 30th Street Landfill in the 1960s and, probably, early 1970s (Nemeth 1989), and buried munitions have been discovered at the landfill, although no records of munitions disposal at this site are available.

A series of geophysical surveys, supported by a site drilling program, was undertaken to define the hydrogeologic framework and potential contaminant migration pathways beneath the study area. The areal extent of metallic wastes was mapped by using magnetic and electromagnetic methods. The following specific conclusions have been drawn based on the results of the surveys:

1. The areal extent of the 30th Street Landfill has largely been defined. No evidence was found of any landfilling to the east, across the wetland from the landfill.

2. No large-scale disposal by burial appears to be associated with the former Kings Creek Disposal Site, but small-scale waste burial cannot be ruled out. Magnetic anomaly maps prepared for the entire study area reveal an unknown subsurface anomaly at $110 \mathrm{~N} / 170 \mathrm{E}$ on the site grid that may represent a buried drum or small tank.

3. The general hydrogeologic framework beneath the Kings Creek study area has been defined. A Pleistocene channel-fill complex greater than $50 \mathrm{ft}$ in depth runs beneath the 30th Street Landfill and into Kings Creek.

4. Seismic profiling revealed Cretaceous sediment ranging in thickness up to $500 \mathrm{ft}$. Gentle easterly dips in the sediment conform to published descriptions of the Cretaceous structure.

5. The Precambrian-age crystalline bedrock lies at a depth of $450-550 \mathrm{ft}$ beneath the Bush River Peninsula.

6. Contaminant pathways from the 30th Street Landfill along the base of the surficial aquifer may be outlined by a conductive subsurface feature extending offshore into Kings Creek. This potential pathway corresponds to the location of a Pleistocene paleochannel outlined by GPR methods (see Conclusion 3). It is not known whether the offshore-trending paleochannel breaches the upper confined aquifer. Soil borings would be necessary to further characterize the subsurface hydrogeology. 


\section{References}

Bennett, R.R., and R.R. Meyer, 1952, Geology and Ground-Water Resources of the Baltimore Area, Bulletin 4, Maryland Department of Geology, Mines, and Water Resources.

Cordell, L., et al., 1992, Potential Field Geophysical Software: Version 2, U.S. Geological Survey Open-File Report 92-18.

Dingman, R.J., et al., 1956, The Water Resources of Baltimore and Harford Counties, Bulletin 17, Maryland Department of Geology, Mines, and Water Resources.

Geonics Limited, 1992, EM-31 Operating Manual (for Models with Two Digital Meters), Mississauga, Ontario, Canada.

Geophysical Survey Systems, Inc., 1987, Operations Manual for Subsurface Interface Radar (SIR System-3).

Kansas Geological Survey, 1993, EAVESDROPPER Seismic Reflection Processing Software, Version 3.0, 1930 Constant Ave., Campus West, Lawrence, Kansas.

Kehrin, R.T., et al., 1988, The Surficial Sediments of the Chesapeake Bay, Maryland - Physical Characteristics and Sediment Budget, Report No. 48, Maryland Geological Survey.

Lorah, M.M., and D.A. Vroblesky, 1989, Inorganic and Organic Ground-Water Chemistry in the Canal Creek Area of Aberdeen Proving Ground, Maryland, Water Resources Investigations Report 89-4022, U.S. Geological Survey.

McGinnis, L.D., et al., 1994a, Environmental Geophysics at Beach Point, Aberdeen Proving Ground, Maryland, ANL/ESD-23, Argonne National Laboratory, Argonne, Ill.

McGinnis, L.D., et al., 1994b, Environmental Geophysics of the Pilot Plant on the West Branch of Canal Creek, Aberdeen Proving Ground, Maryland, ANL/ESD/TM-74, Argonne National Laboratory, Argonne, $\mathrm{Ill}$.

Nemeth, G., 1989, RCRA Facility Assessment Report, Edgewood Area, Aberdeen Proving Ground, Maryland, prepared by U.S. Army Environmental Hygiene Agency for Aberdeen Proving Ground, Test and Evaluation Command, U.S. Army Material Command.

Oliveros, J.P., and D.A. Vroblesky, 1989, Hydrogeology of the Canal Creek Area, Aberdeen Proving Ground, Maryland, Water Resources Investigations Report 89-4021, U.S. Geological Survey. 
Otton, E.G., and R.J. Mandle, 1984, Hydrogeology of the Upper Chesapeake Bay Area, Maryland, with Emphasis on Aquifers in the Potomac Group, Report No. 39, Maryland Geological Survey.

RIMROCK Geophysics, Inc., 1992, SIPT2 Refraction Processing Software, Version 3.2, Boulder, Colo.

Southwick, D.L., J.P. Owens, and J. Edwards, Jr., 1969, The Geology of Harford County, Maryland, Maryland Geological Survey.

Thurmond, V., 1993, North-South Stratigraphic Cross-Section of the Bush River Area, U.S. Army Corps of Engineers - Baltimore District, Internal Document.

U.S. Army Corps of Engineers, Baltimore District, 1994, Detailed RI Work Plan for Cluster 15, Edgewood Area, Aberdeen Proving Ground, Maryland. 
Appendix A:

Soil Boring Logs 


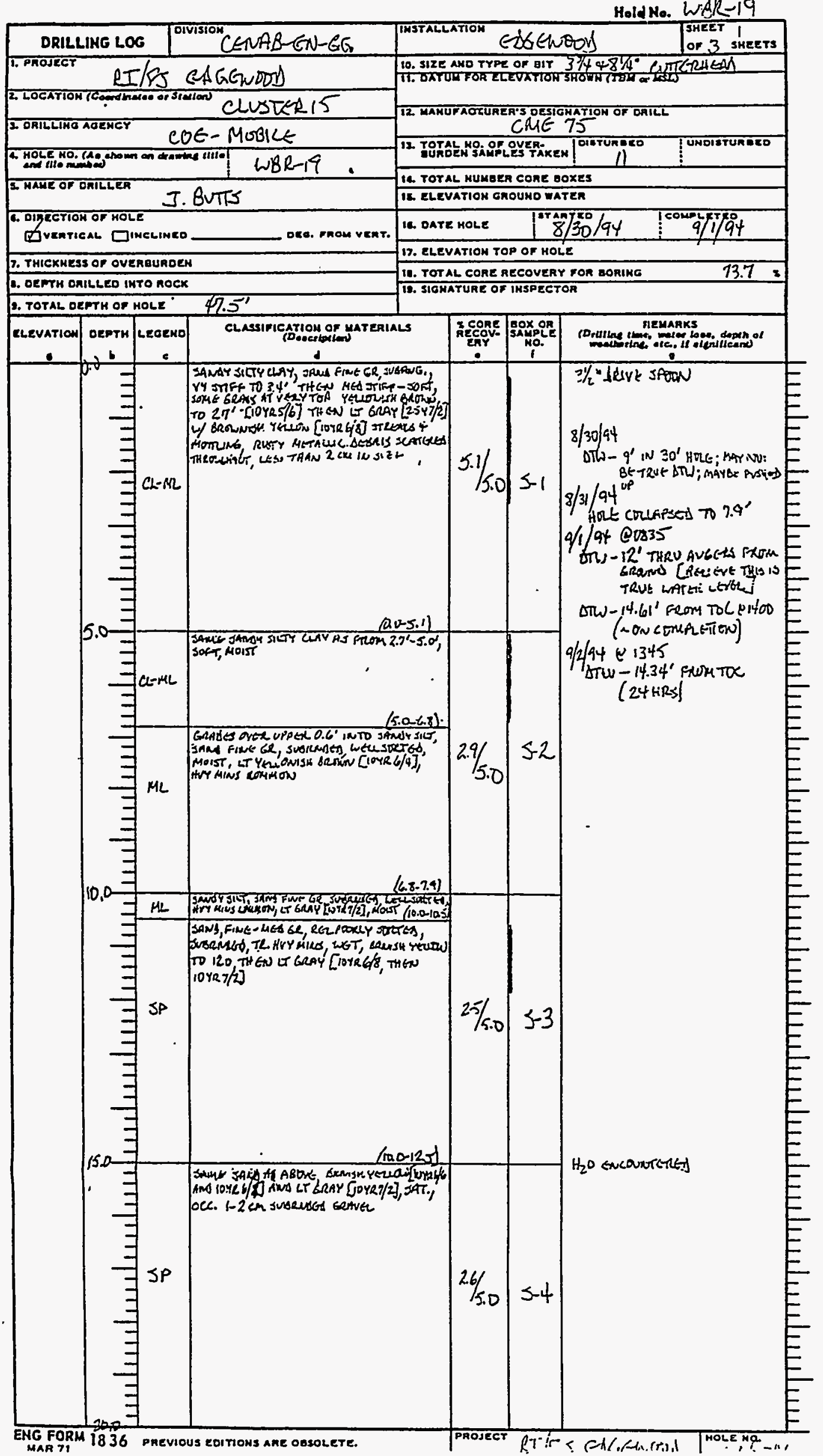




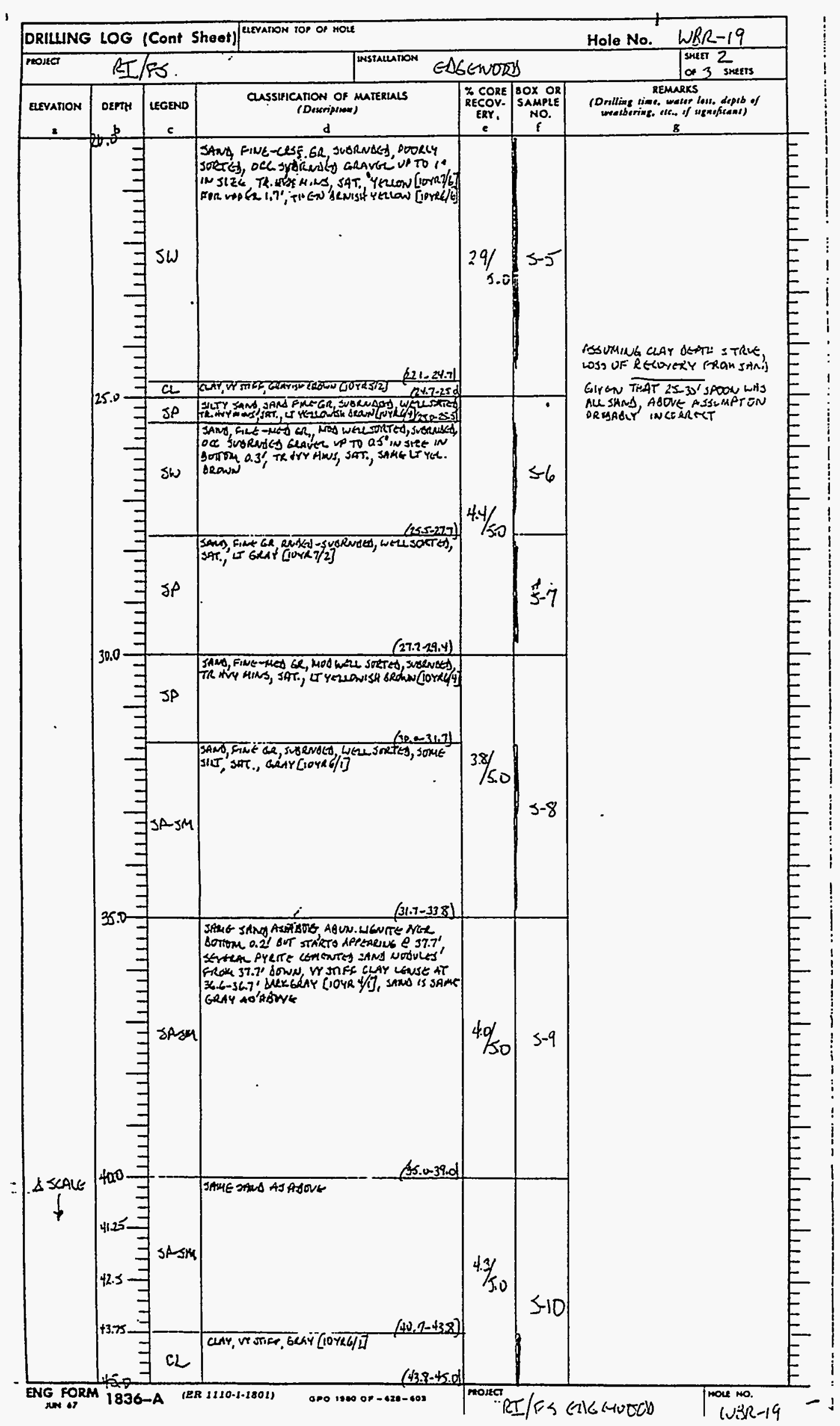




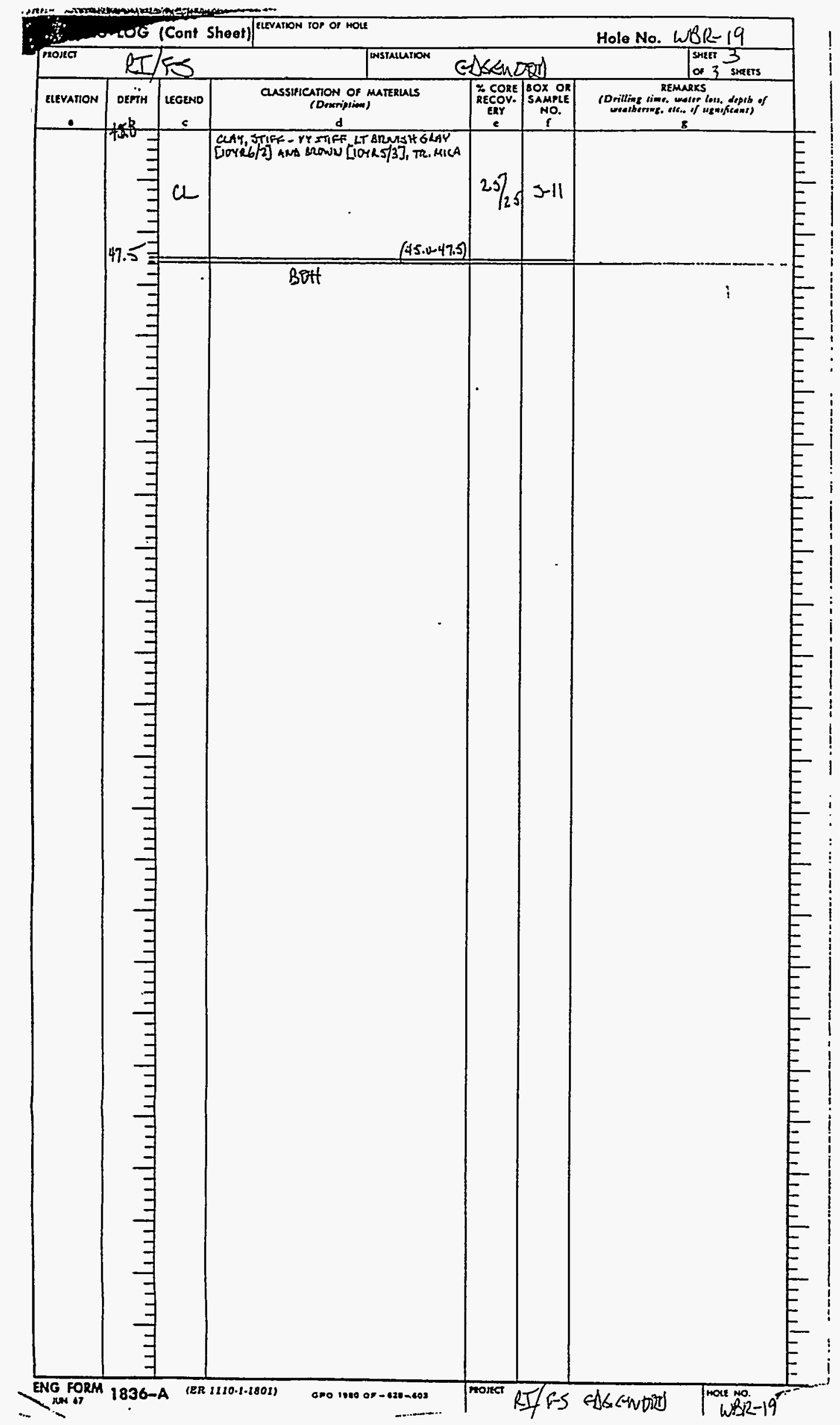




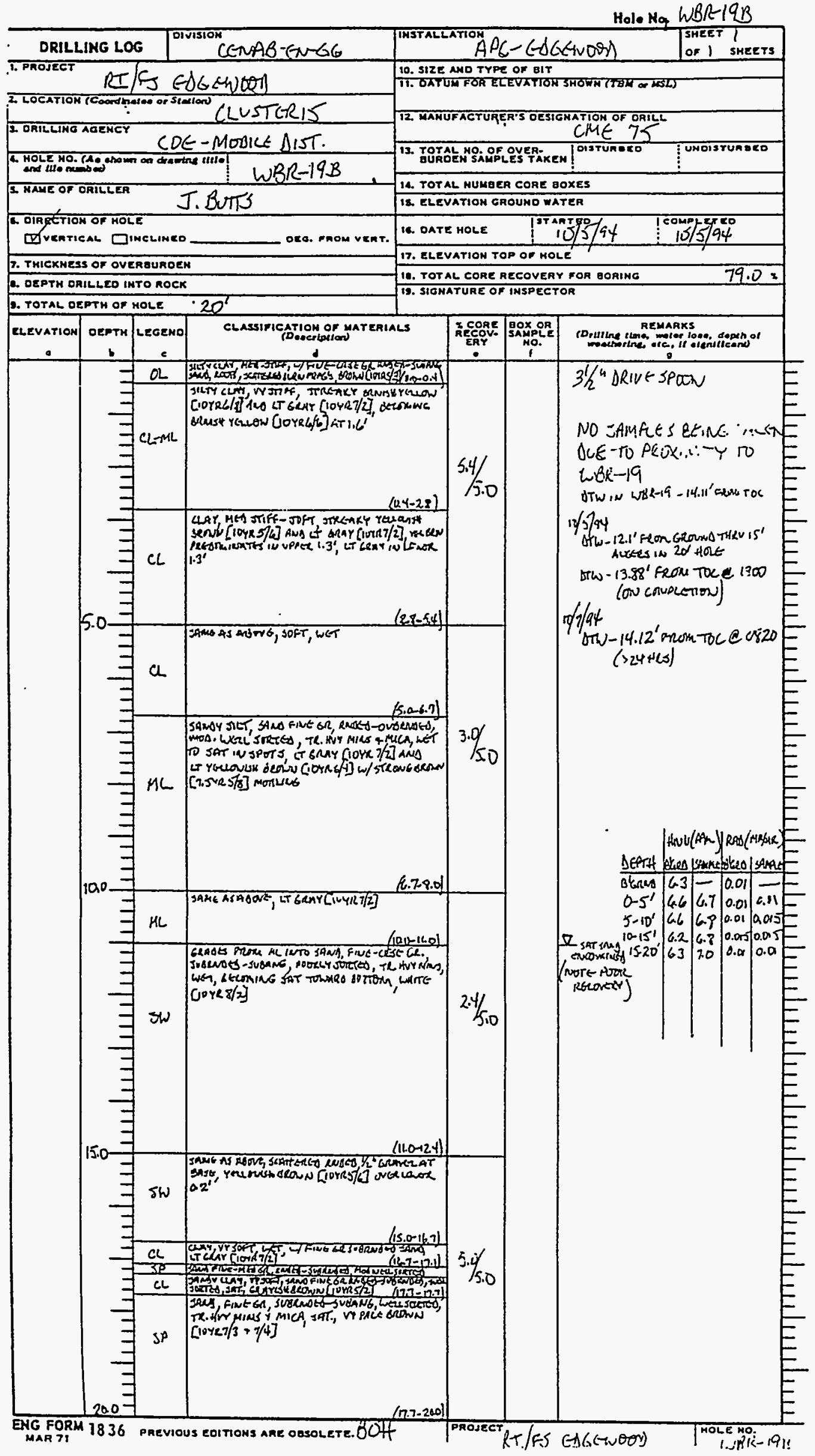




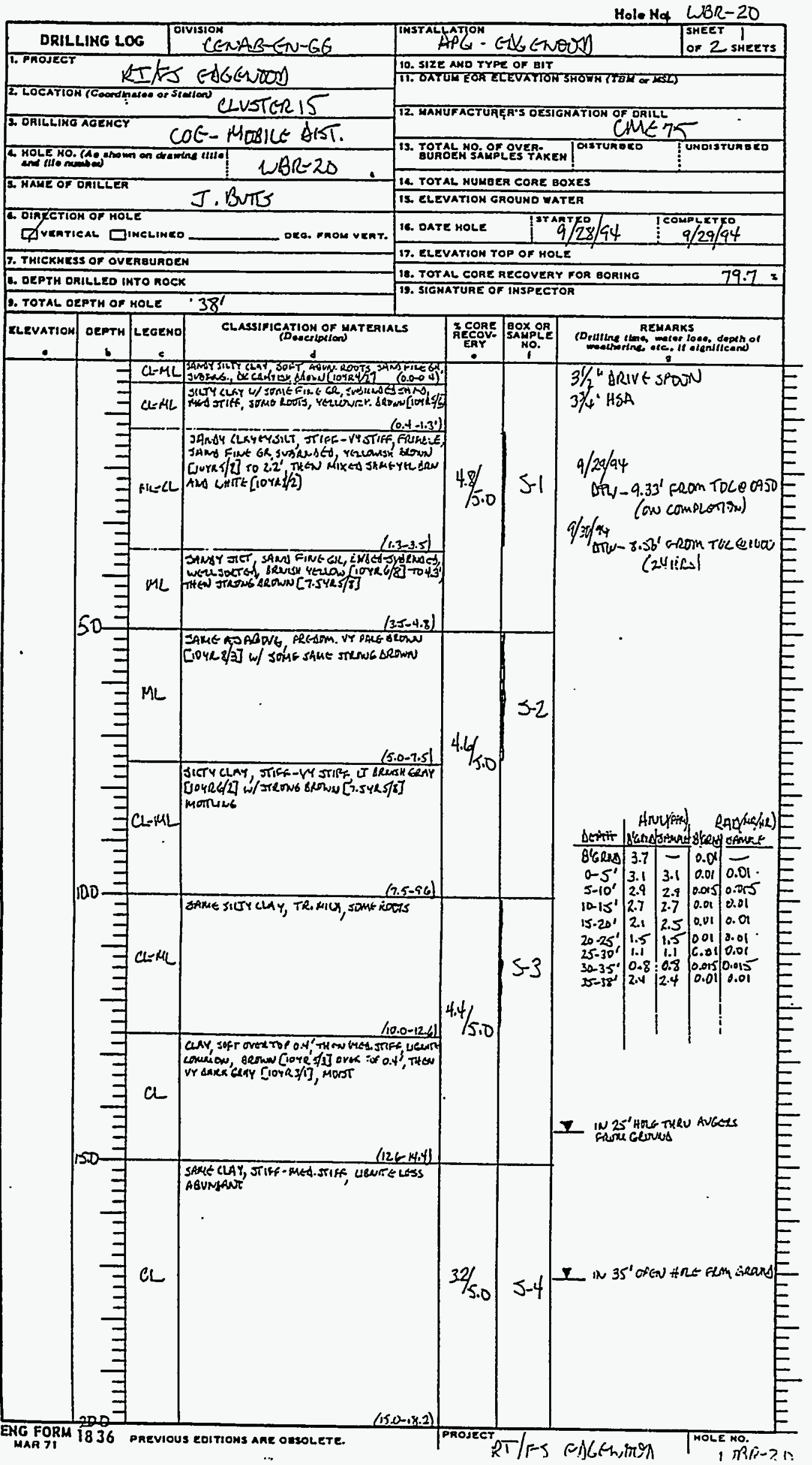




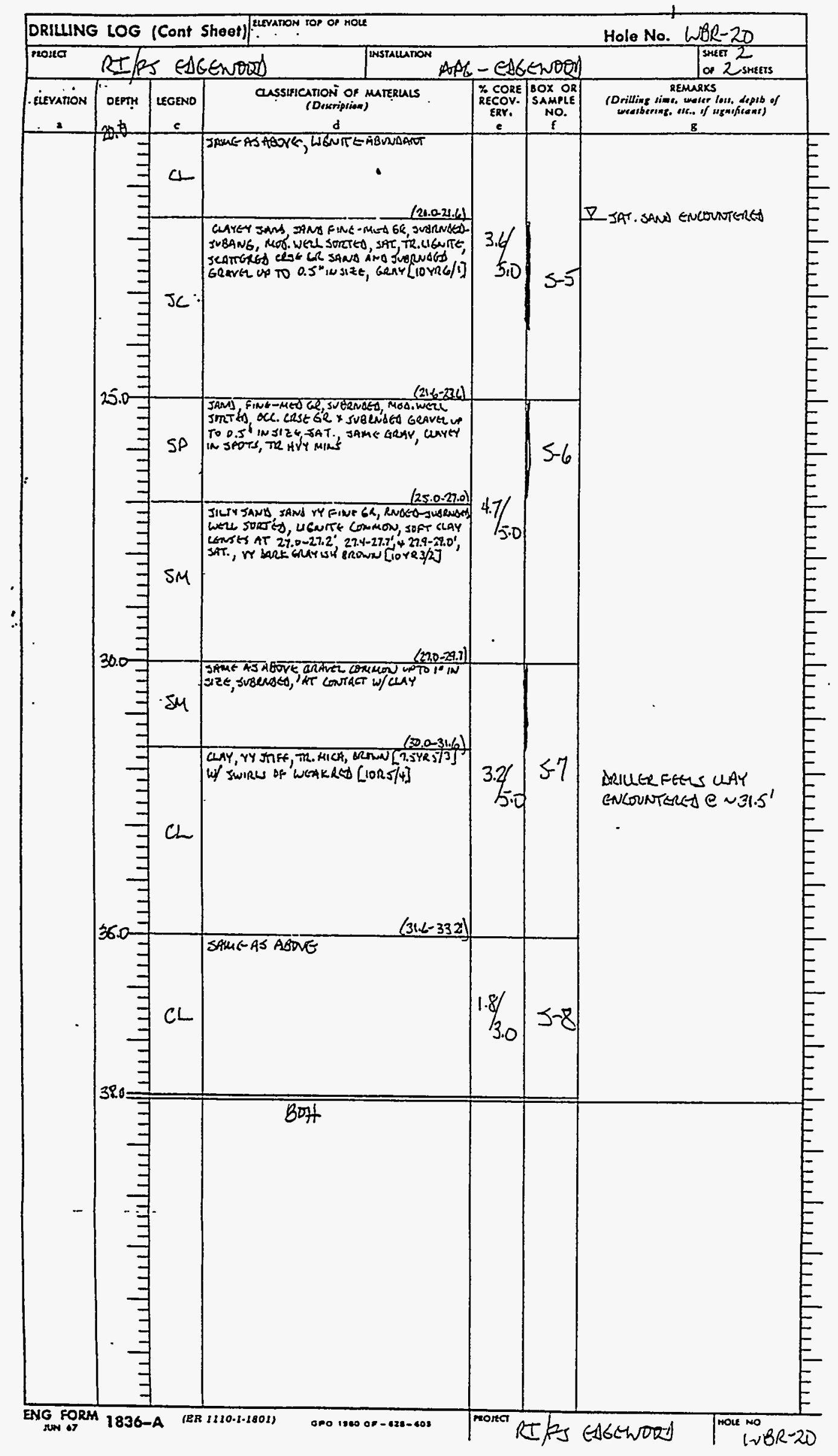




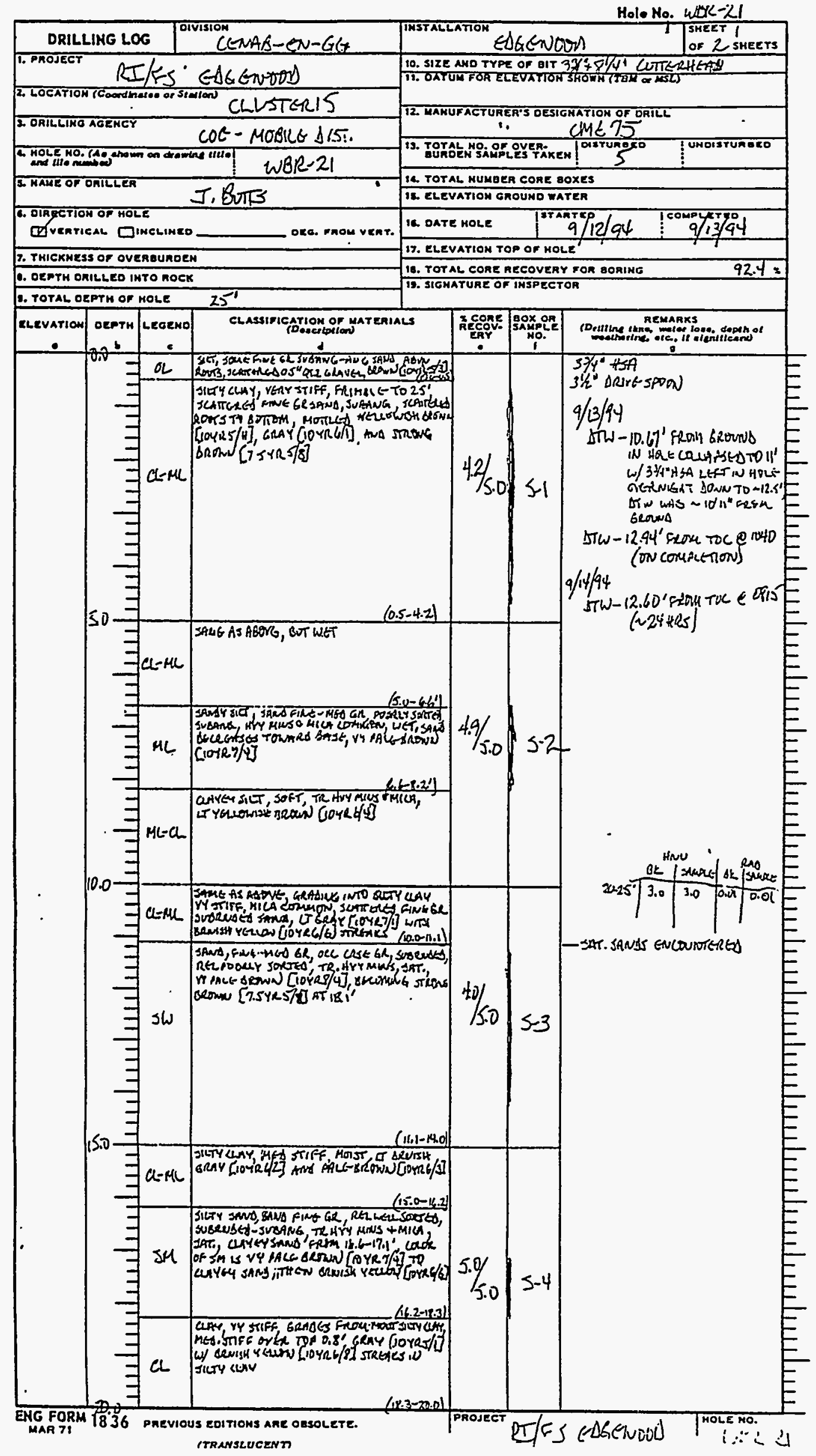




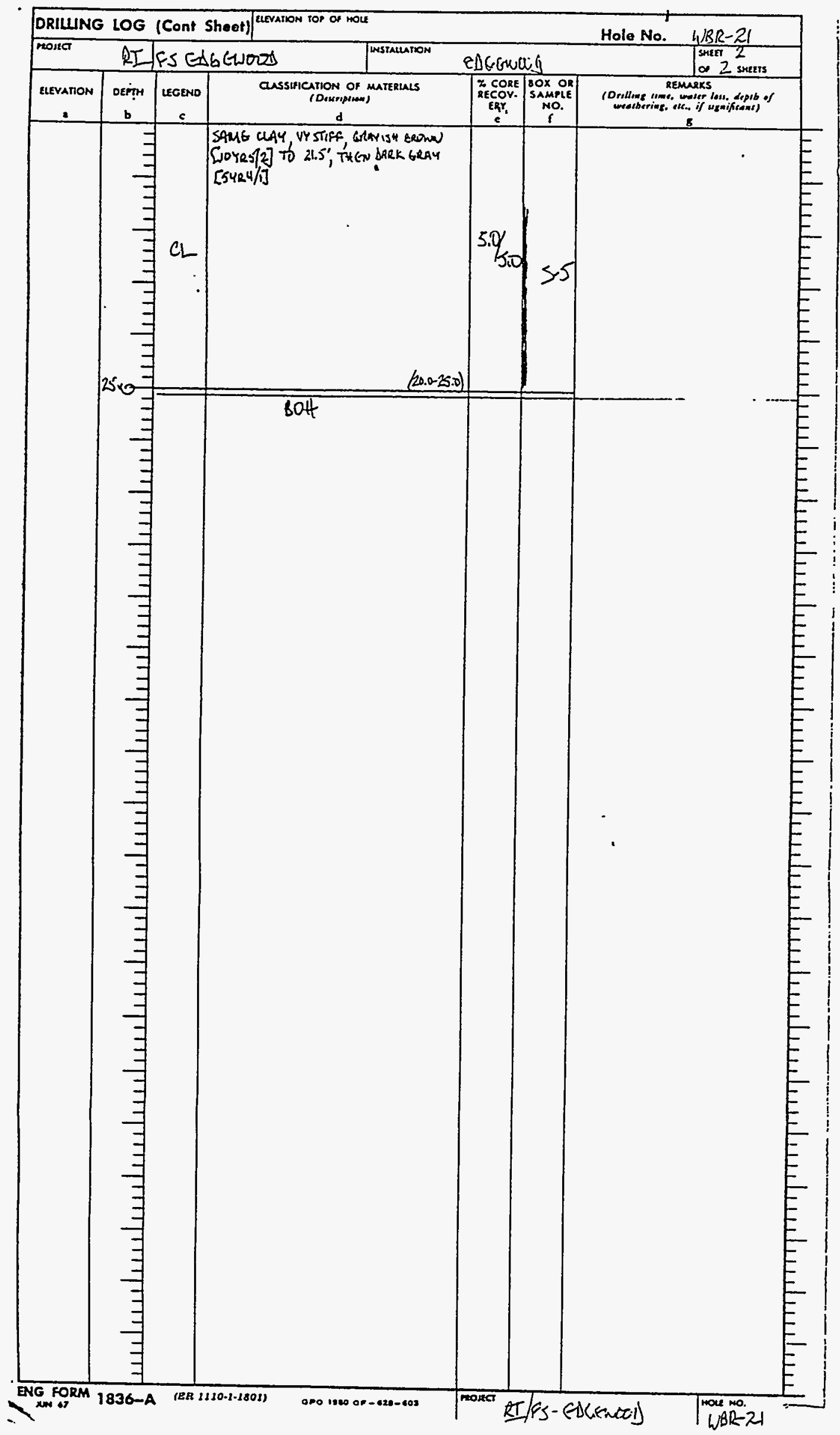


90

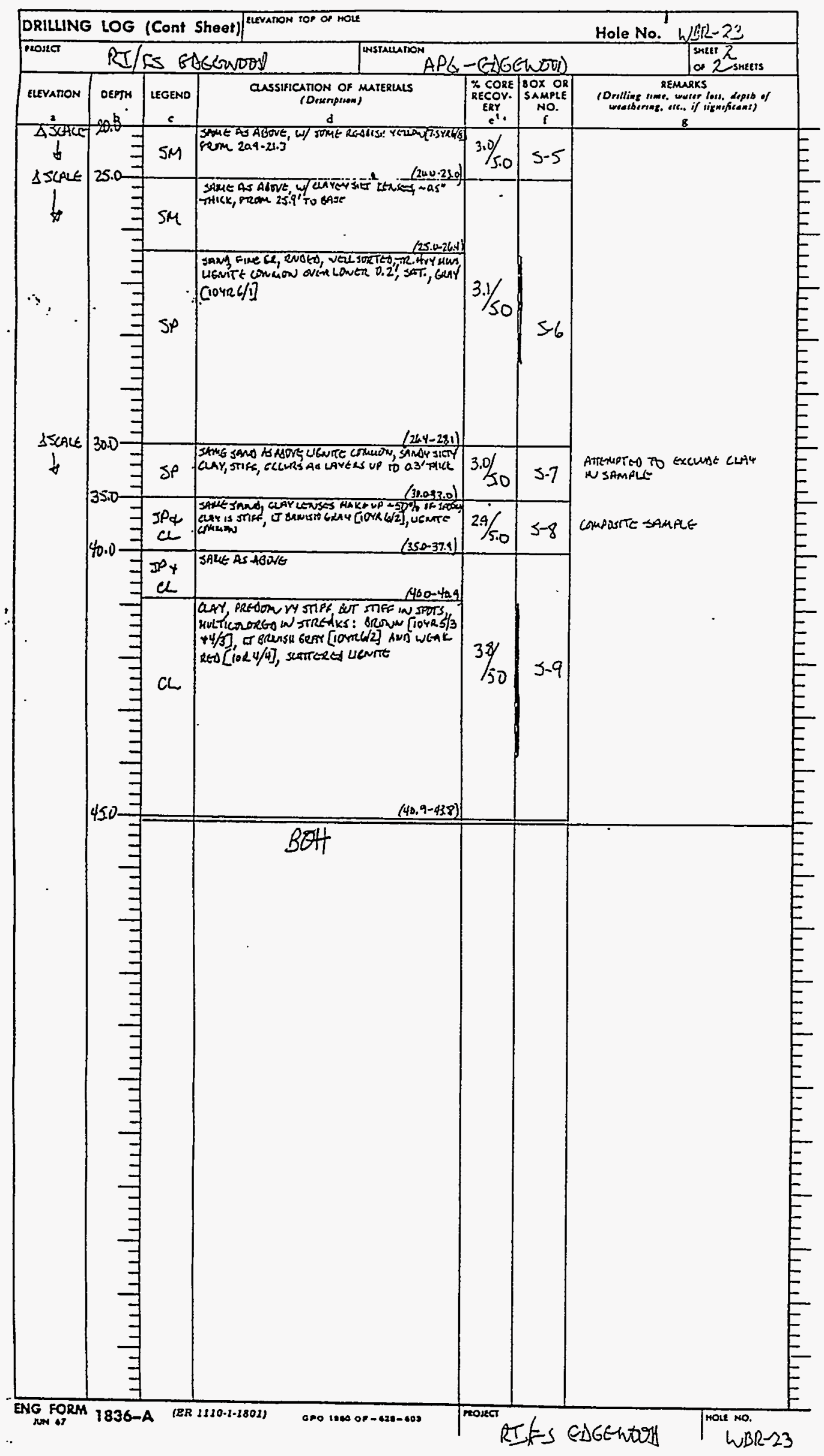




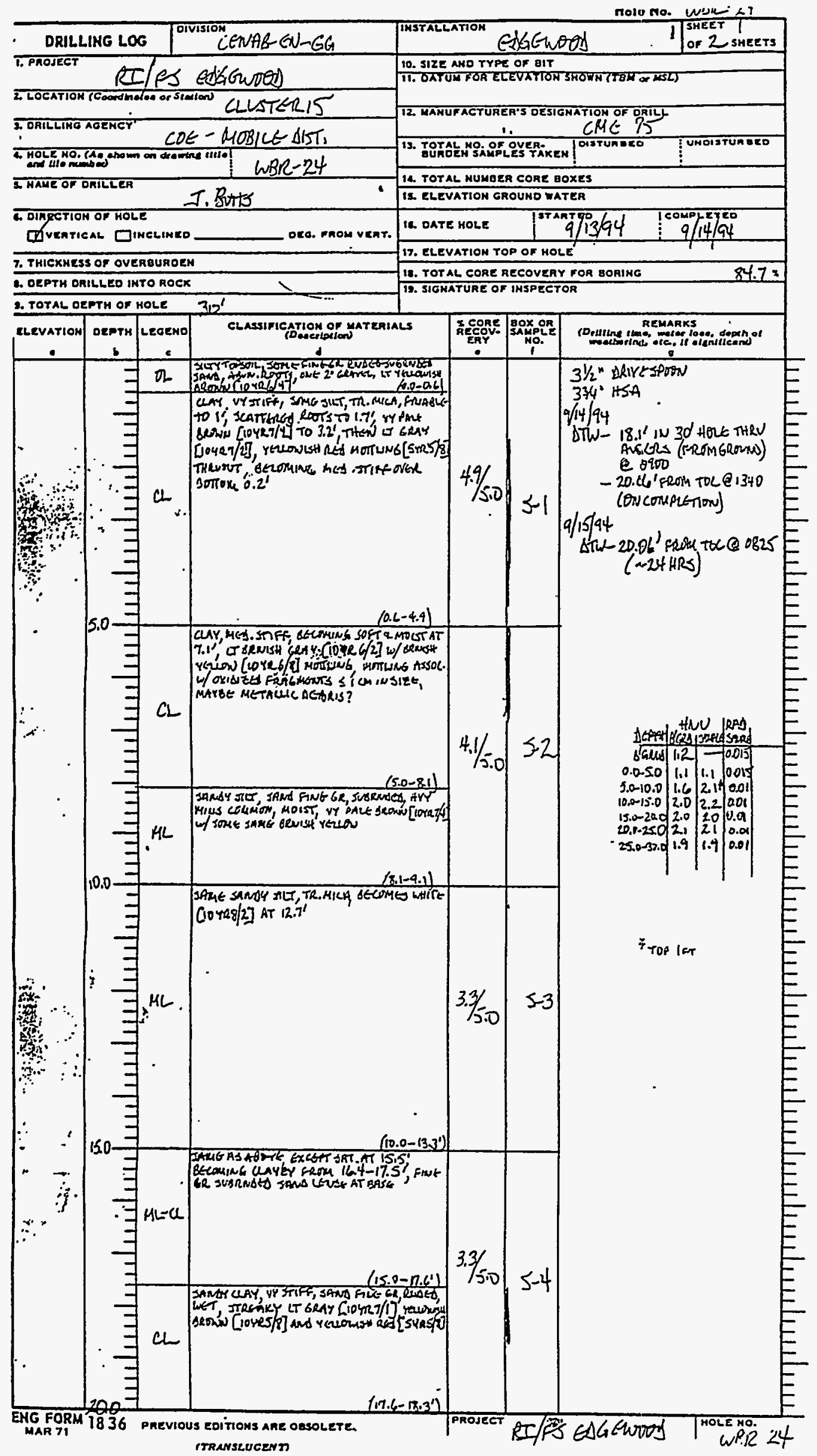




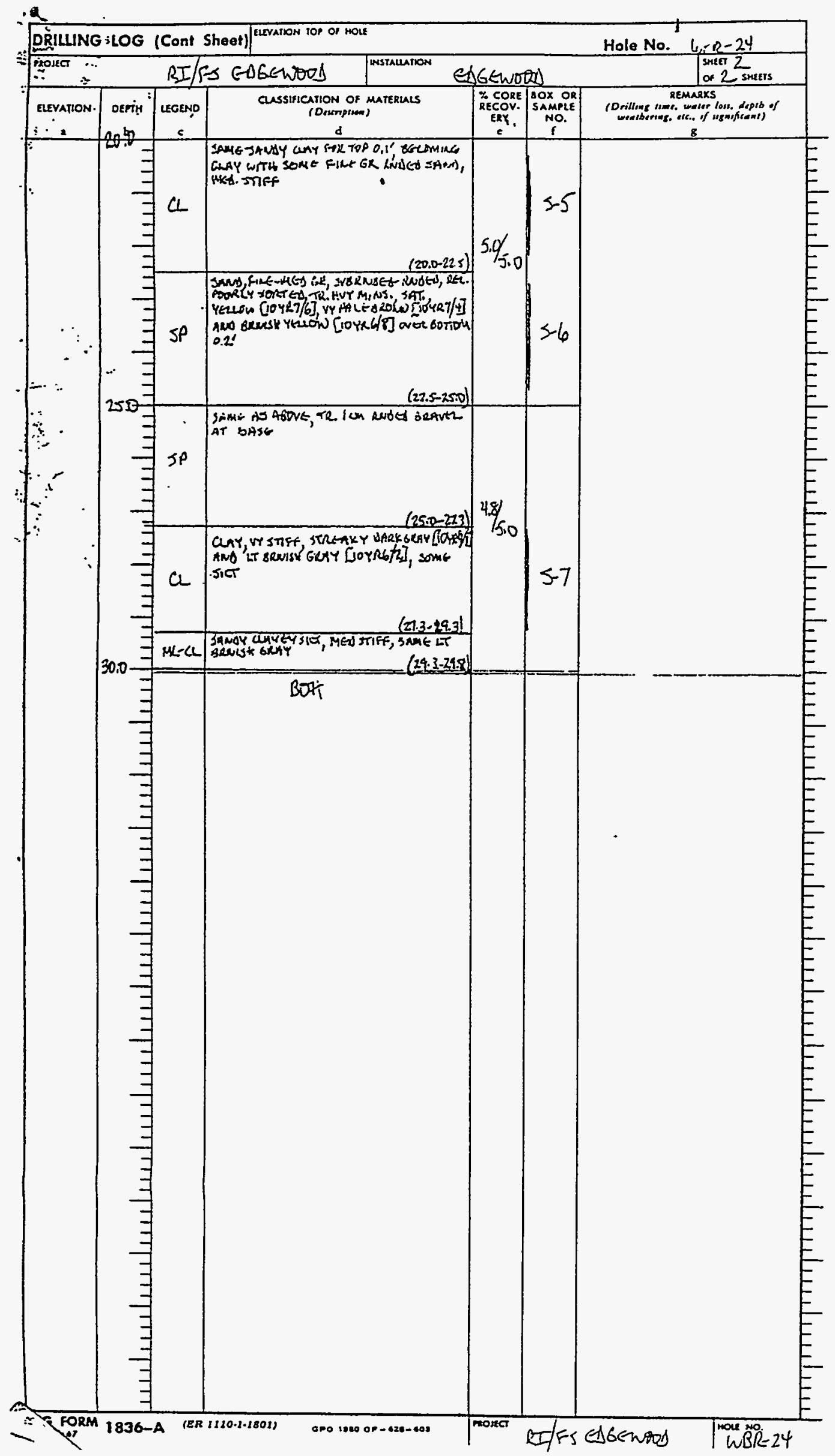




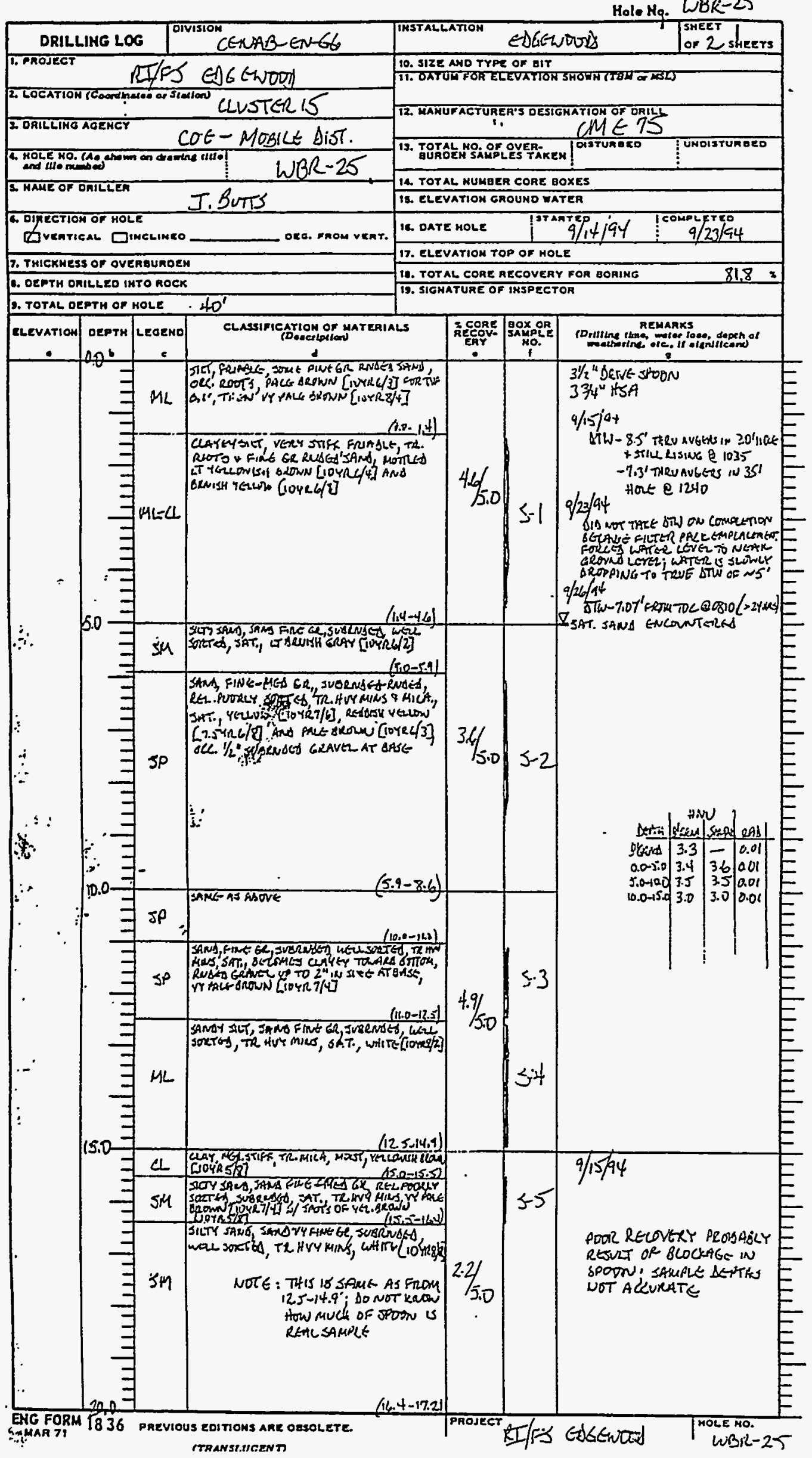




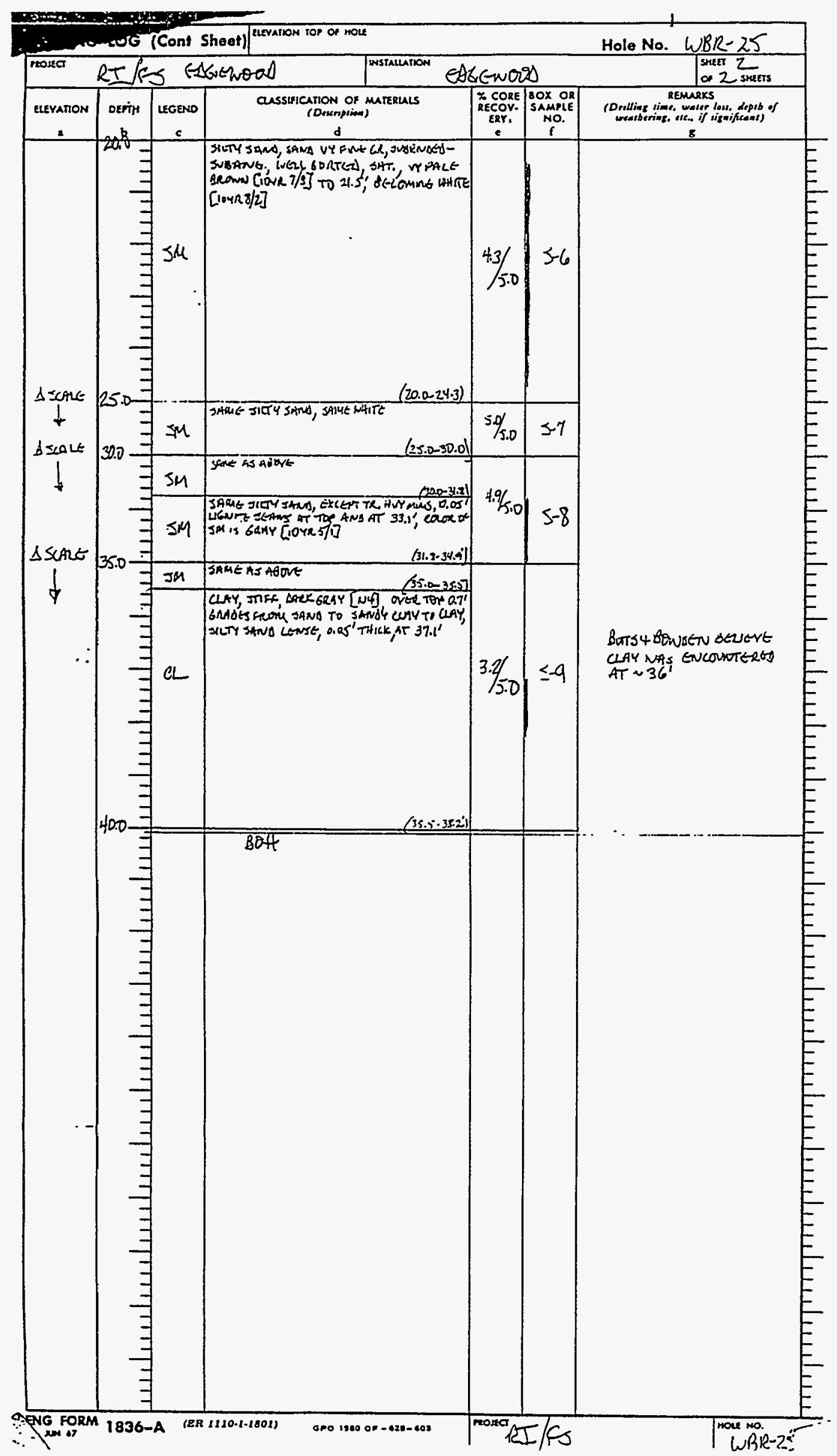




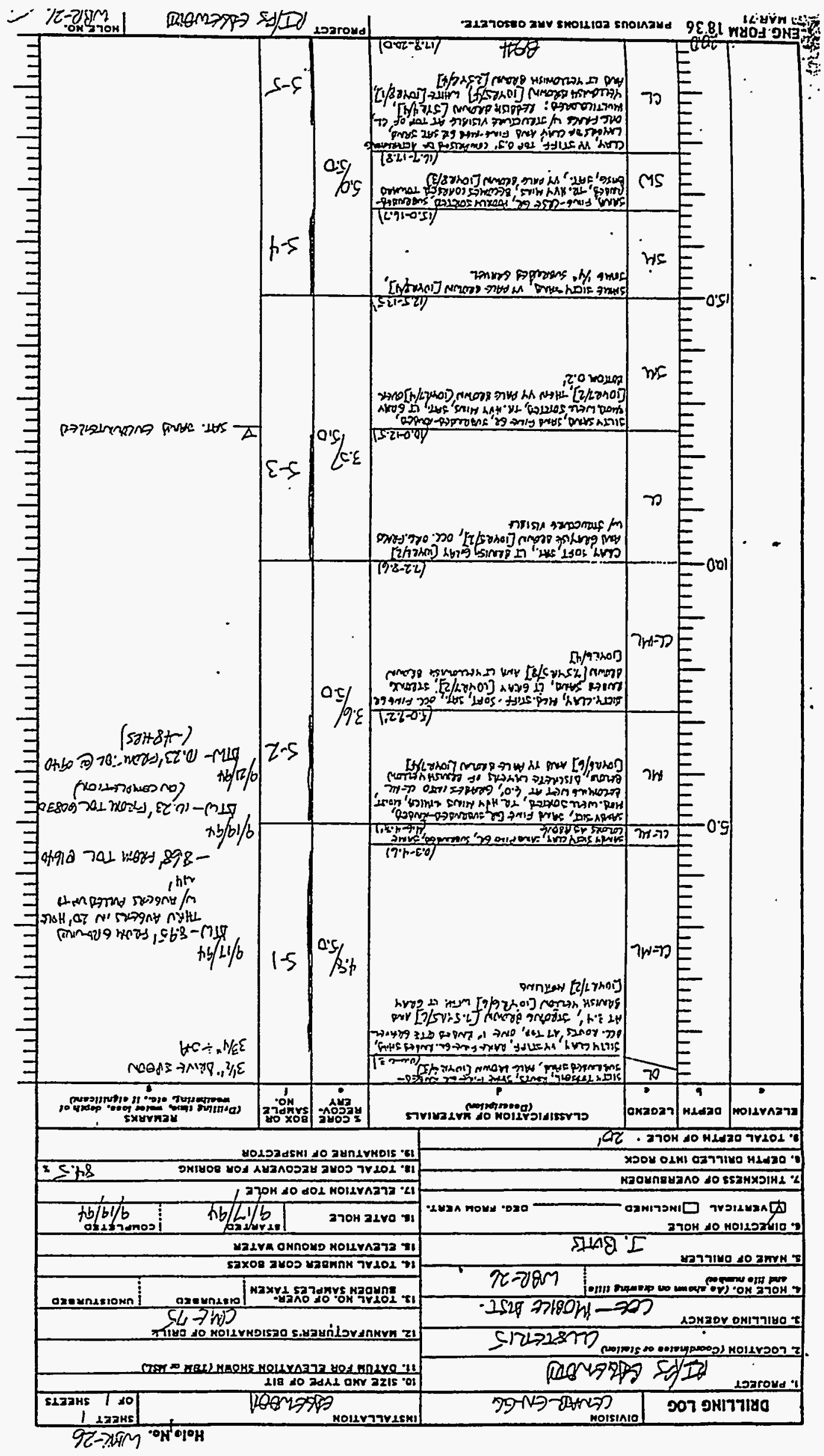




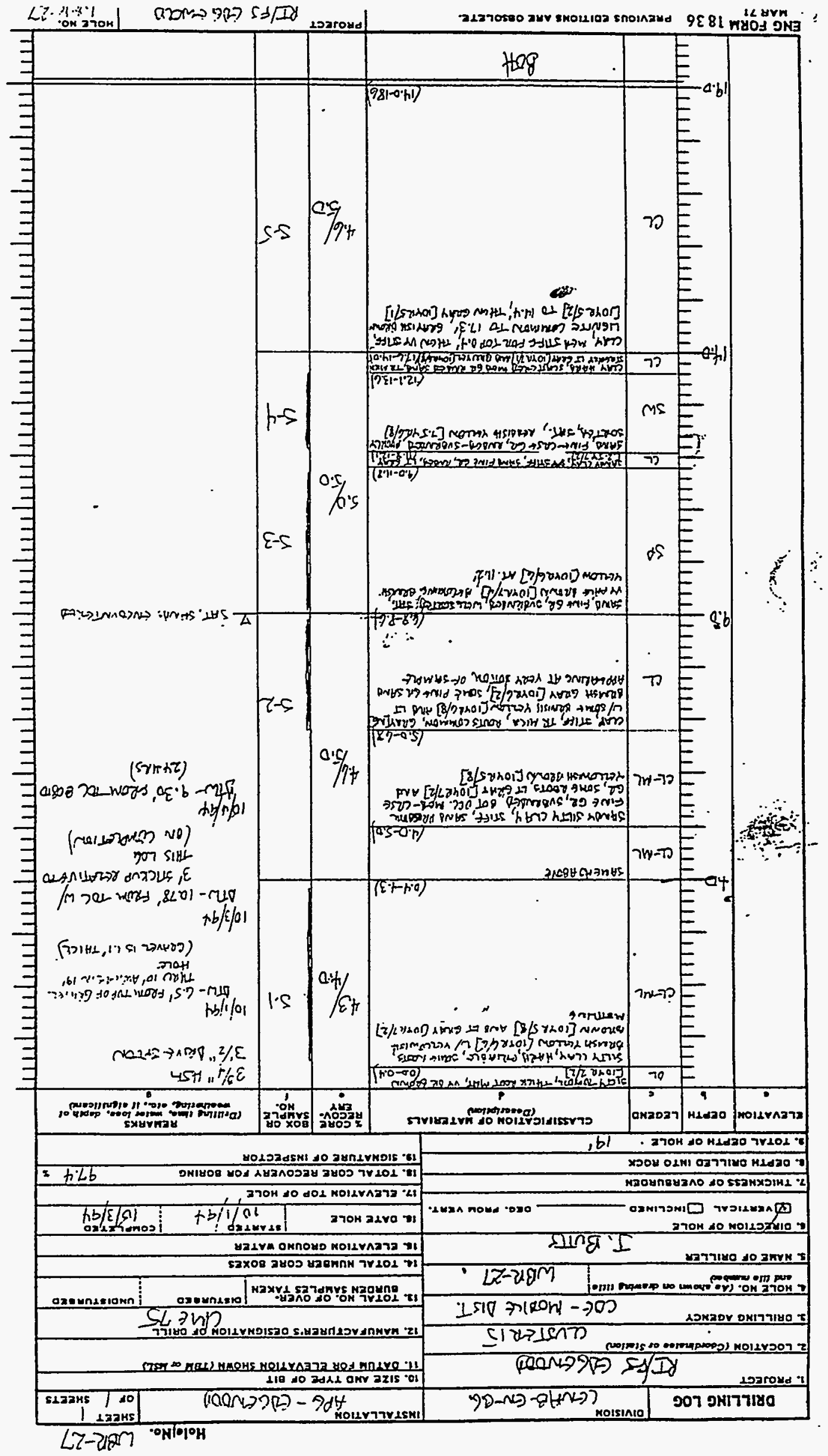




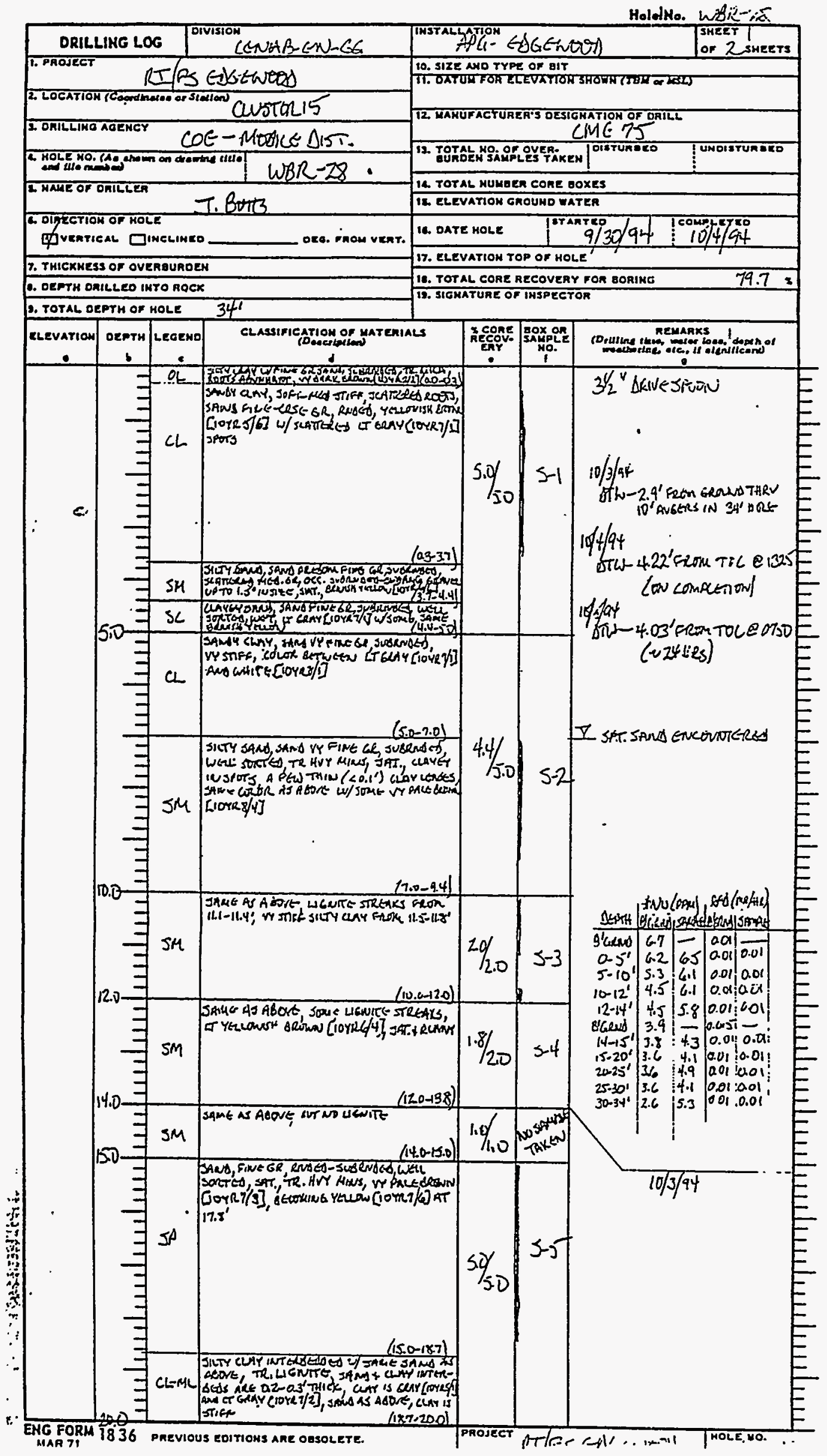




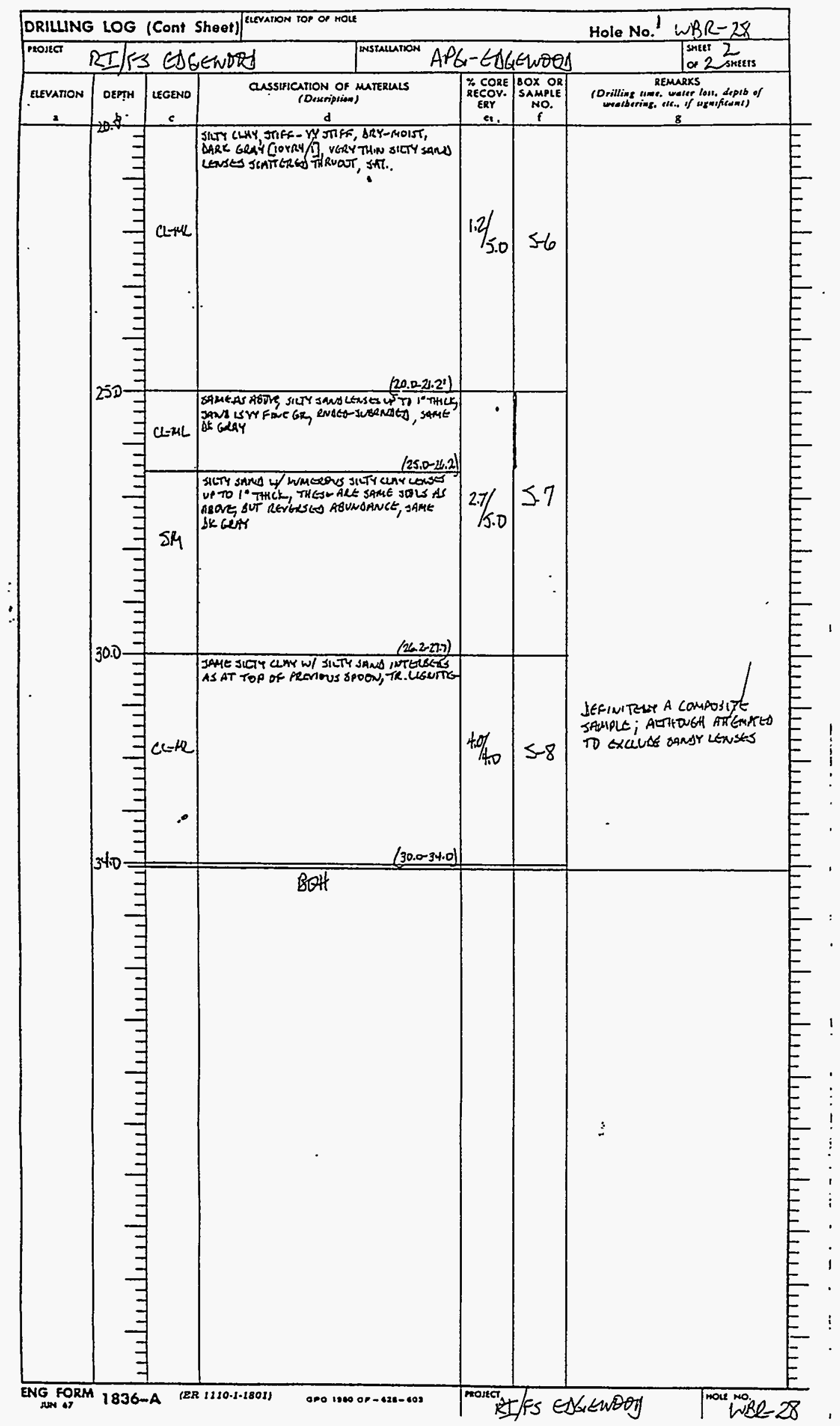




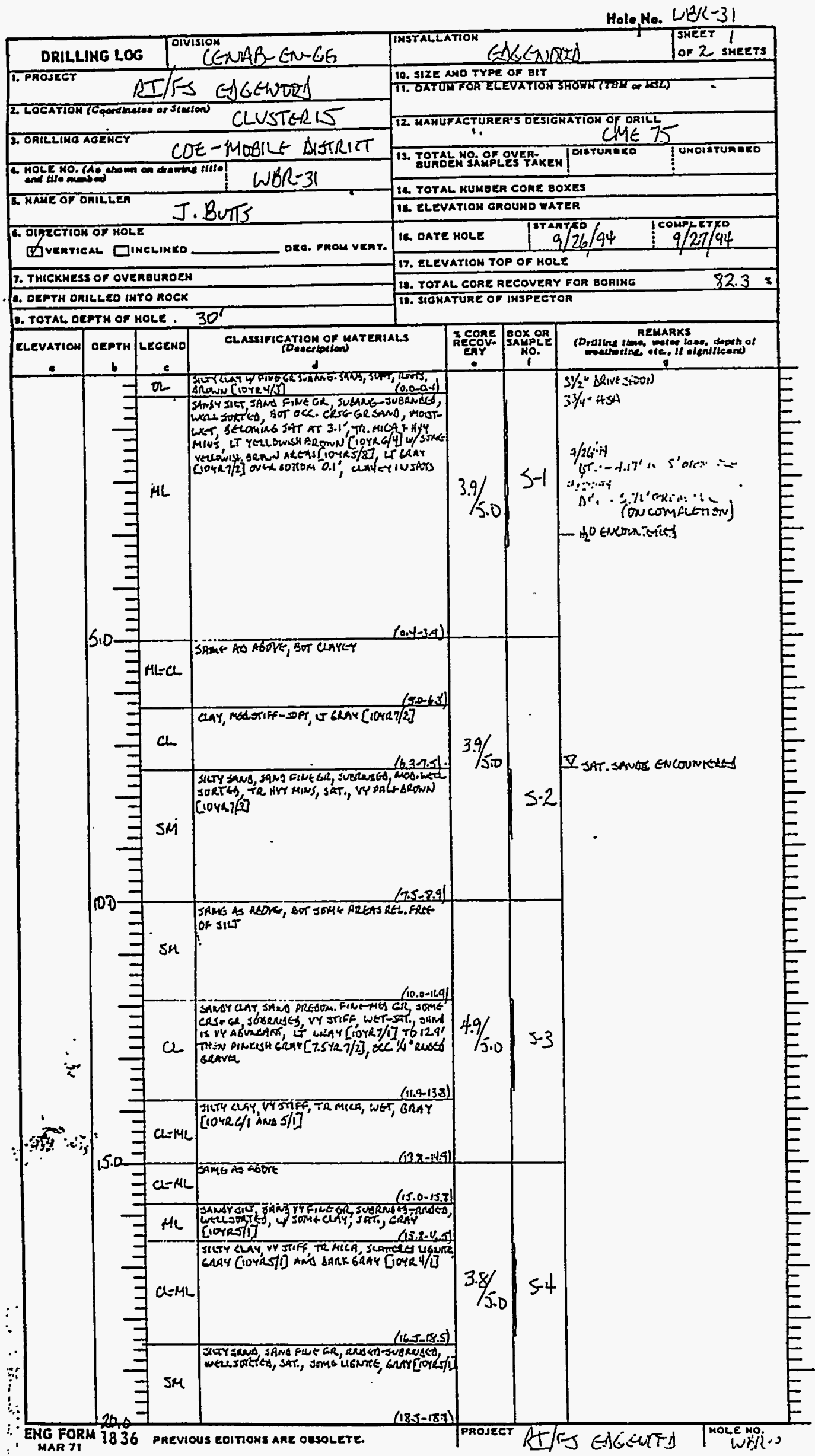




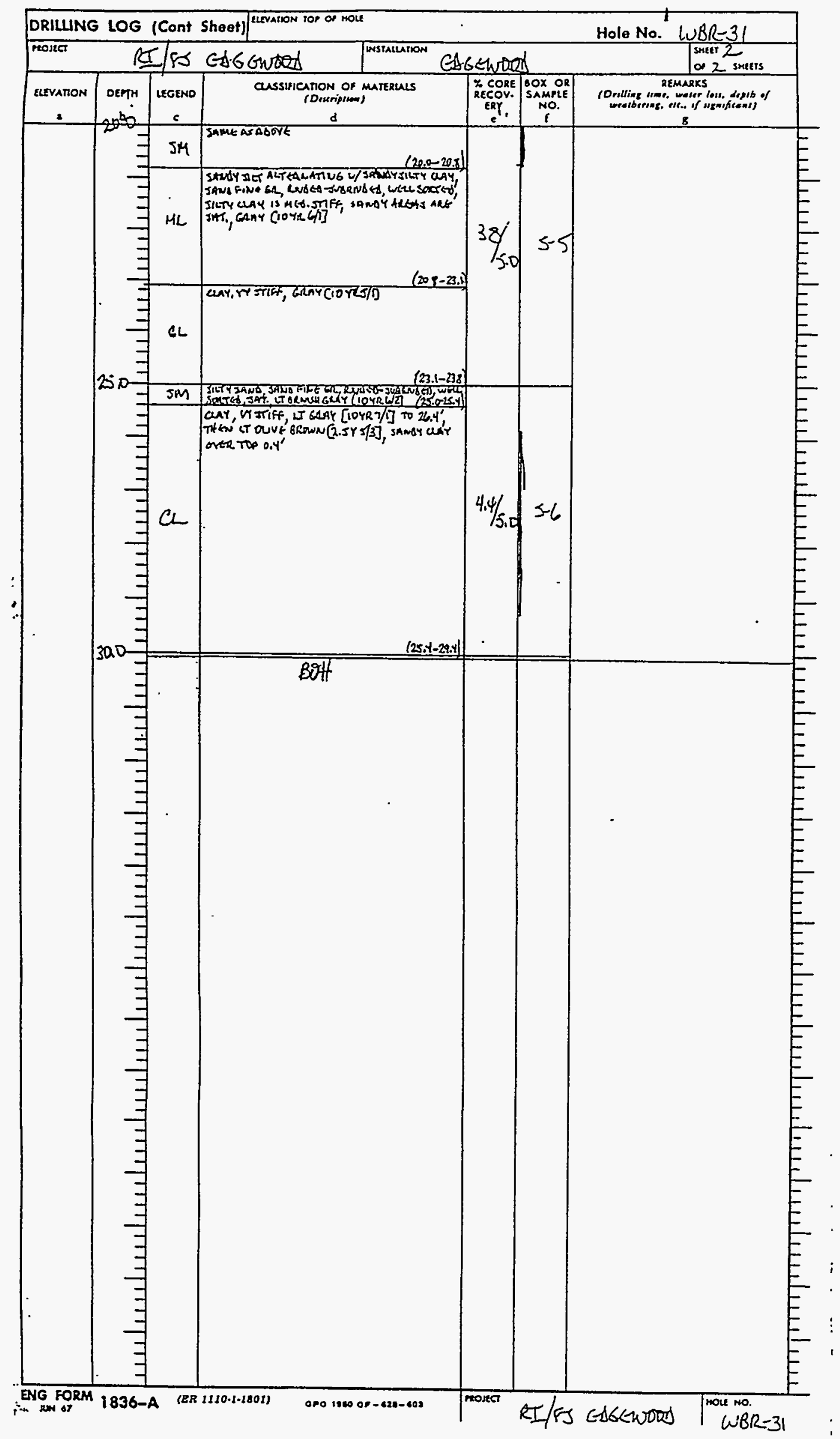


Holo No. WSKL-45

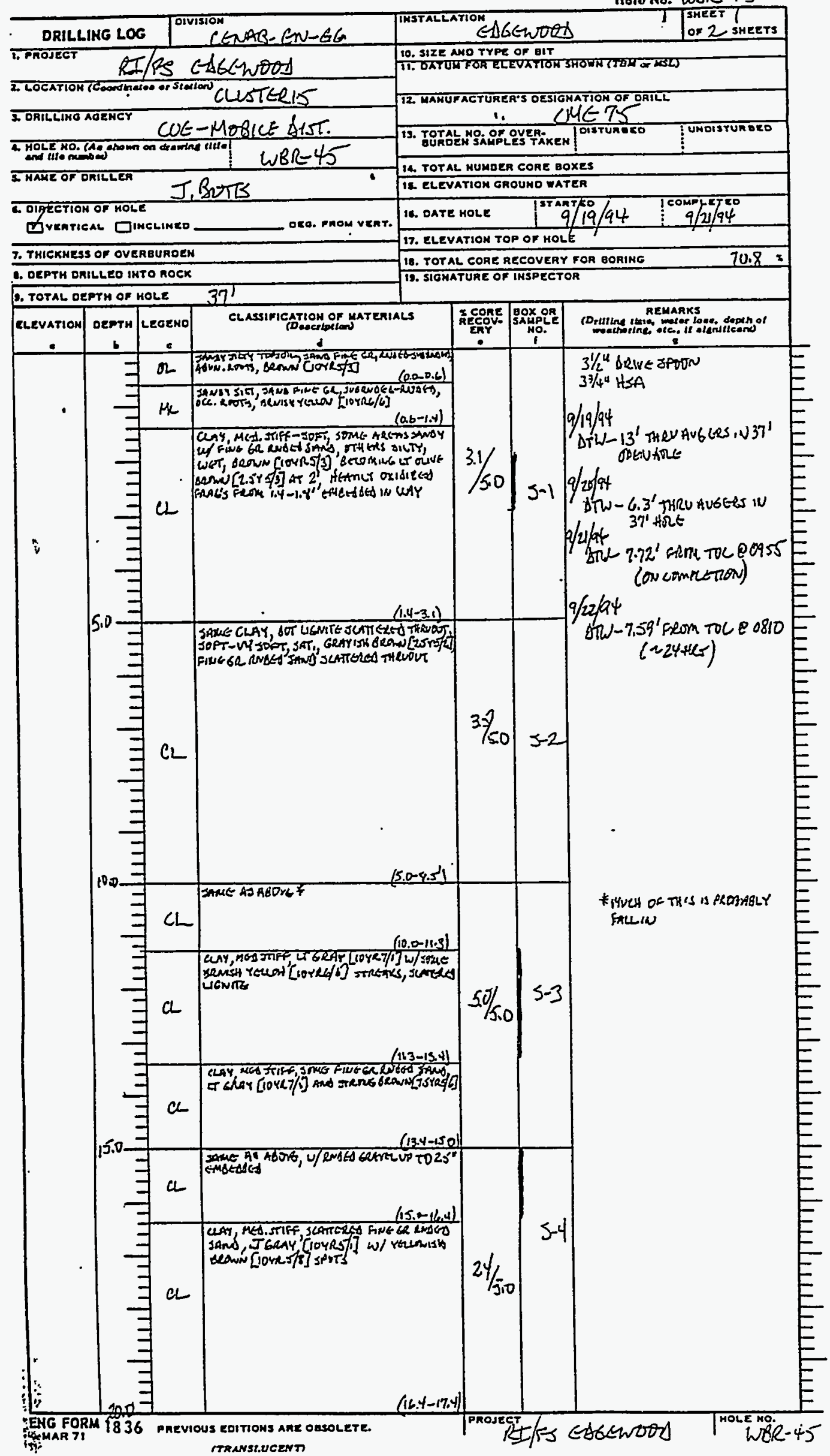




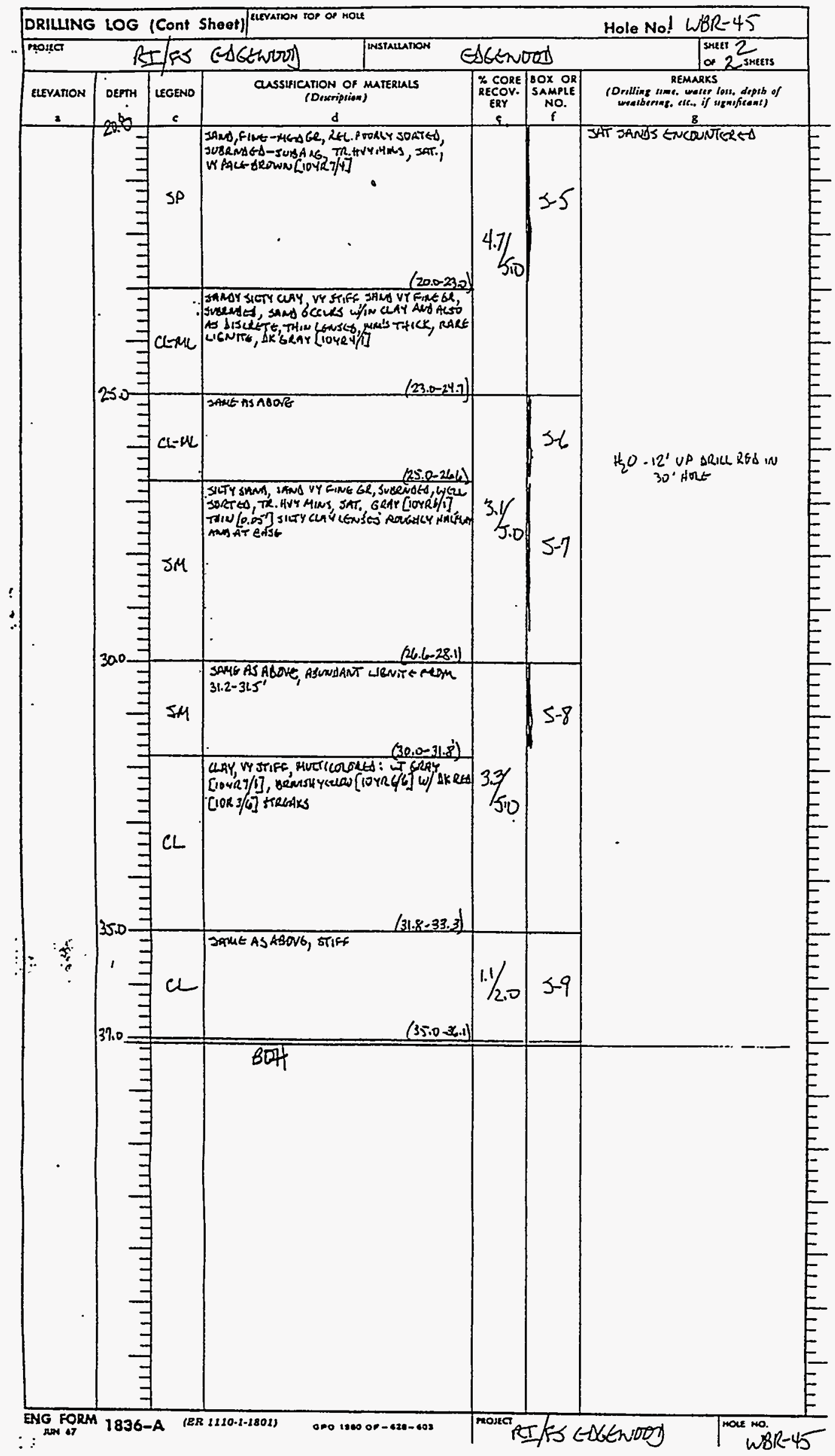




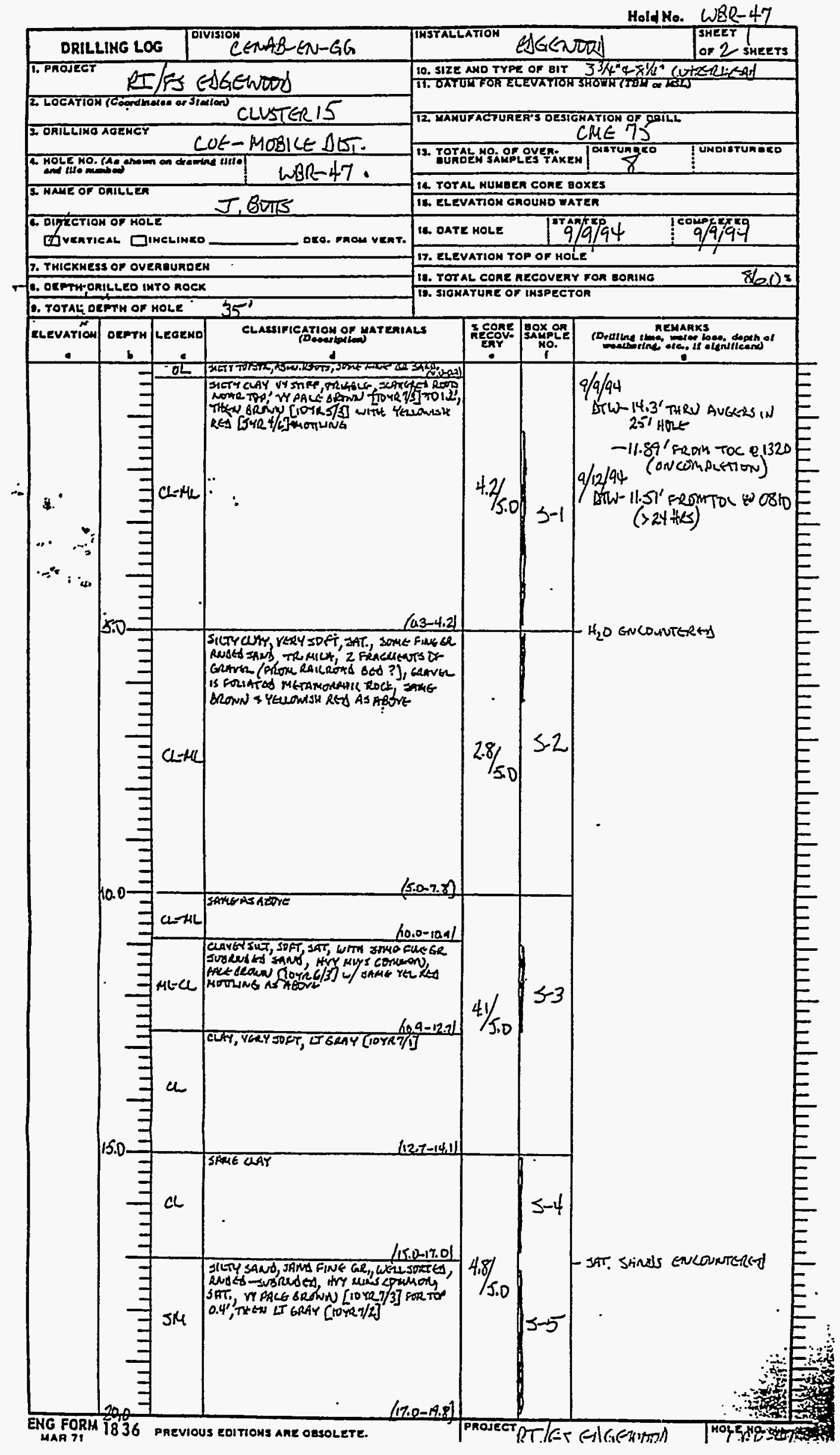




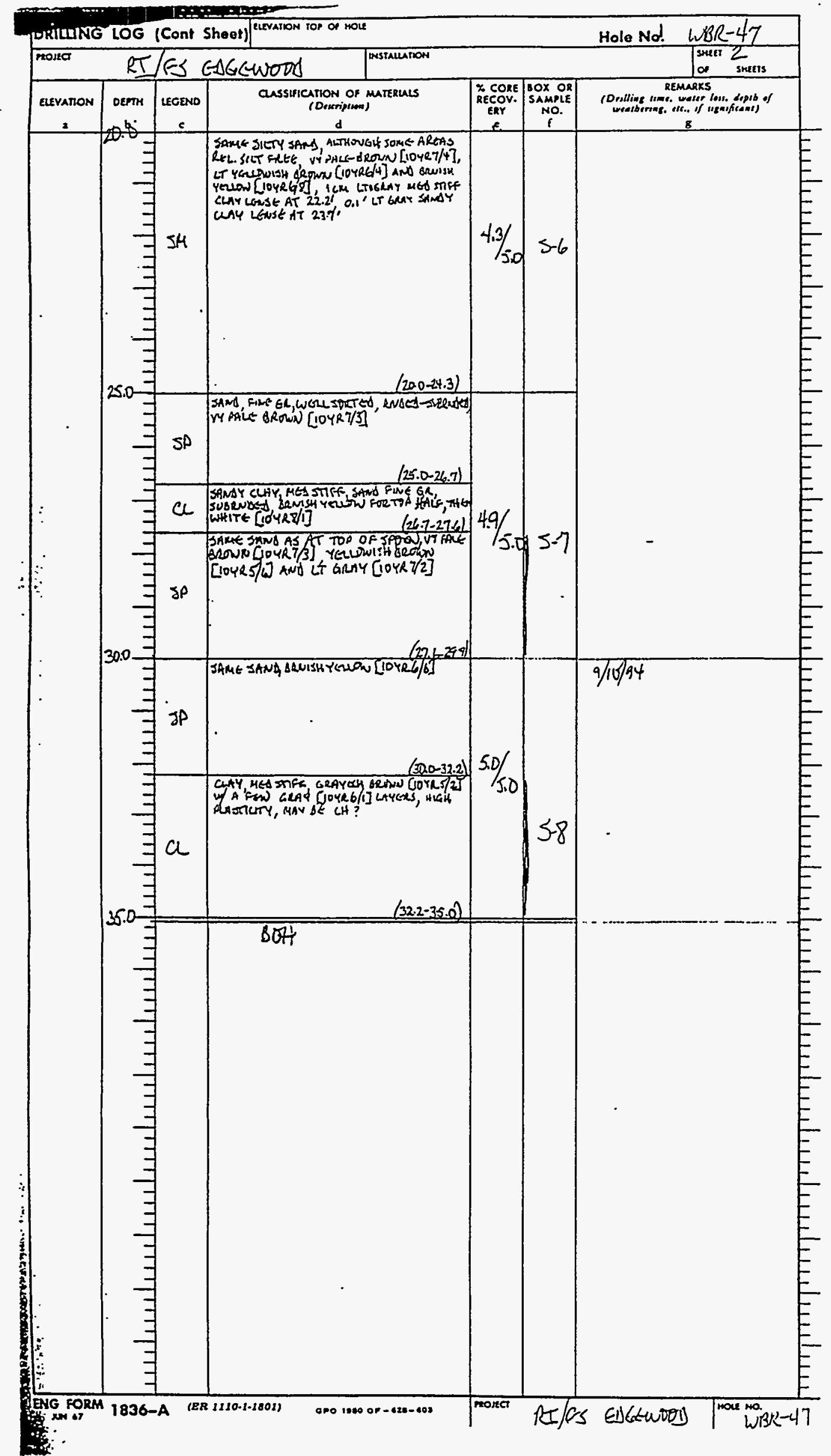




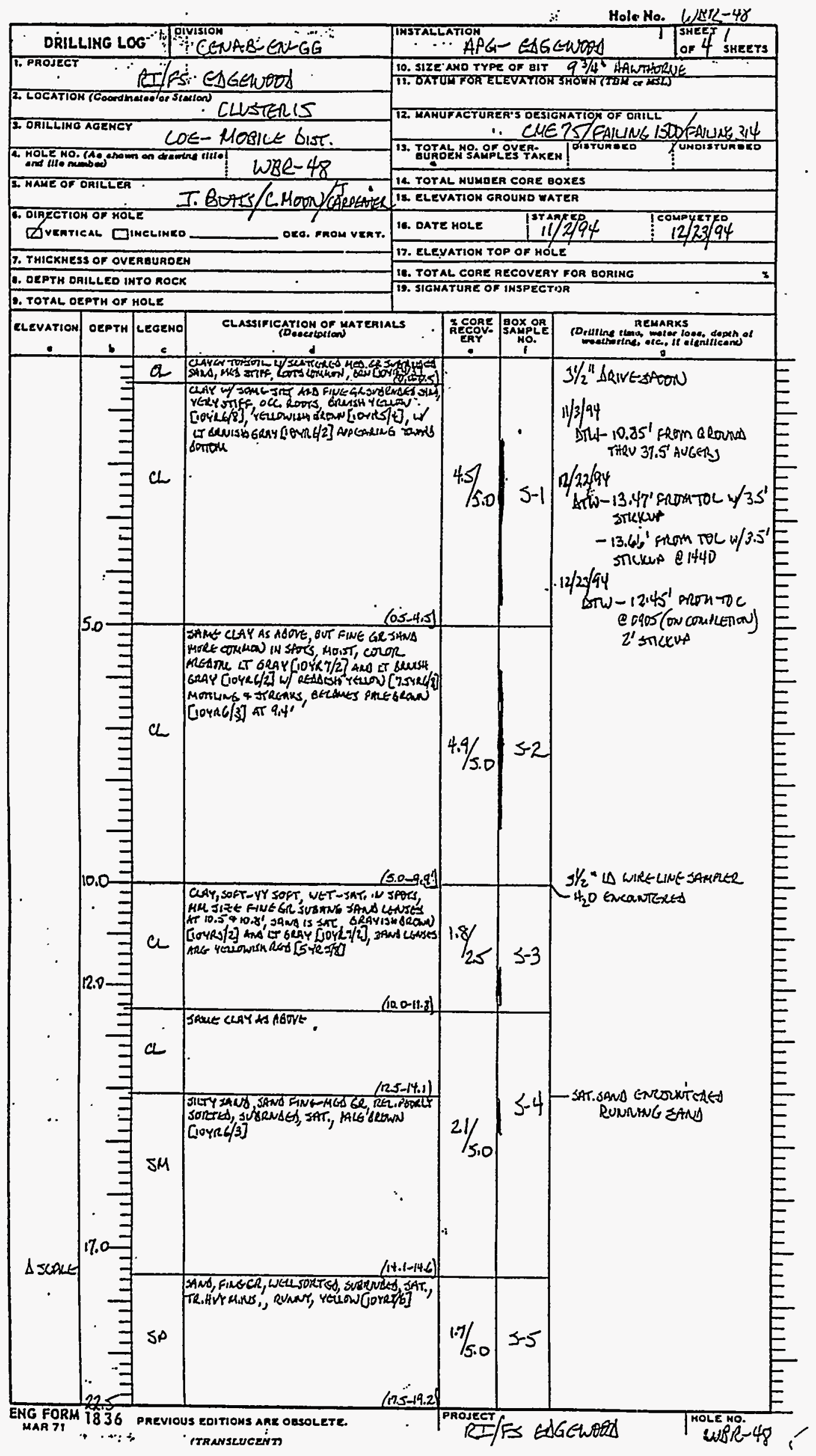




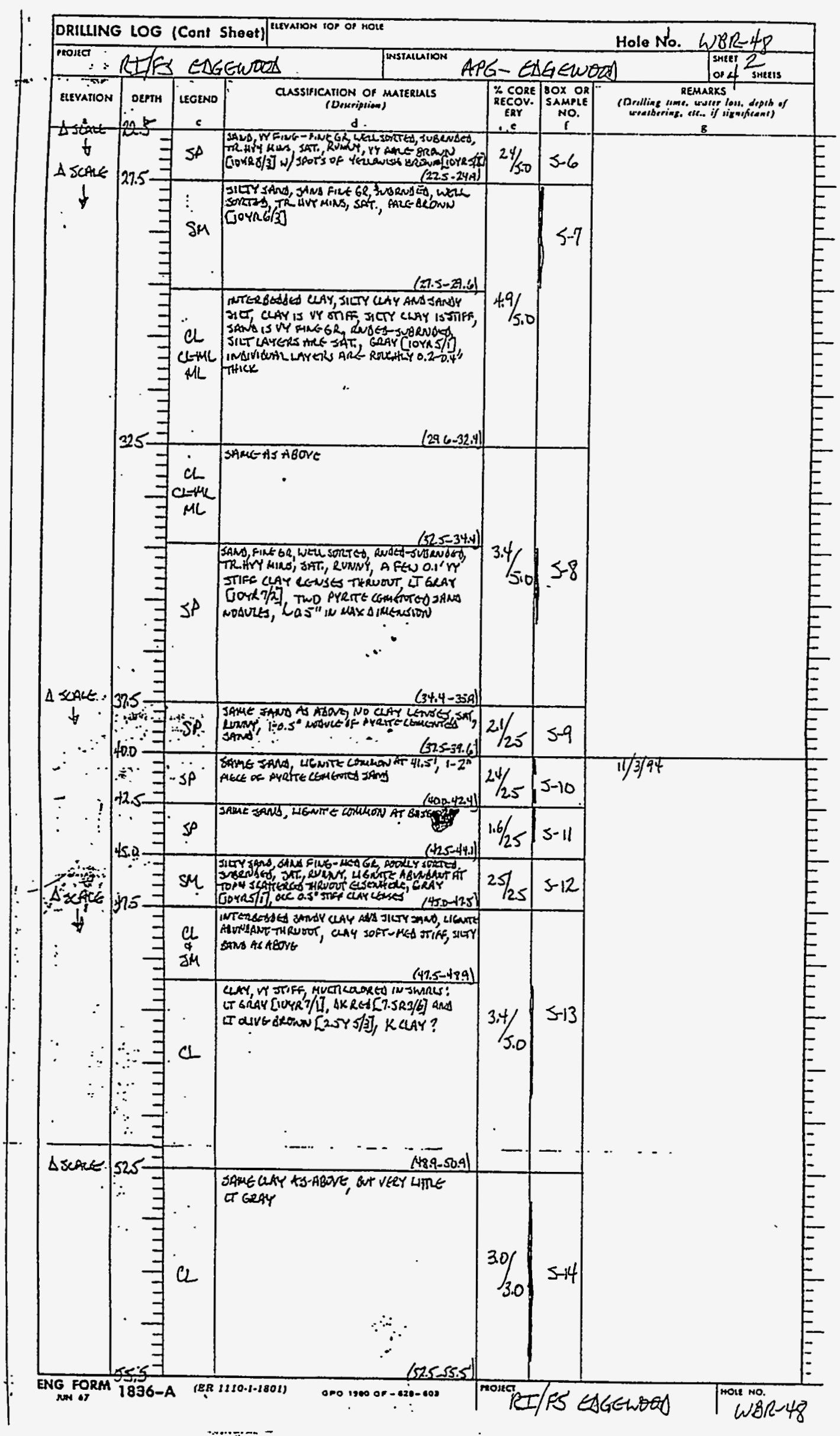




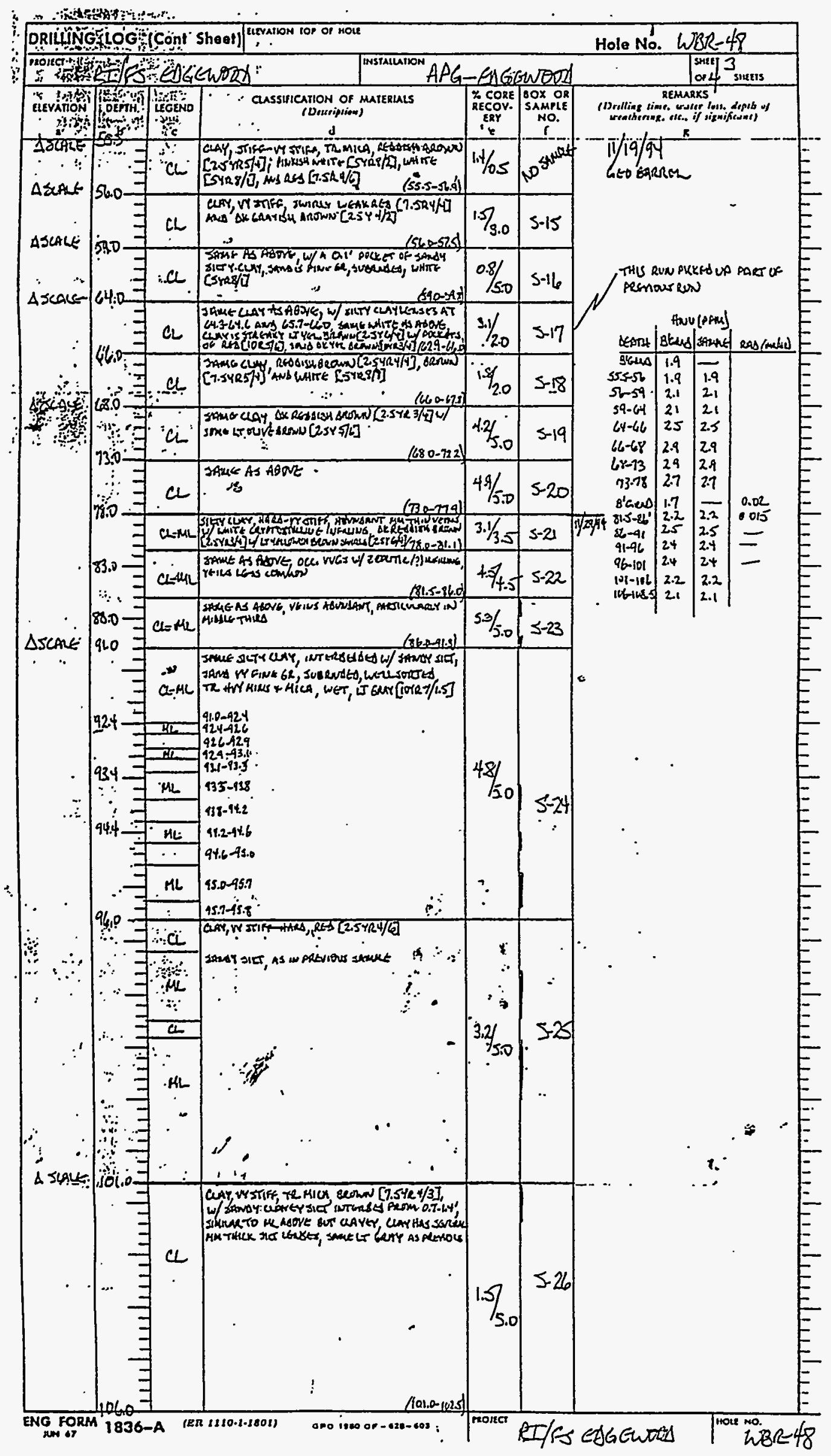




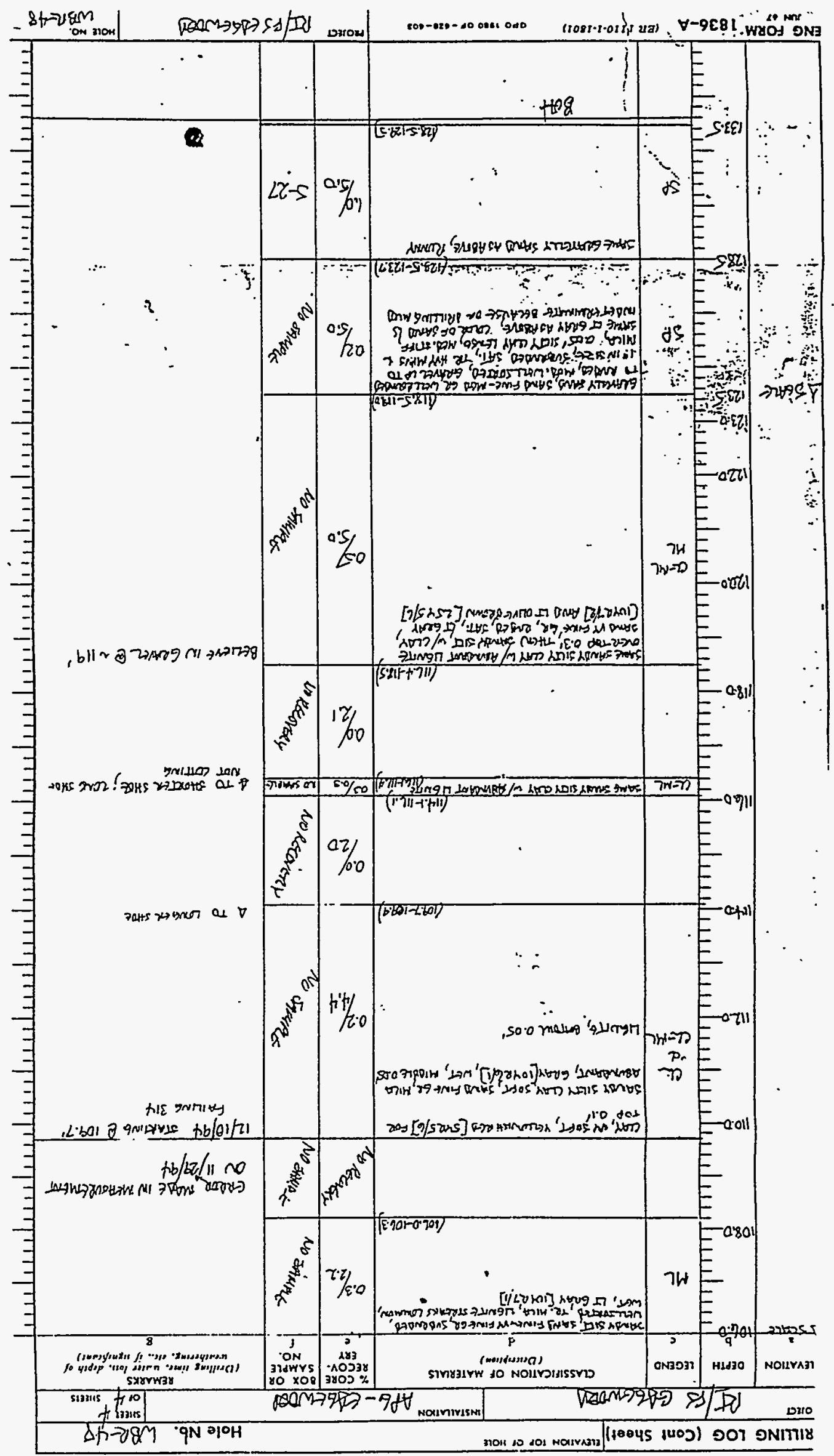




\section{Appendix B:}

Gamma and Induction Logs 


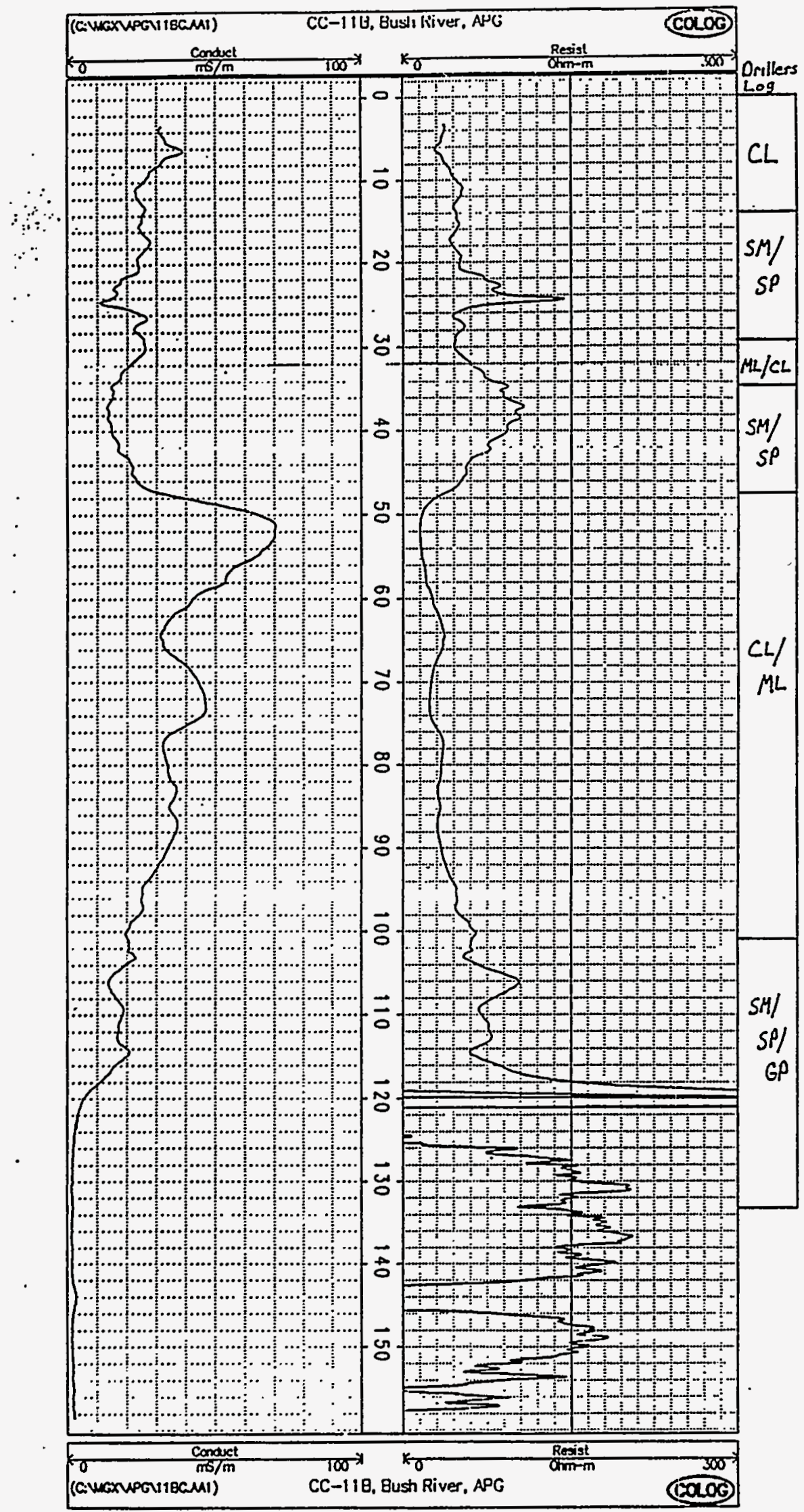




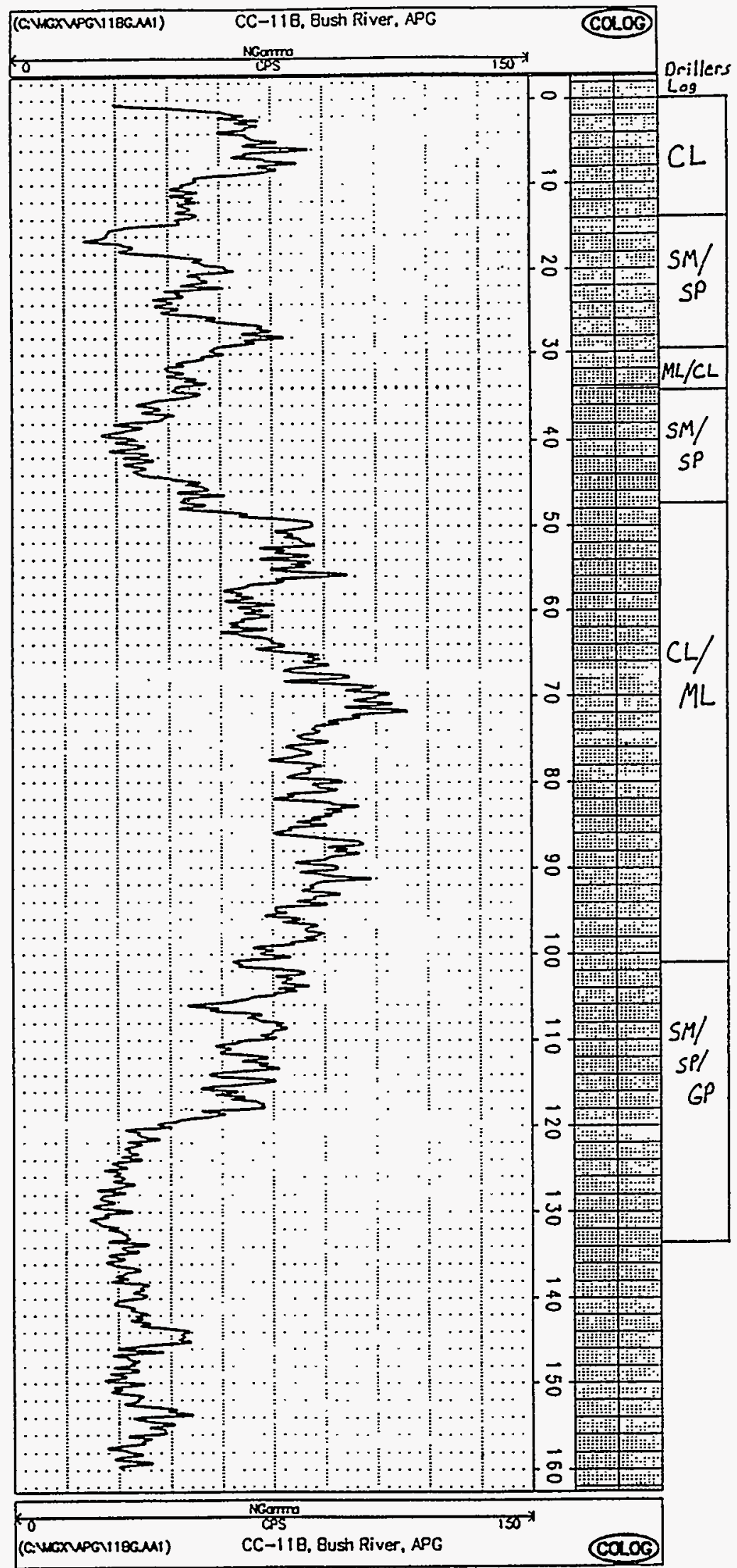




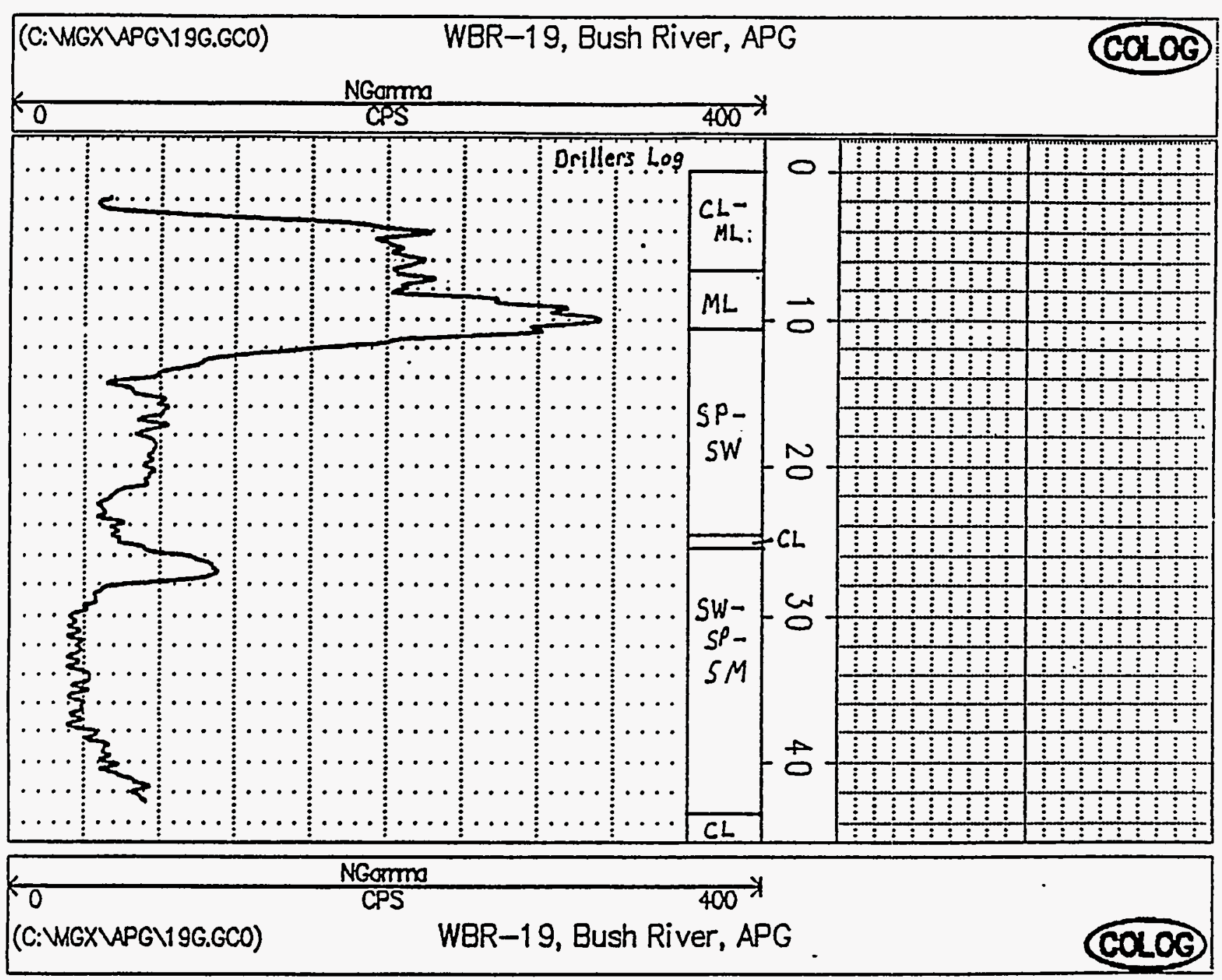




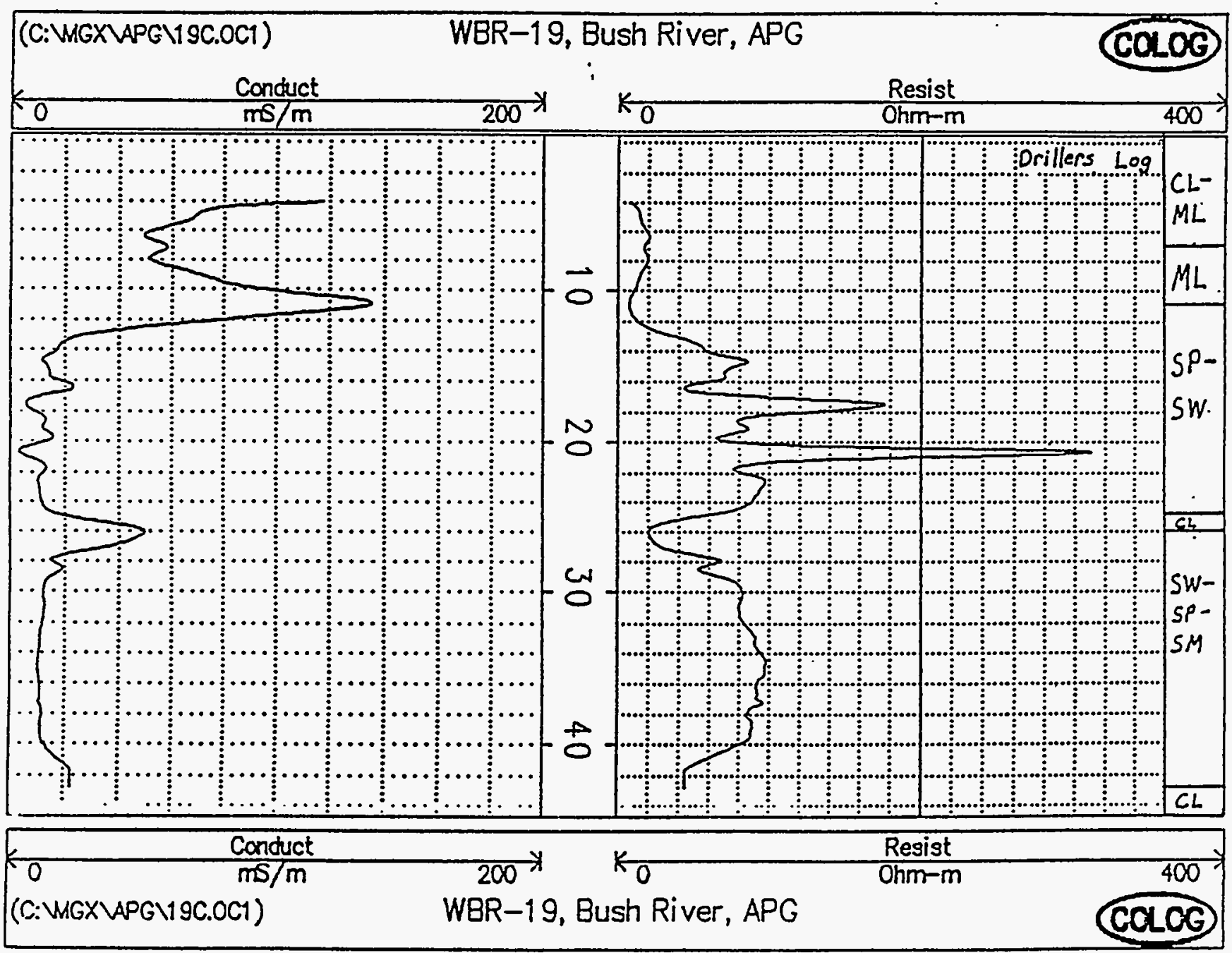




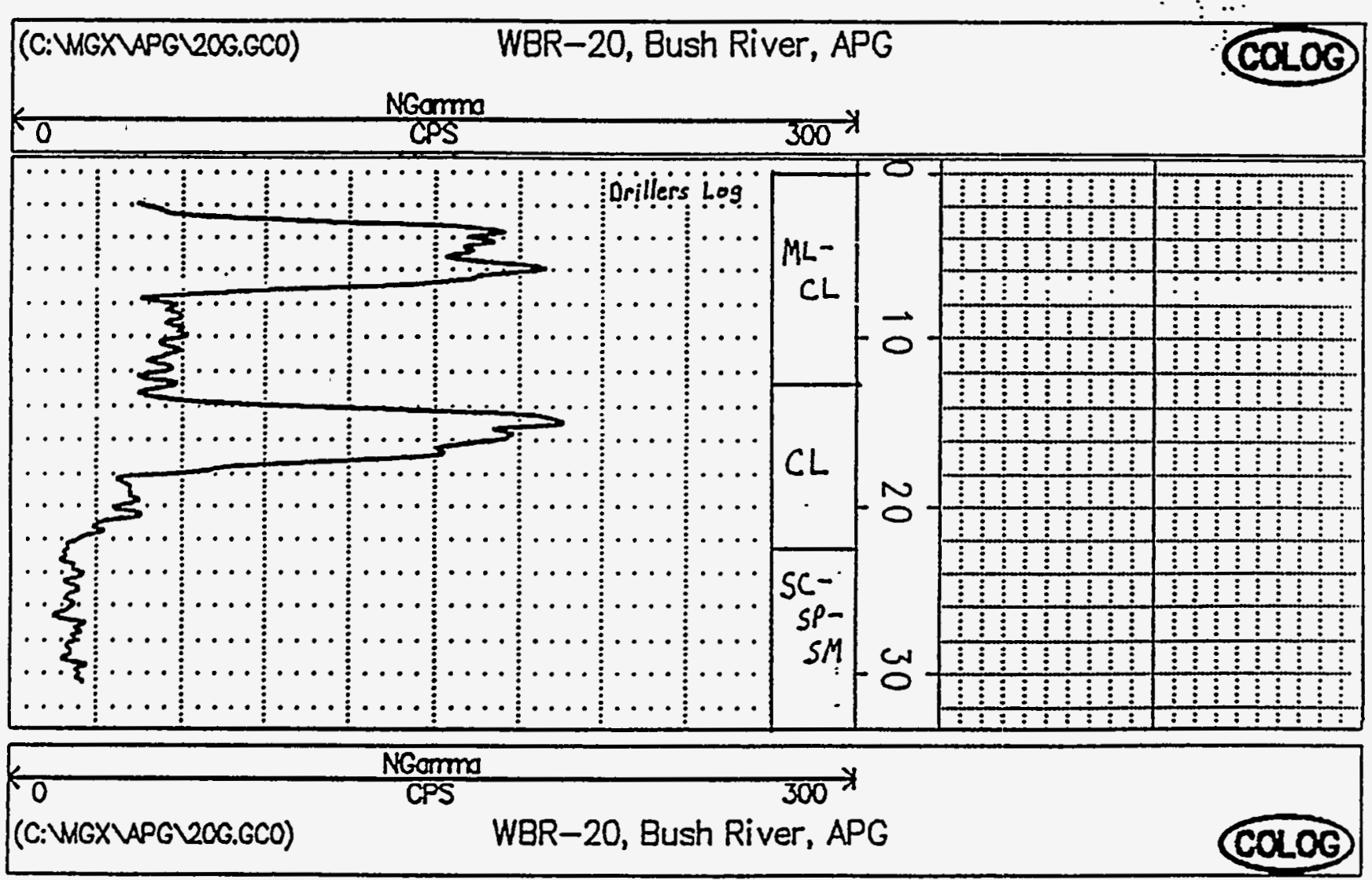




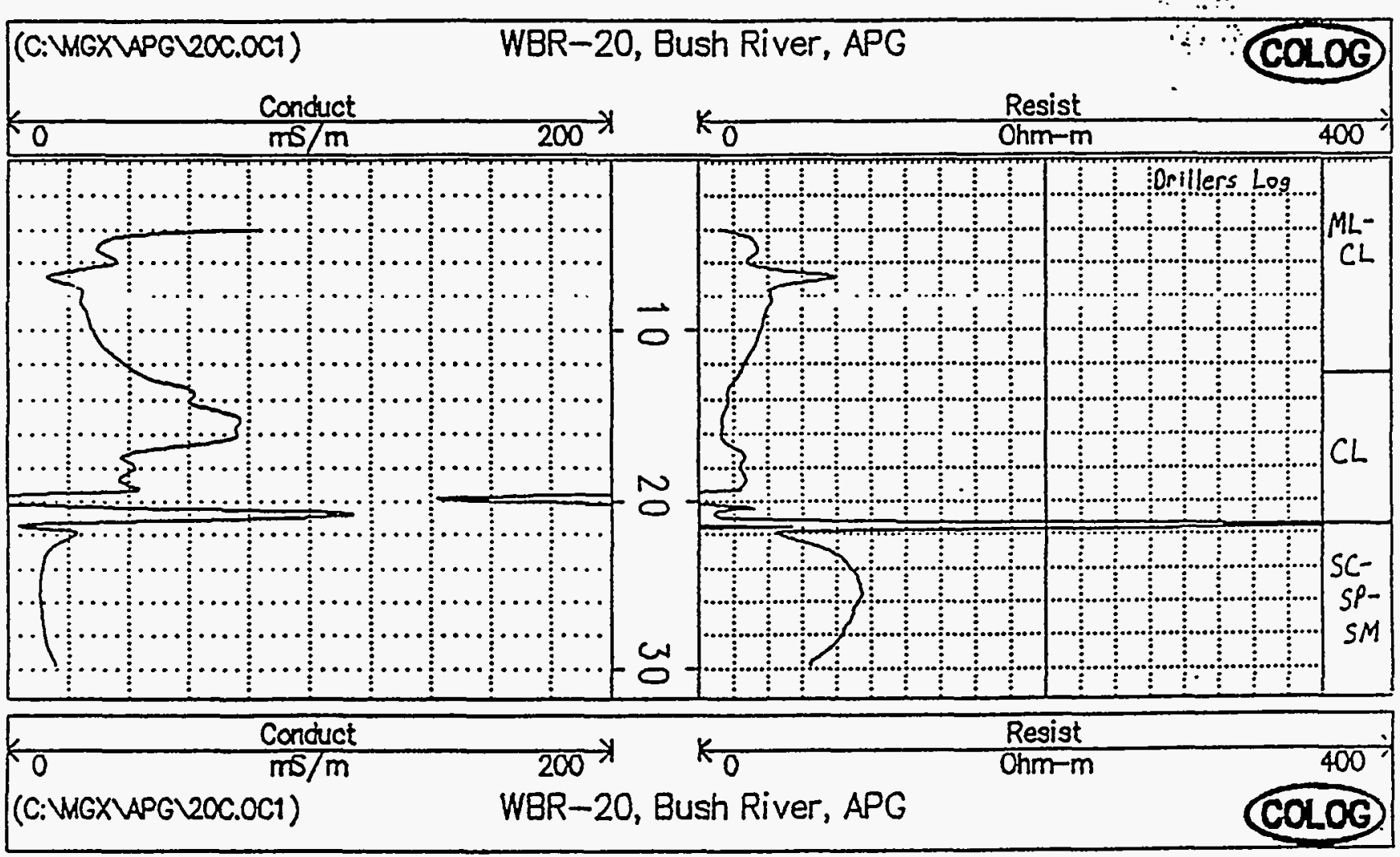




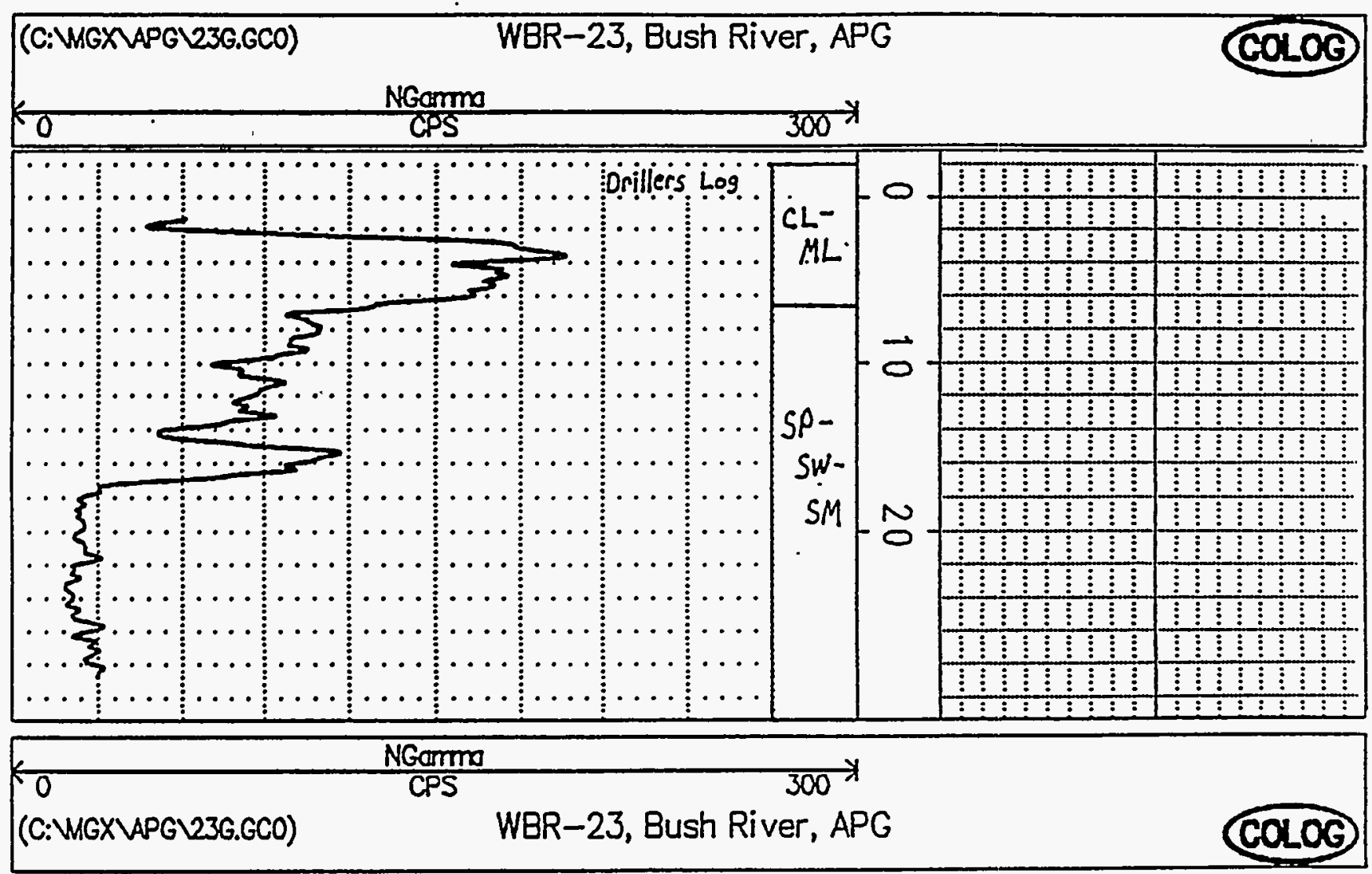




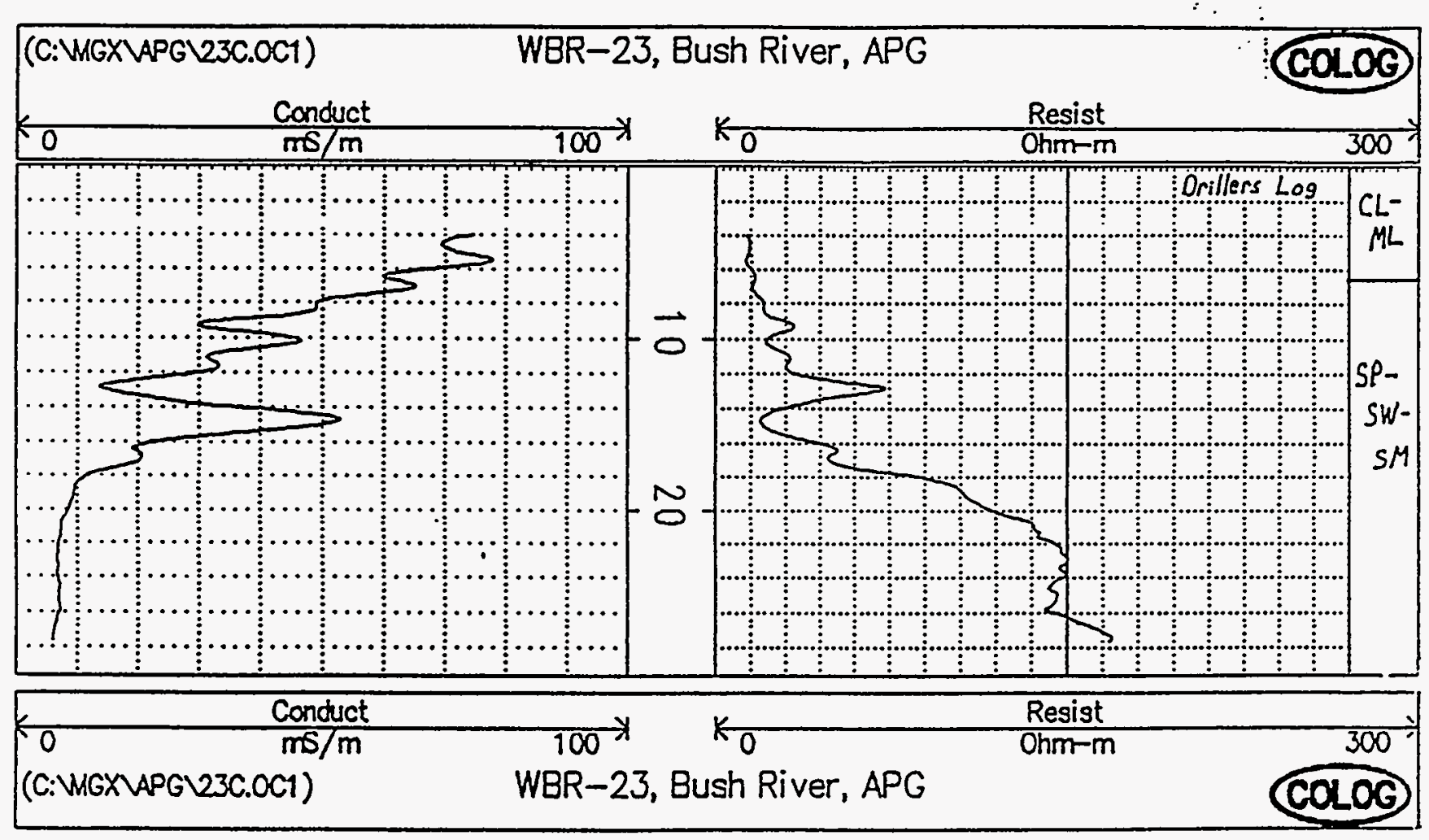




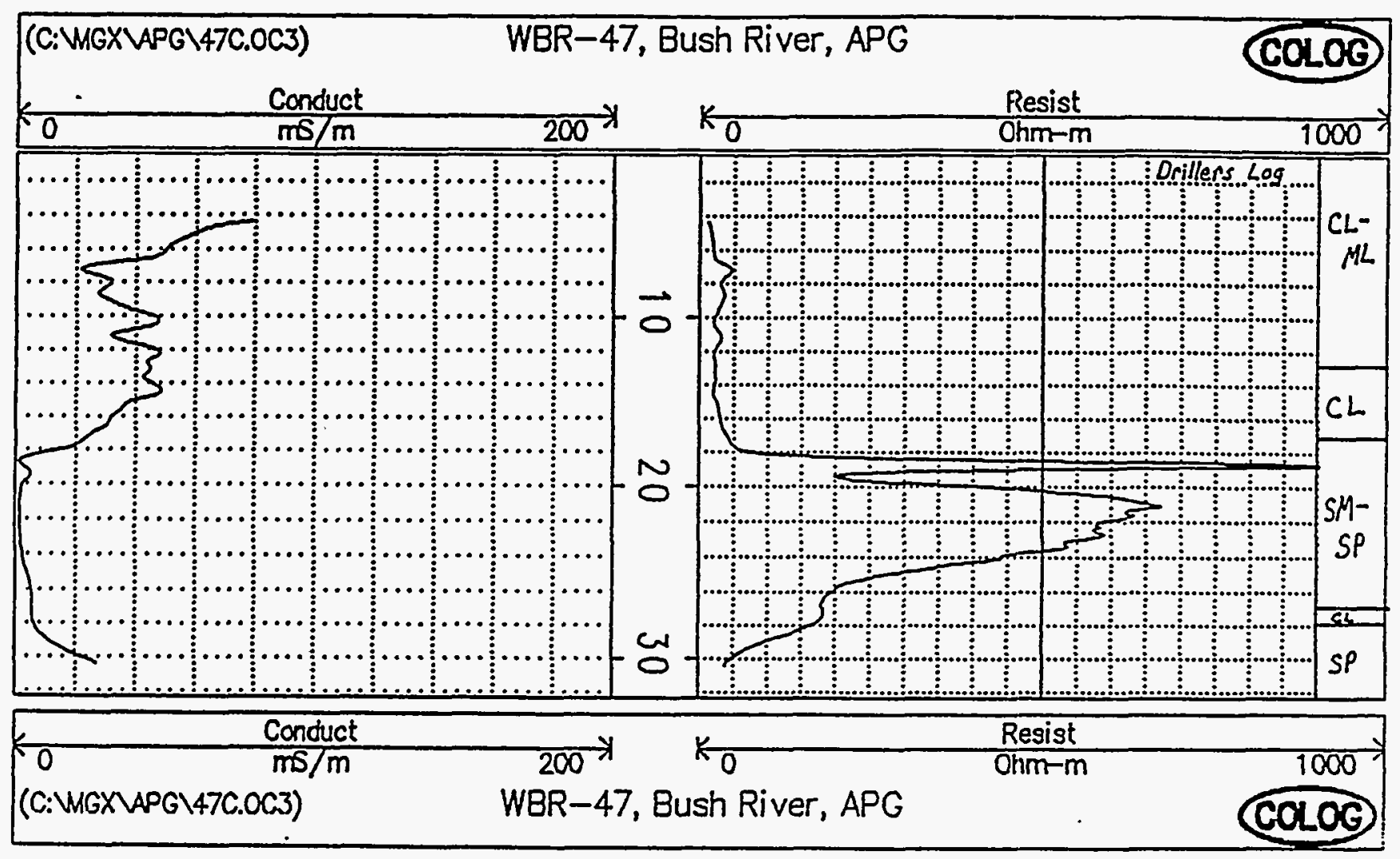




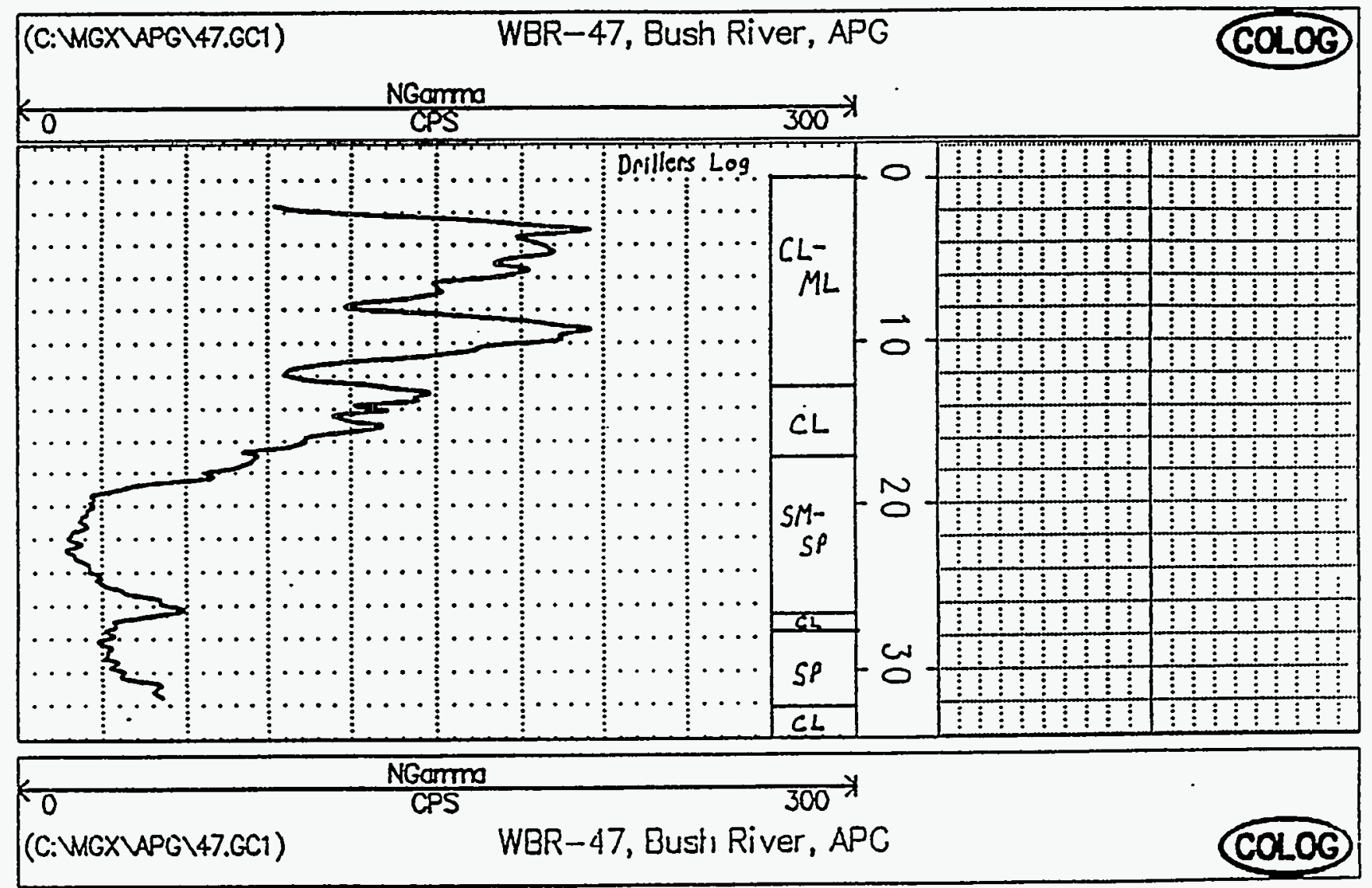




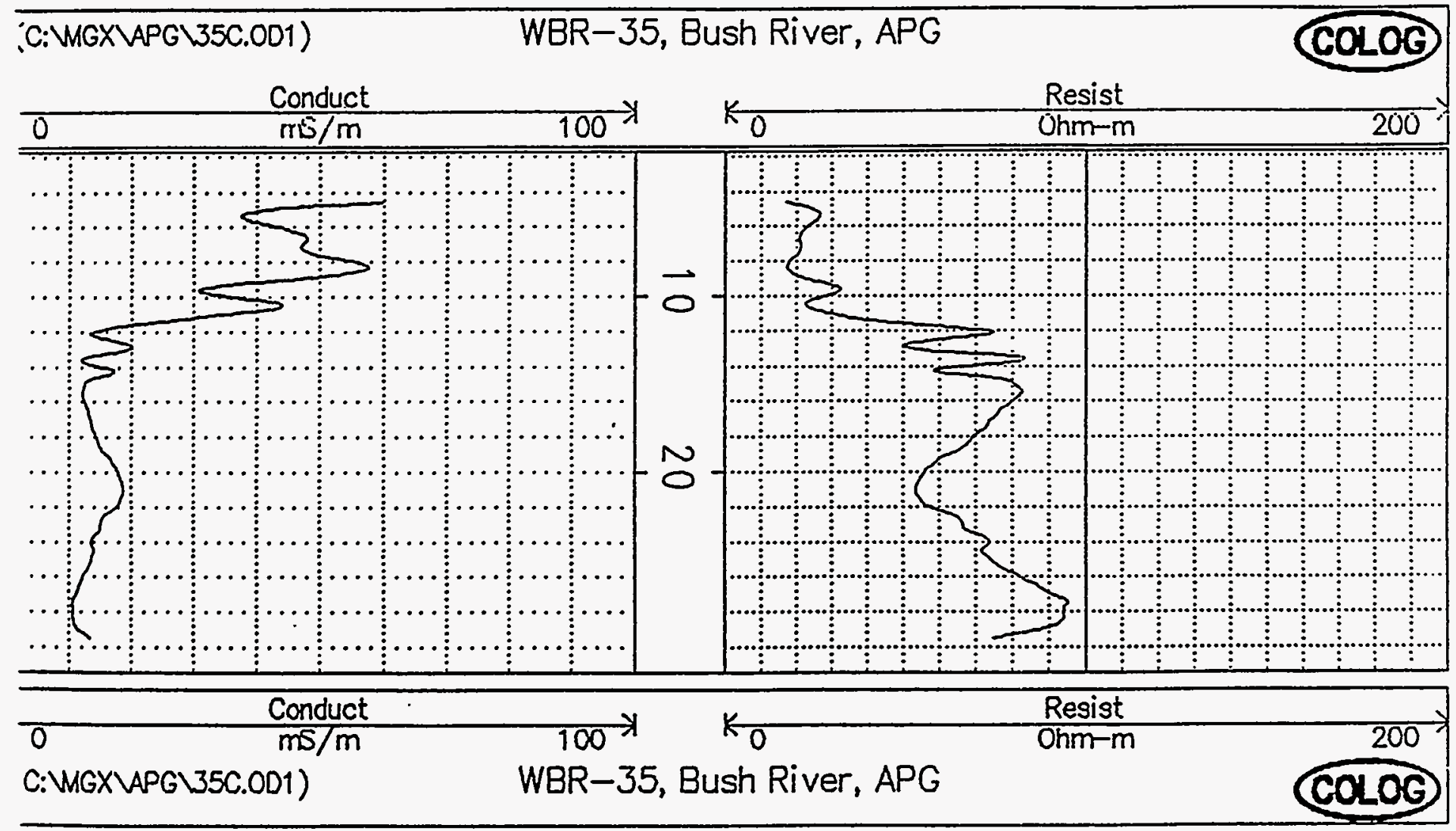




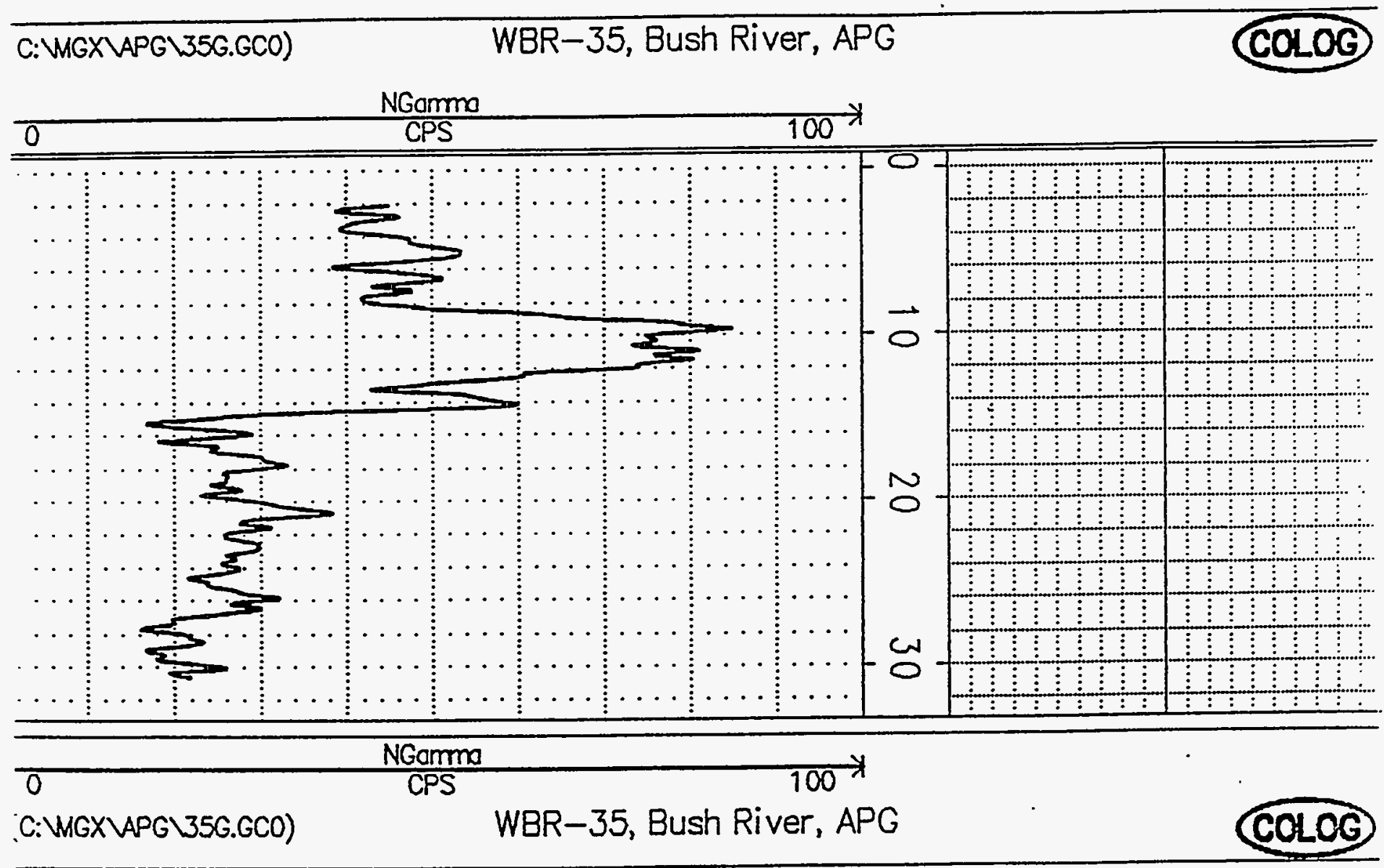




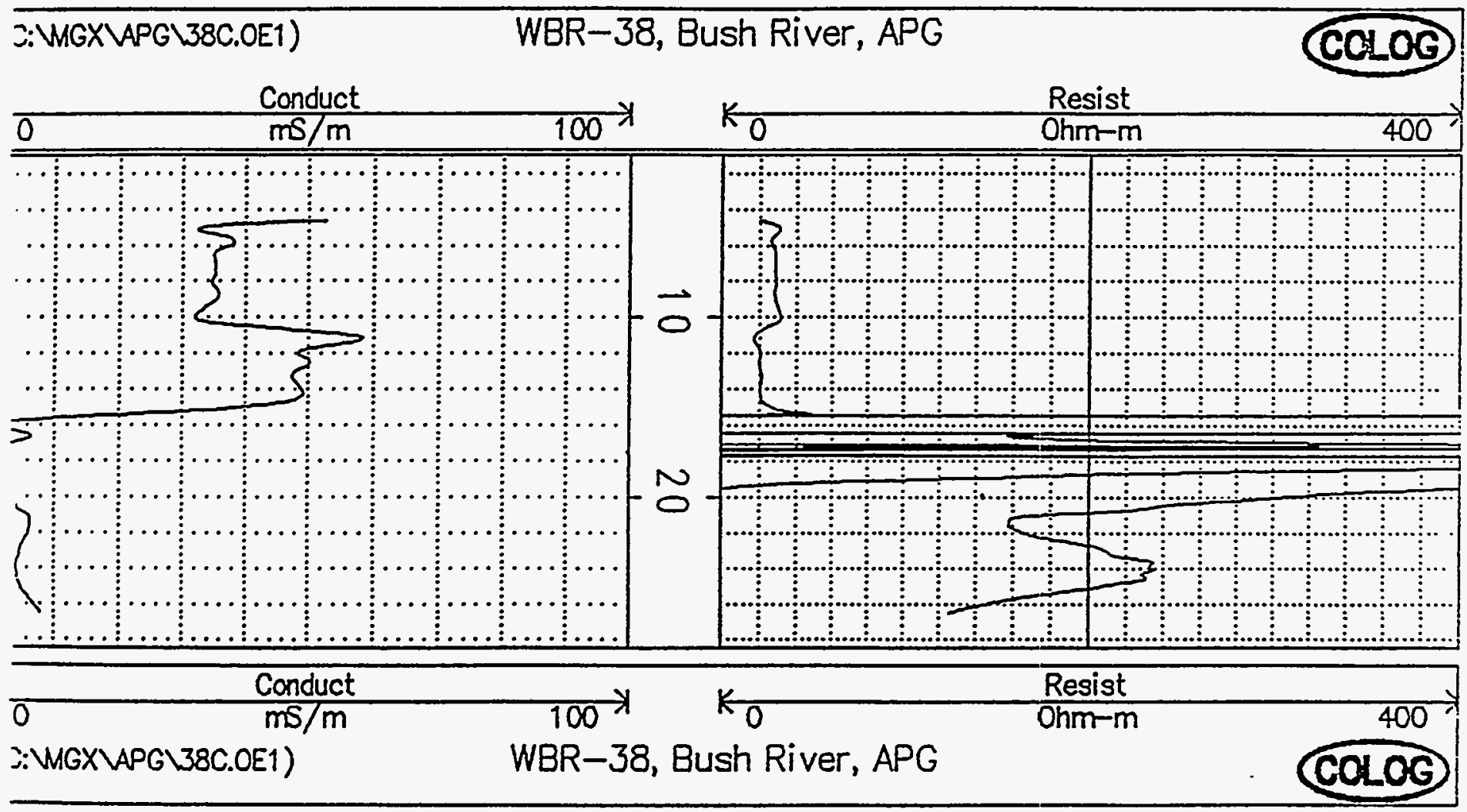




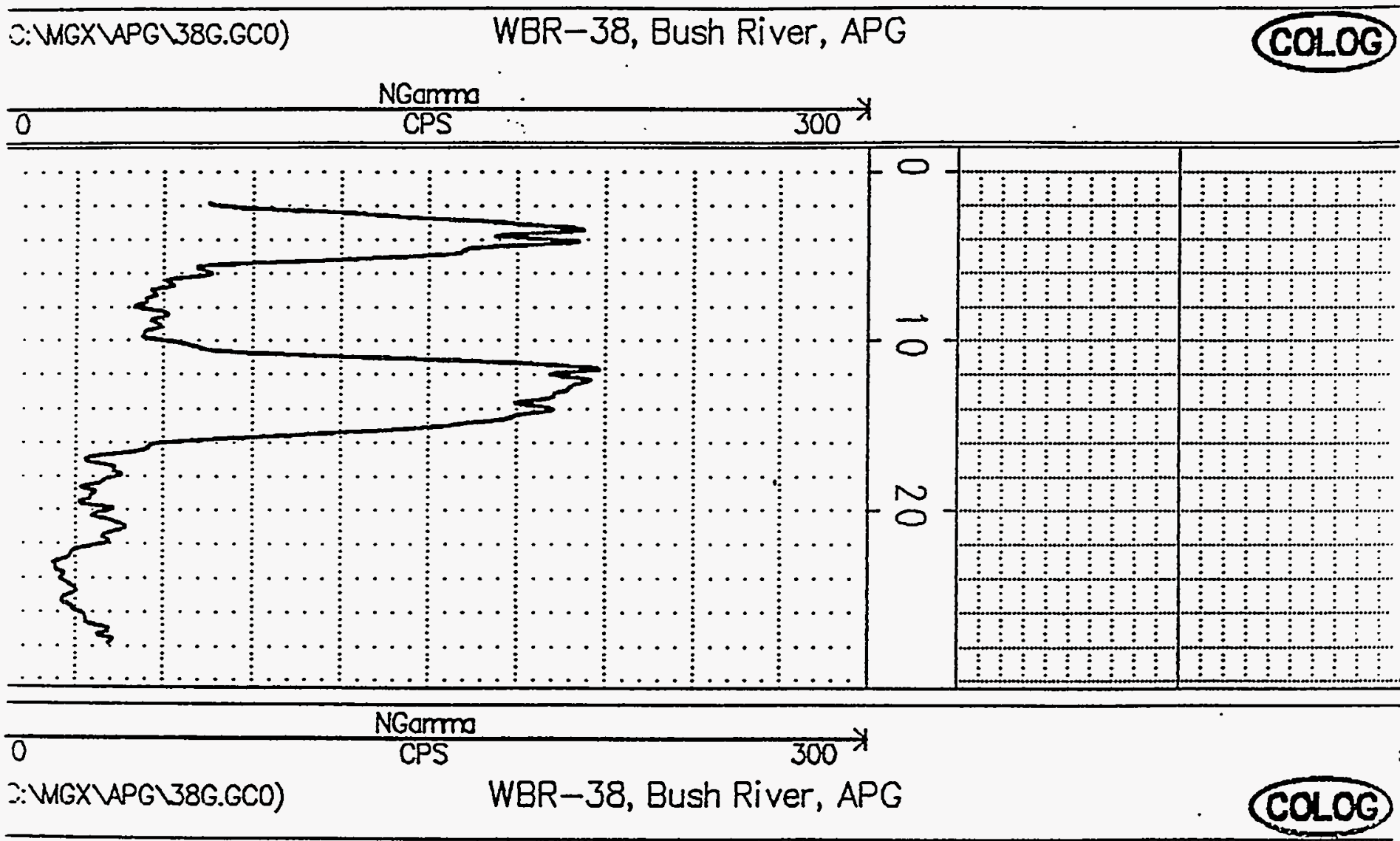




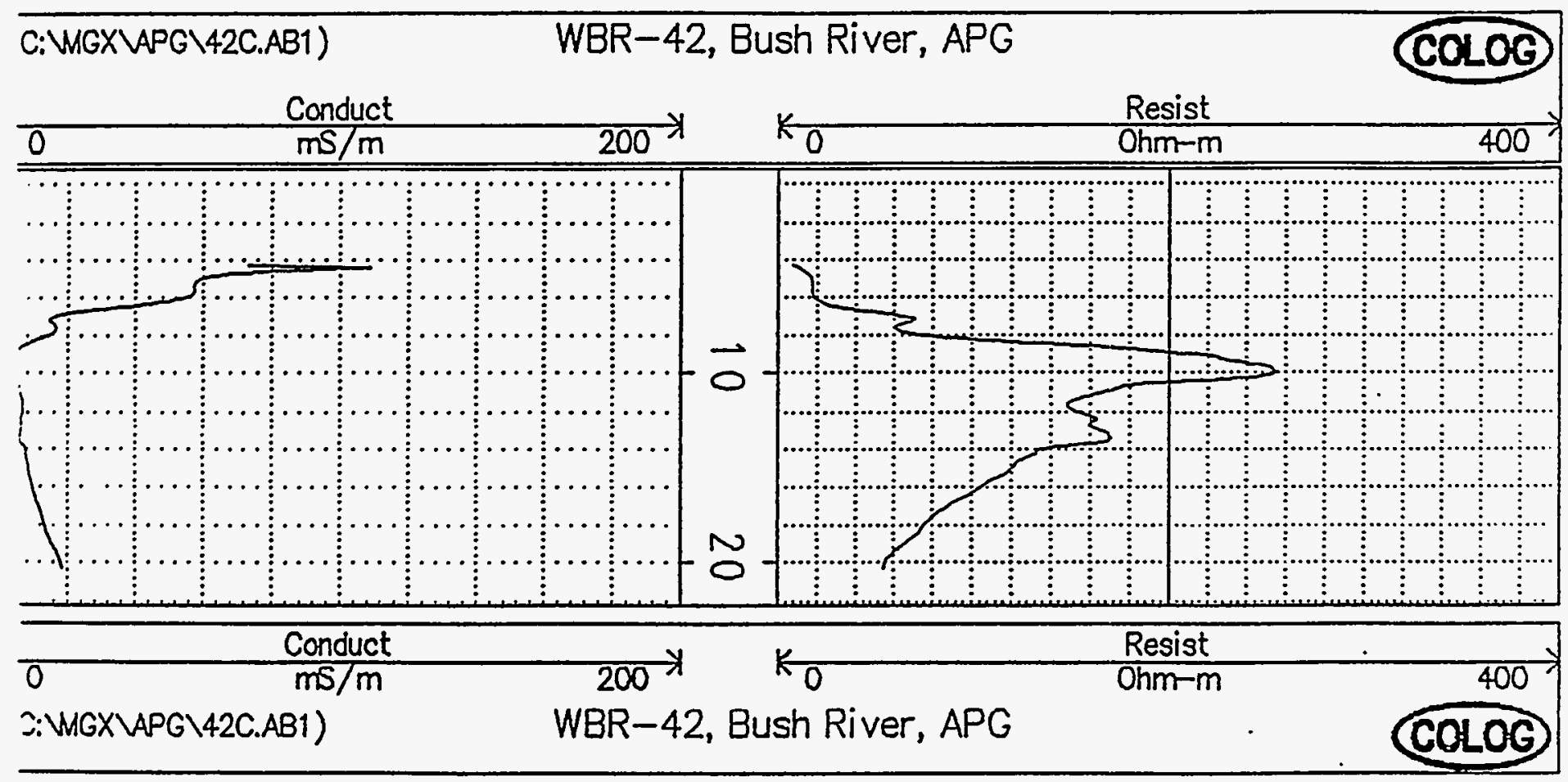




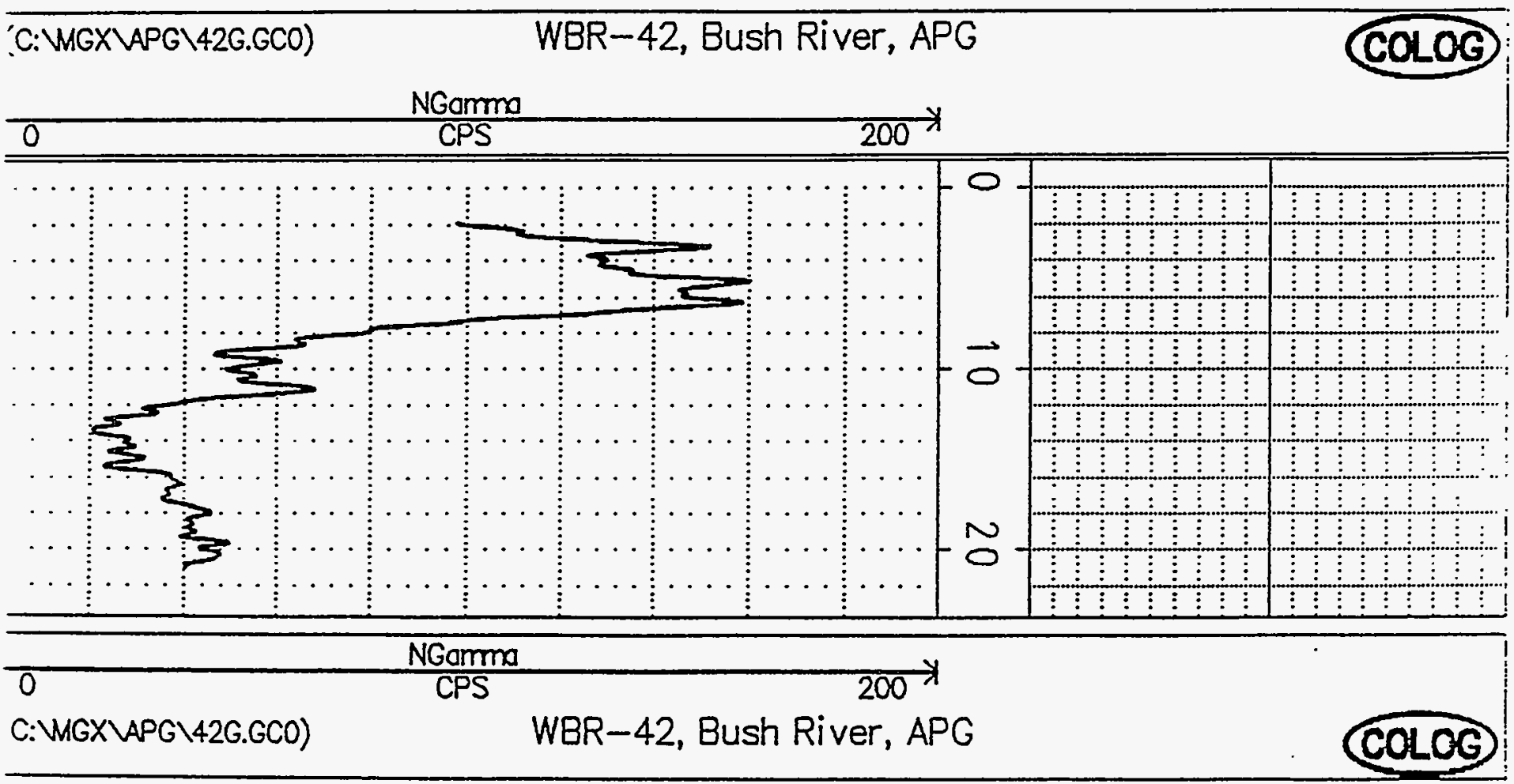




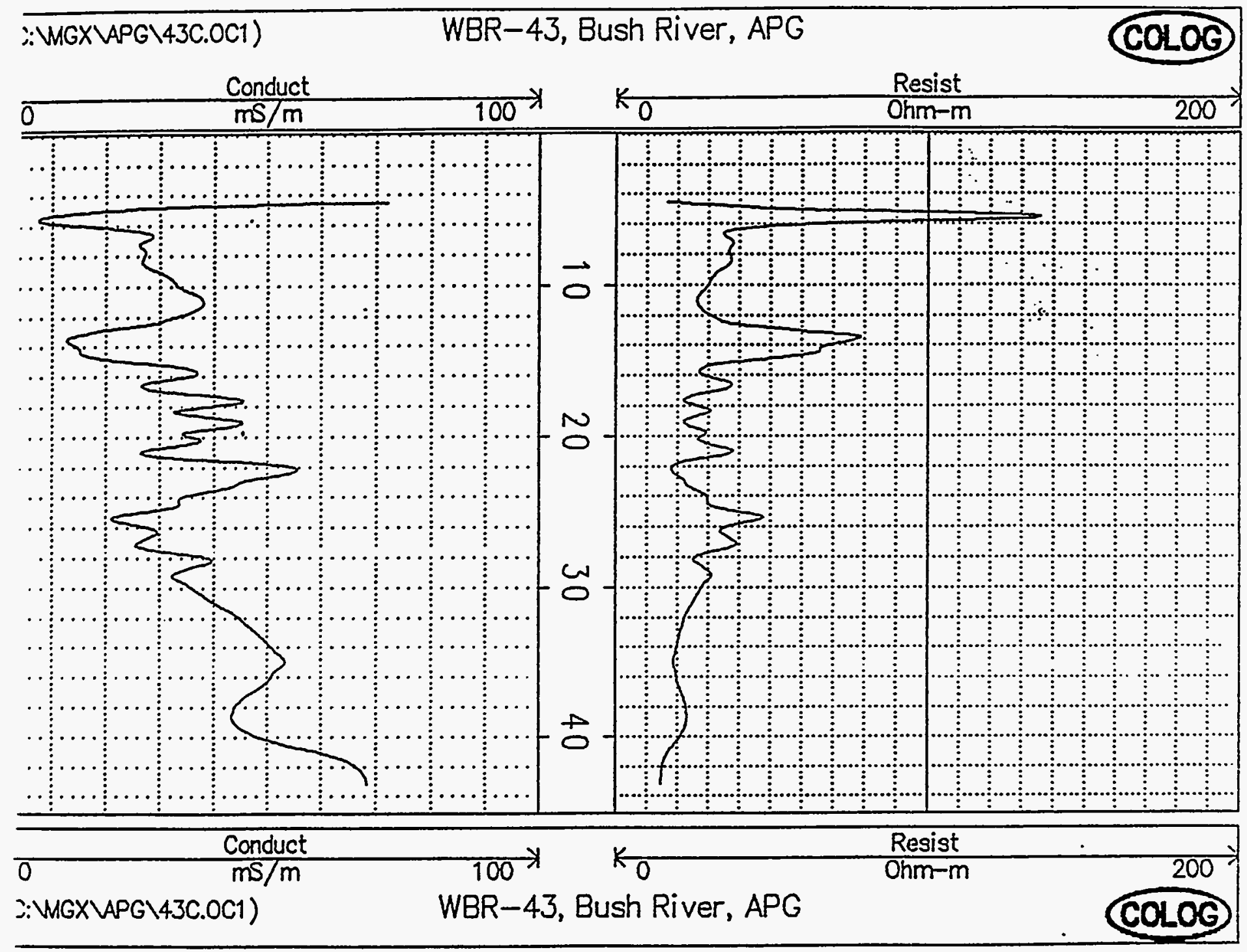




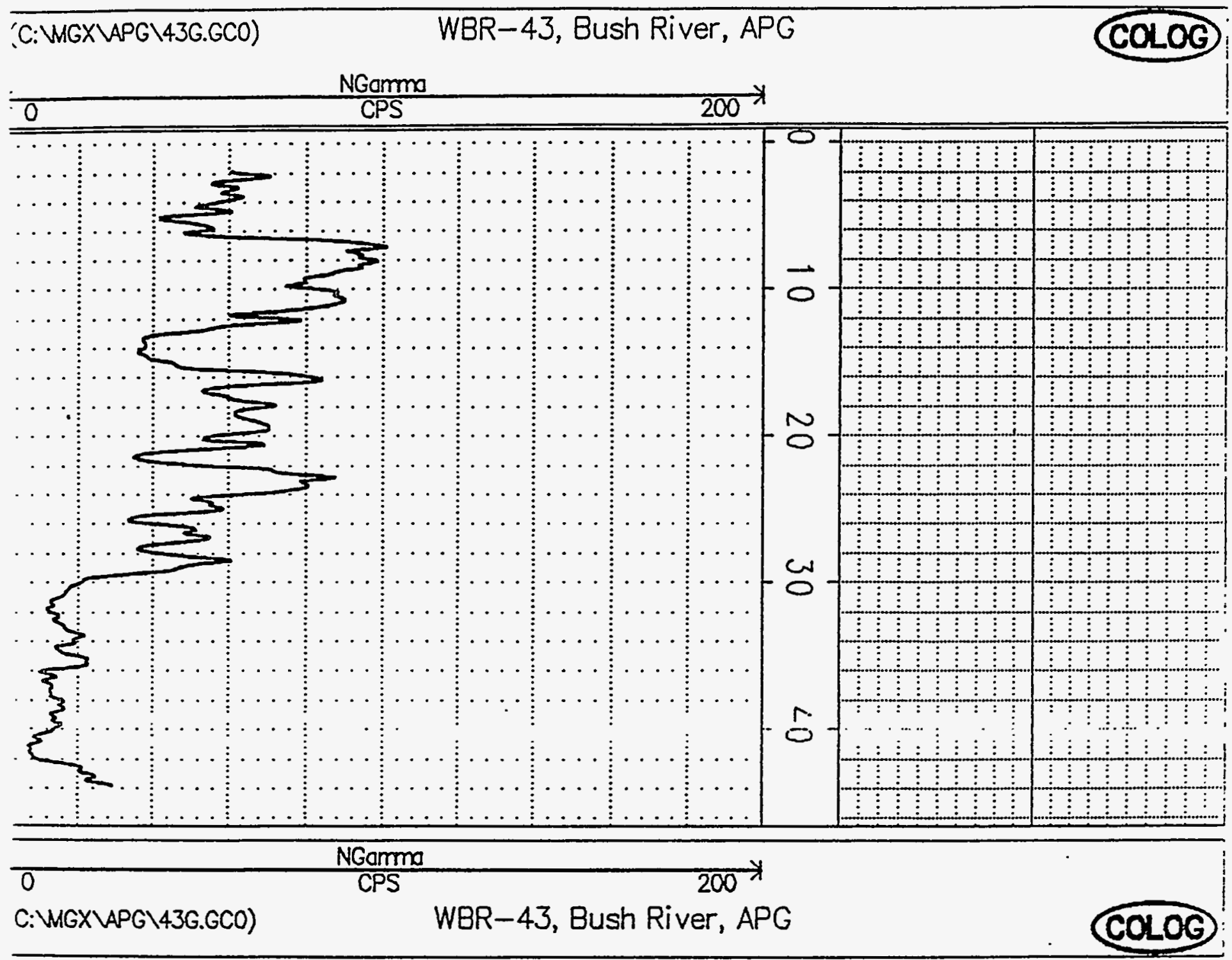




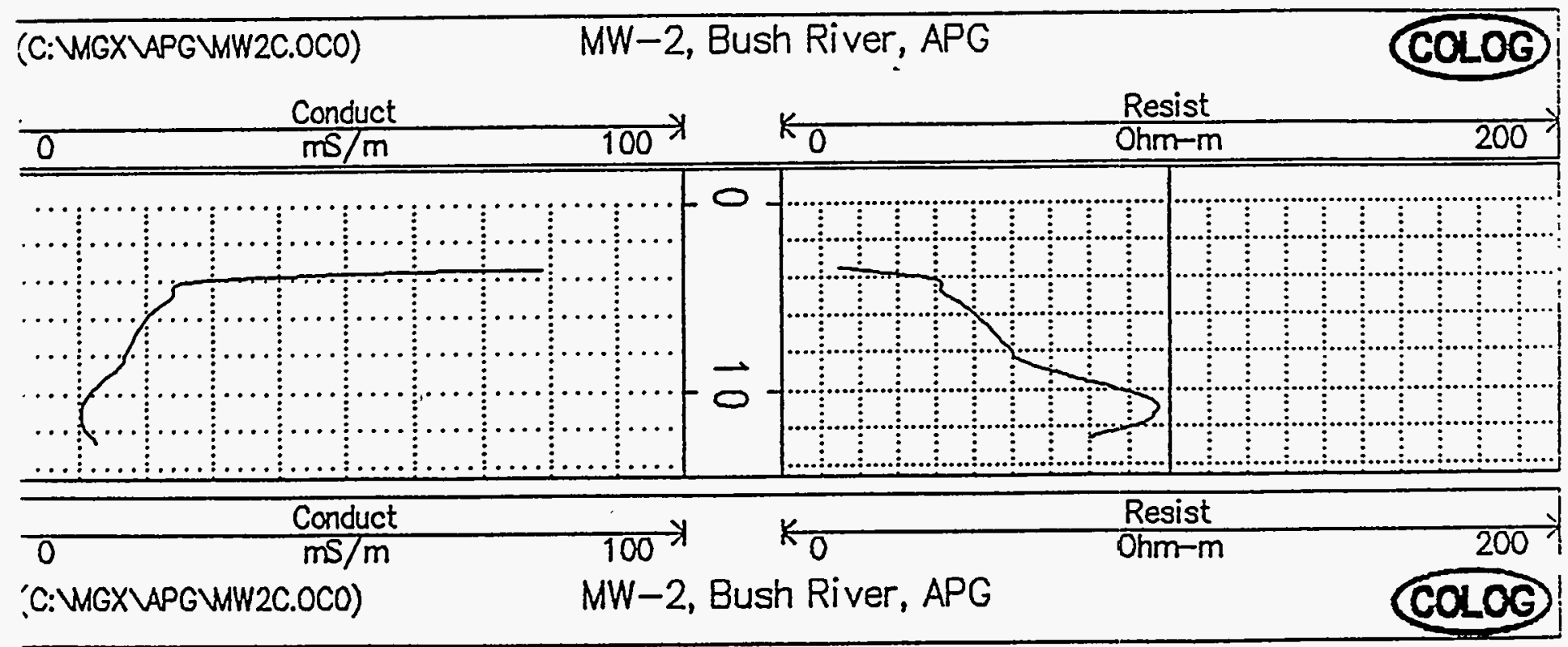




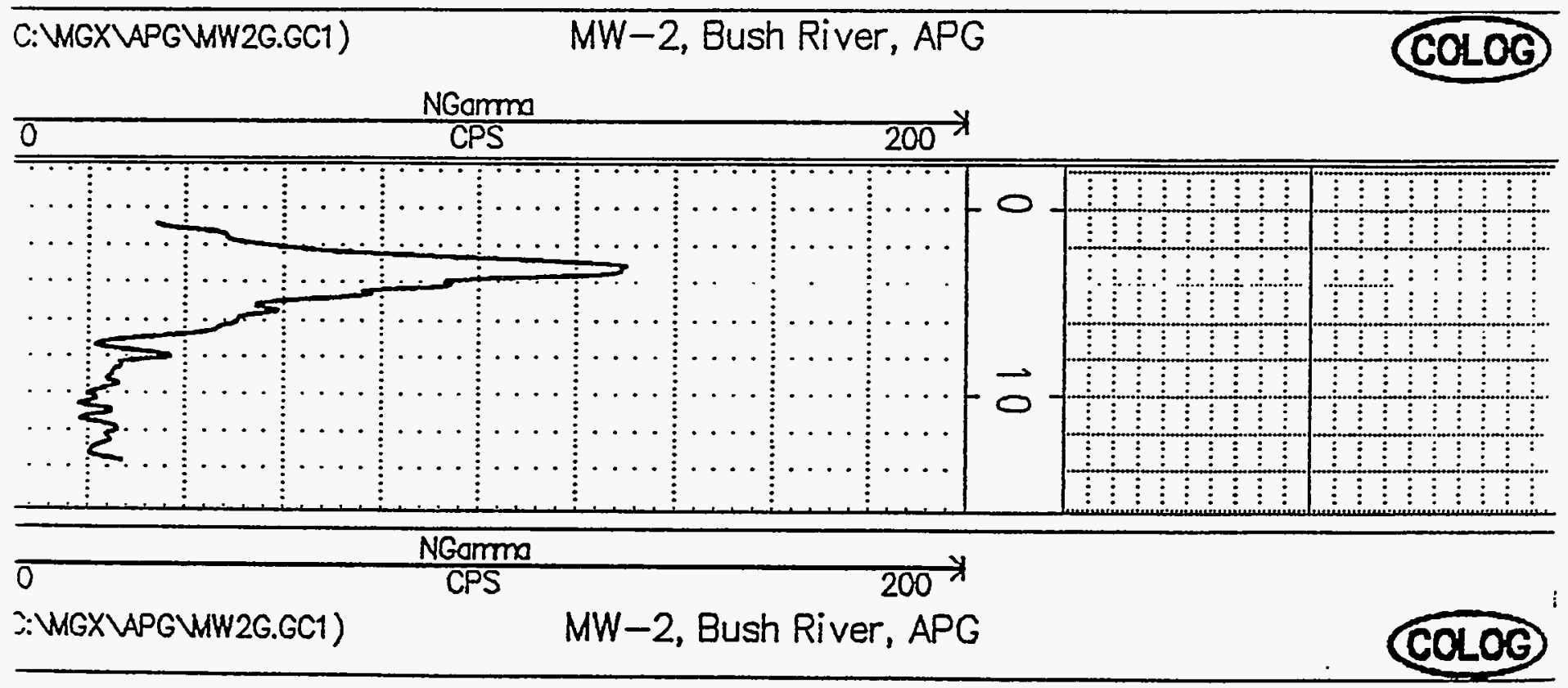

